
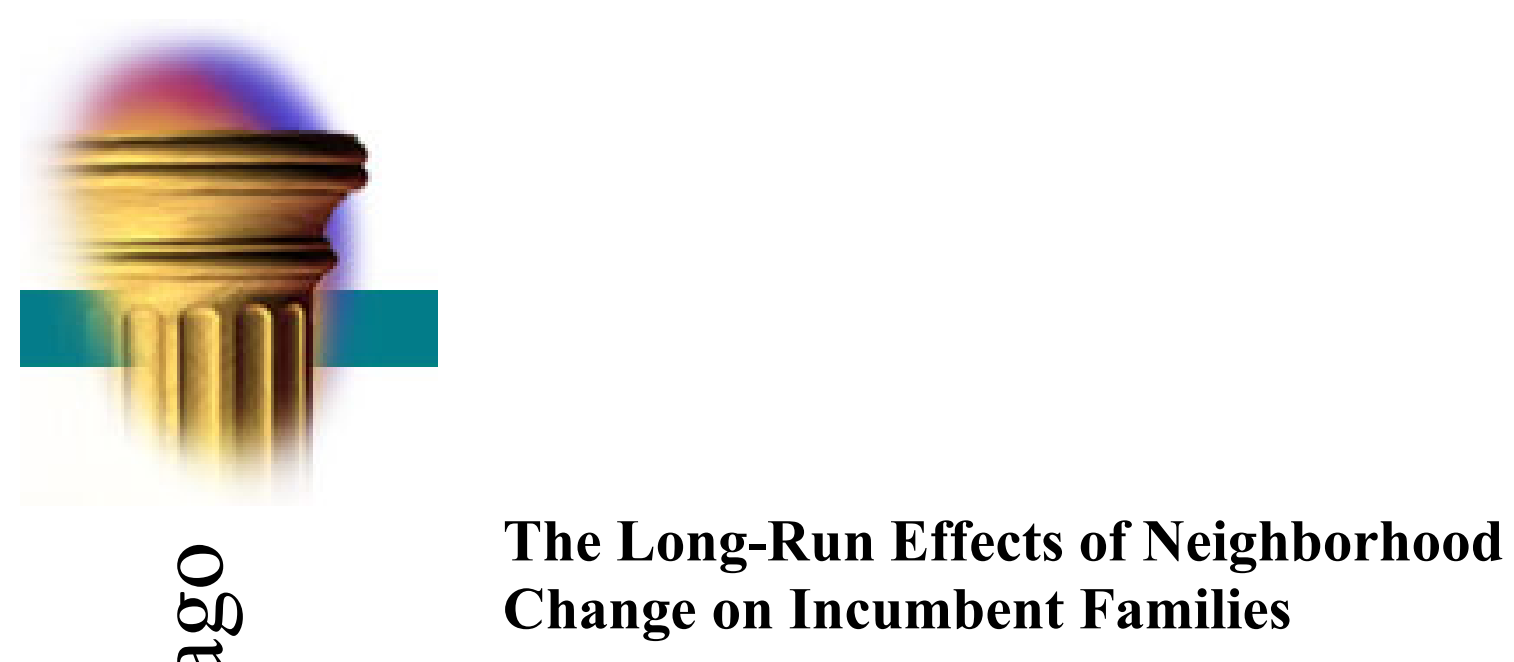

Nathaniel Baum-Snow, Daniel Hartley, and Kwan Ok Lee

\author{
March 18, 2019
}

WP 2019-02

https://doi.org/10.21033/wp-2019-02

${ }^{*}$ Working papers are not edited, and all opinions and errors are the responsibility of the author(s). The views expressed do not necessarily reflect the views of the Federal Reserve Bank of Chicago or the Federal Reserve System. 


\title{
The Long-Run Effects of Neighborhood Change on Incumbent Families*
}

\author{
Nathaniel Baum-Snow, University of Toronto \\ Daniel Hartley, Federal Reserve Bank of Chicago \\ Kwan Ok Lee, National University of Singapore
}

March 18, 2019

\begin{abstract}
A number of prominent studies examine the long-run effects of neighborhood attributes on children by leveraging variation in neighborhood exposure through household moves. However, much neighborhood change comes in place rather than through moving. Using an urban economic geography model as a basis, this paper estimates the causal effects of changes in neighborhood attributes on long-run outcomes for incumbent children and households. For identification, we make use of quasi-random variation in 1990-2000 and 2000-2005 skill-specific labor demand shocks hitting each residential metro area census tract in the U.S. Our results indicate that children in suburban neighborhoods with a one standard deviation greater increase in the share of resident adults with a college degree experienced a 0.4 to 0.7 standard deviation improvement in credit outcomes 12-17 years later. Since parental outcomes are not affected, we interpret these results as operating through neighborhood effects. Finally, we provide evidence that most of the estimated effects operate through public schools.
\end{abstract}

\section{Introduction}

There is considerable empirical evidence that neighborhood and school environments are important determinants of human capital accumulation and long-run life outcomes. Chetty et al. (2018) show the existence of considerable heterogeneity in rates of intergenerational mobility across census tracts in which children grow up, even those within a few miles of each other. Chetty et al. (2016), Chyn (2016), Chetty \& Hendren (2018a, b) and Laliberté (2018) show that children with longer

*We thank Raj Chetty, Gilles Duranton, Remi Jedwab, Santiago Pinto, Tony Yezer and various seminar participants for valuable comments on earlier drafts of the paper. The views expressed are those of the authors and do not necessarily represent the views of the Federal Reserve Bank of Chicago or the Federal Reserve System. 
exposure to lower poverty neighborhoods and areas with higher rates of intergenerational income mobility have higher earnings and educational attainment in adulthood. Gould et al. (2011) and Damm \& Dustmann (2014) show that attributes of the neighborhoods to which immigrant children are randomly assigned have large effects on incomes and the propensity to commit crimes in adulthood. These and other existing studies identify causal effects of neighborhoods through quasi-randomization achieved by observing household moves to new neighborhoods. While evidence on neighborhood effects through household moves comes with appealing identification properties, Aliprantis \& Richter (2018) and Chyn (2018) demonstrate wide treatment effect heterogeneity, even among the public housing population that is their focus. The low takeup rate of housing voucher offers among public housing residents observed in the Moving to Opportunity experiment analyzed by Chetty et al. (2016) and Aliprantis \& Richter (2018) suggests that, absent forced moves through demolitions, the largest effects of neighborhood change may occur in place rather than through household moves. Despite considerable policy interest about the impacts of gentrifying neighborhoods on incumbent residents, there is relatively little evidence in the literature about these effects.

This paper provides estimates of causal effects of neighborhood change on long-run outcomes for parents and children in incumbent households. We isolate variation in changes in residential neighborhood demographic composition using skill-oriented labor demand shocks to potential commuting destinations. This allows us to separate out the effects of neighborhood change on children that run through neighborhoods from those that run through wealth effects of the children's parents. Our key treatment variable is "Resident Market Access" (RMA), a commuting time discounted aggregate of employment accessible from each residential census tract that also incorporates competition effects in labor supply from other residential locations. Tsivanidis (2018) shows that RMA is a conceptually appealing measure, as it exhibits iso-elastic equilibrium relationships with income net of commuting cost, housing prices and population in an urban economic geography model similar to that developed in Ahlfeldt et al. (2015), based on Eaton \& Kortum (2002). While our key treatment variables are theoretically founded, they are also highly correlated with intuitive measures of commuting time discounted aggregates of employment by skill. As such, our analysis does not depend on model structure to be informative.

For identification, we isolate (conditionally) exogenous variation in RMA growth rates through Bartik (1991) type skill-oriented labor demand shocks to employment locations within short commuting times of residential locations. We build instruments by constructing counterfactual post1990 RMA for each census tract using 1990 employment shares by industry in each tract and national industry growth rates excluding the metropolitan region in question. To strengthen identification and limit the potential for trends in local consumer amenities to influence our results, we exclude labor demand shocks in the census tracts of residence when constructing the instruments, condition on neighborhood attributes that may be correlated with industry composition in nearby 
employment locations and make use of variation within metro areas interacted with 2-2.5 km wide distance bands from central business districts. We show that these three measures eliminate correlations between instruments and pre-treatment trends of demographic variables of interest in most settings we analyze. Selection of skilled employment growth into more affluent and educated neighborhoods, which exhibit lower than average rates of gentrification, means that OLS regressions tend to understate the true causal effects of nearby employment growth on neighborhood change. Severen (2019) uses a similar strategy to structurally estimate parameters governing the Los Angeles area economic geography, facilitating a welfare analysis of the Los Angeles Metro Rail construction during the 1990s.

We measure outcomes for four separate samples of individuals who were treated with neighborhood change in the 2000-2005 or 1990-2000 periods. Our primary analysis uses panel data on about 10,000 children in the 1985-1989 birth cohorts of the Federal Reserve Bank of New York Consumer Credit Panel / Equifax (CCP) data, and their parents. For this group, we observe information on individuals' credit records (credit score, credit card limits, loan delinquencies, mortgages, etc.) plus census block of residence in years 2000 through 2017. We also examine outcomes of 1990-2000 neighborhood change on about 1,500 children born 1972-1989 in the Panel Study of Income Dynamics (PSID) and their parents. Each outcome data set has its advantages and drawbacks. The PSID data include more informative outcome measures, allow us to look at younger children at treatment, and allow us to follow people for a longer time period after treatment. However, its smaller sample size results in wider confidence bands and less scope for investigation of heterogeneity in treatment effects. Moreover, because 1990 microgeographic information is used to build the instruments, the 1990-2000 period presents more identification challenges. The CCP has larger sample sizes and exists for a time frame with arguably better identification, but only allows us to see proxies for income and examine the effects of neighborhood change for at most 17 years. Our sample region includes the 254 metropolitan areas for which data on 1990 employment by industry exists at the microgeographic level from the Census Transportation Planning Package (CTPP) and for which census tract-level data existed in 1970.

Our results indicate that labor demand shocks oriented toward those with a college degree cause neighborhood change, measured as increases in either the share of residents in the neighborhood with a college degree or as increases in a composite index of neighborhood quality, conditional on labor demand conditions for those with less than a college degree in both the 1990-2000 and 2000-2007 periods. For the later period, a one standard deviation greater increase in collegedegree oriented RMA (henceforth "skilled RMA") is estimated to cause a neighborhood to move up its metropolitan area's distributions of growth in college fraction by 23-38 percent of a standard deviation and growth in neighborhood quality by 14-24 percent of a standard deviation. While these estimates are more precise for suburban areas, the point estimates are similar for central and suburban regions. 
Our evidence from the CCP data indicates that neighborhoods that change in the direction of higher educational attainment or higher quality have positive long-run effects on incumbent children growing up in these neighborhoods in suburban areas only. The effect of these shocks appears to run through neighborhood or school channels rather than through parent wealth effects. In particular, we find that 11-15 year old children that experience a one standard deviation higher skilled labor demand shock in suburban neighborhoods have about an 18 point gain in their credit scores, a $\$ 2,000$ higher credit limit and are 7 percentage points more likely to have a mortgage (a proxy for owning a home) 17 years later. These numbers represent about 15 percent of a (cross-sectional) standard deviation for this cohort. The estimates grow from about zero at ages 21-25 and are typically slightly greater for children growing up in the least educated neighborhoods.

We present compelling evidence that exposure to improved school quality rather than other types of neighborhood effects primarily drives our results. Conditioning on school district fixed effects reduces the estimated effects on children to about zero. That is, variation in gentrification across neighborhoods within the same school district has no estimated effect on long-run outcomes of resident children. This evidence matches that of Laliberté (2018), who uses unique data from Montreal to estimate that about $80 \%$ of "neighborhood effects" run through school quality. Using variation between school districts, we find that the effects are larger for children growing up in higher quality school districts. This may reflect the effect of school quality on the propensity for college educated parents to send their children to the local public schools.

We show that there are no effects of shocks to skilled RMA on credit outcomes for the parents of children in our sample, indicating no evidence that parental wealth effects are driving the results. Moreover, we find that once their children leave the home, parents whose neighborhoods gentrified after 2000 choose to move to neighborhoods with educational attainment compositions looking much like the ones in which they lived in 2000 (pre-gentrification). This comes despite the fact that their children, after a period of living in less educated neighborhoods in their 20s, upgrade their neighborhoods through migration to neighborhoods that have a higher share of residents with a college degree (henceforth, "college share" or "fraction college") by about 1-2 percentage points above the direct effects of the shocks on their 2000 neighborhoods. These extra effects are greater for those that grow up in the least educated neighborhoods. Exposure to higher quality neighborhoods in youth leads to the choice of living in higher educated neighborhoods in adulthood.

In summary, our CCP results indicate that a one standard deviation increase in neighborhood college share leads to 40-70 percent of a standard deviation improvement in incumbent child outcomes, on average, in the suburbs. For those growing up in the most disadvantaged neighborhoods, the effect is on the higher end of this range. School quality appears to be the main driver of these effects, with larger effects in higher quality school districts.

Our results for the 1990-2000 period corroborate those for the later period but come with additional empirical challenges. Higher 1990-2000 skilled RMA growth predicts higher test scores 
for young adults and higher 2015 employment rates and family incomes. It is difficult to use the PSID to recover the mechanisms that drive the reduced form 1990-2000 treatment effects for several reasons. First, we find evidence that parent's incomes are affected in addition to child outcomes. Second, we estimate large confidence intervals for some outcomes of interest. Finally, there are limits to the possibility of breaking out the effects by parental education due to a lack of statistical power. The positive wealth effects that we measure for the parents are likely due to the higher conditional correlation of skilled and unskilled RMA shocks during this period making it difficult to isolate a shock that makes the neighborhood better but has no effect on the parents.

Our evidence on the effects of neighborhood change highlights a potentially important force driving increased income inequality and reduced intergenerational mobility. More educated households have been disproportionately exposed to improvements in neighborhood quality in recent decades. Figure 1 shows kernel density graphs of 1990-2000 and 2000-2010 changes in the share of one's Census tract with a college degree for resident children whose parents are imputed to have either less than a high school degree or a college degree or higher educational attainment. In both decades, but especially in the 1990s, there is clear evidence that the distribution of neighborhood upgrades for college graduate residents has more mass on the right side than the distribution for residents without a high school degree. This trend reinforces the 1990 baseline in which less educated children already live in predominately less educated neighborhoods (seen in Figure A1). Such exposure to educated neighbors can have important long-run impacts. Indeed, Fogli \& Guerrieri (2018) calibrate an OLG model with neighborhood choice to show that magnitudes of neighborhood effects in line with those estimated in this paper and Chetty \& Hendren (2018a, b) interacted with a shock to the distribution of skill prices generate changes in the distribution of skill quantities that increase income inequality by 25-40 percent beyond the impact of the skill price shock alone.

With high returns to neighborhood quality, the logic of revealed preference would indicate that people should migrate toward more educated neighborhoods, all else equal. Figure 2 shows evidence to this effect, but also that the choice to migrate does not depend as much on future neighborhood change as it does on initial neighborhood quality. Panel A shows distributions of 2000 fraction college by the choice to migrate to a different tract by 2017 for parents in our CCP sample (left side) and their children (right side). The left graph shows clear selection of moving parents from the least educated neighborhoods, relative to stayers (the red dashed line is to the left of the blue solid line). In the CCP sample 69 percent of the parents end up moving to a new tract by 2017. These movers are much more likely to come from less educated neighborhoods, perhaps in order to invest more in their children. However, the right side shows that the same pattern is less pronounced for their children. Given that 85 percent of children have migrated to a new tract by 2017 , mostly to establish their own households, it is not surprising that the ones that remain in the same neighborhood do so for reasons other than neighborhood attributes.

The evidence in Panel B of Figure 2 shows that the educational composition in migration 
destination neighborhoods indeed suggests that households value having more educated neighbors. However, the distribution of neighborhood change from which migrants depart looks very similar to that for households that do not move. Panel B depicts three distributions of changes in fraction college for parents and their children. The solid blue lines are the distributions of 2000-2007 changes in fraction college for the year 2000 tract of residence for those that are living in the same tract in 2017 as in 2000. The short-dashed red lines depict the distributions of 2007 fraction college in 2017 tract of residence minus 2000 fraction college for the 2000 tract of residence amongst movers only. The long-dashed green lines are the distributions of 2000-2007 changes in fraction college in movers' 2000 tracts of residence. Comparing the red and green lines in the two graphs indicates that the children use mobility to upgrade their neighborhood quality more than their parents (red distribution has more mass to the right for the children). However, the green and blue lines coincide very closely in both Panel B graphs, indicating little selection of movers on the subsequent changes in neighborhood quality of their initial neighborhoods. Beyond using identifying variation from labor demand shocks in commuting destinations, our evidence of more selection on levels-of than changes-in neighborhood college fraction further supports our empirical strategy of using variation in neighborhood change for identification. The results shown in Figure 2 are similar when broken out by the educational attainment of the household.

This paper complements the existing literature on neighborhood effects by presenting estimates that apply to a broad population, including those who choose not to move, and to more local neighborhoods relative to many of the best identified estimates in the literature to date. Chetty et al. (2018a, b) make causal statements about children in households who choose to move across commuting zones or county boundaries and can measure "neighborhood effects" down to the county level. Laliberté (2018) corroborates their estimates for movers within Montréal. While they can estimate the effects of census tract attributes, Chyn (2018) and a series of papers about the Moving to Opportunity program including Chetty et al. (2016) and Aliprantis \& Richter (2018) are limited to estimating effects for public housing residents who may not be representative of the broader population. Altonji \& Mansfield (2018) use assumptions about the ability to invert the local amenity vector into observable characteristics of neighborhood residents to identify lower bounds on neighborhood effects. Using restricted access census data, Brummet and Reed's (2019) empirical setting is perhaps most similar to ours; both papers find consistent evidence that high rates of household mobility insulate incumbents from negative effects of gentrification, and also find no long-run positive or negative effects for urban children.

With rapid gentrification occurring in the centers of many U.S. cities (Baum-Snow \& Hartley, 2018; Couture \& Handbury, 2017; Edlund et al., 2016), the effects of gentrification on incumbent residents has particular current policy relevance in the United States. In addition to its contribution to the neighborhood effects literature, this paper also relates to literatures about the long-run effects on workers of job loss and shifting labor market opportunities plus the intergenerational effects of 
parent wealth shocks. Davis \& von Wachter (2012) and Couch \& Placzek (2010) show that job loss has persistent effects. Heisz, Oreopolous and von Wachter (2012) show similar long run deleterious effects of graduating college in a recession, especially for less able graduates. Dahl \& Lochner (2012) and Hilger (2015) find that negative parental wealth shocks have small effects on child college enrollment probabilities and long run labor market outcomes of their children. Our study shows that even if parental wealth effects are small, children's outcomes can be affected in the long run through neighborhood change due to spatially correlated shocks to labor market opportunities for parents.

This paper proceeds as follows. Section 2 lays out our estimation problem conceptually and shows how we separate out the effects of neighborhood change that run through parents from more direct effects on children. Section 3 discusses the data. Section 4 explores the neighborhood-level identifying variation in the data. Section 5 provides a theoretical framework that defines our key RMA predictor variables. Section 6 presents the details of our empirical implementation, including the construction of the instruments. Section 7 presents our results. Section 8 concludes.

\section{Empirical Framework}

This section lays out the equations that we aim to estimate and shows how our estimation procedure facilitates separating out parental wealth effects that are caused by the labor or housing market from neighborhood effects. We face a hierarchical estimation problem within each metropolitan area. At the top of the hierarchy, a vector of demographic attributes and housing costs, $n_{i}$ in each neighborhood $i$ depends on neighborhood-specific labor demand conditions and local amenities. Below neighborhoods are parents, whose outcomes may depend on neighborhood attributes, labor demand conditions, and some pre-determined factors like their human capital. Finally, children's

long-run outcomes depend on parental inputs when they are children, neighborhood attributes and neighborhood amenities.

In general terms, our empirical approach is to focus on the variation in neighborhood change that is induced by labor demand shocks oriented toward college-educated (henceforth, "skilled") workers, while conditioning on unskilled labor demand shocks. We show below that this variation does not generate direct wealth effects through the labor market for incumbent resident parents. For unskilled parents, our direct conditioning on low skilled labor demand shocks holds labor demand conditions constant. Since skilled parents typically move to a new neighborhood to take a new job, we show that incomes of incumbent skilled residents are also unaffected by the skilled labor demand shocks hitting neighborhood $i$.

Anticipating the discussions of the data and theoretical framework in Sections 3 and 5, we lay out our targeted estimation equations in each level of the hierarchy below. When discussing the practical identification challenges in Section 6, we fill in more details about the exact empirical 
specifications used.

\subsection{Neighborhoods}

Equation (1) describes our conceptualization of the data generating process for the change between periods $t-1$ and $t$ in the vector of neighborhood demographic attributes and housing costs, $n_{i}$. We denote changes in labor market opportunities for skilled workers living in tract $i$ as $\Delta_{t} \ln R M A_{i}^{S}$ and unskilled workers living in tract $i$ as $\Delta_{t} \ln R M A_{i}^{U}$. The details of how we measure these objects are developed in Section 5. Our primary goal in the neighborhood analysis is to estimate the parameter $\alpha^{n S}$ in the equation below, which is the treatment effect of labor market opportunities for skilled workers in and near tract $i$ on attributes of tract $i$, while holding unskilled labor market opportunities constant. $X_{i}$ is a set of pre-determined observed tract characteristics and amenities, conditional on which the instruments for $\Delta_{t} \ln R M A_{i}^{S}$ and $\Delta_{t} \ln R M A_{i}^{U}$ are exogenous.

$$
\Delta_{t} n_{i}=\alpha_{0}^{n}+\alpha^{n S} \Delta_{t} \ln R M A_{i}^{S}+\alpha^{n U} \Delta_{t} \ln R M A_{i}^{U}+X_{i} \phi^{n}+\nu_{i}^{n}
$$

We will estimate the parameter vector $\alpha^{n S}$ using instrumental variables (IV). The specifics of our IV strategy are described in detail in Section 6.

\subsection{Parents}

The following equations describe the process that we conceptualize generates the data on labor market and credit outcomes for children's parents, indexed by $\omega$, at time $\tau \geq t$ who live in neighborhood $i$ in period $t-1 .^{1}$

$$
\begin{aligned}
& z_{i \omega, \tau}^{U}=\alpha_{0}^{p_{U}}+\alpha^{p_{U} S} \Delta_{t} \ln R M A_{i}^{S}+\alpha^{p_{U} U} \Delta_{t} \ln R M A_{i}^{U}+X_{i \omega}^{p} \phi^{p_{U}}+\nu_{i \omega}^{p_{U}} \\
& z_{i \omega, \tau}^{S}=\alpha_{0}^{p_{S}}+\alpha^{p_{S} S} \Delta_{t} \ln R M A_{i}^{S}+\alpha^{p_{S} U} \Delta_{t} \ln R M A_{i}^{U}+X_{i \omega}^{p} \phi^{p_{S}}+\nu_{i \omega}^{p_{S}}
\end{aligned}
$$

In these equations, we condition on the same controls $X_{i}$ as for the neighborhood analysis above plus some additional parent-specific controls in the base period $(t-1)$.

The effects of nearby changes in labor demand conditions may run through the labor market, the housing market or through changing spillovers from neighbors. For example, consider $\alpha^{p_{U} S}$, the average effect of skilled RMA growth on unskilled parents' outcomes. $\alpha^{p_{U} S}$ incorporates a direct effect holding neighborhood demographic composition constant and an indirect effect that

\footnotetext{
${ }^{1}$ In the data, we follow parents as they move, thus they do not have to remain in neighborhood $i$ in periods $\tau>t-1$.
} 
runs through its impact on neighborhood demographic composition $\alpha^{n S}$.

$$
\alpha^{p_{U} S}=E\left[\frac{\partial z_{i \omega, \tau}^{U}}{\partial \Delta_{t} \ln R M A_{i}^{S}} \mid \Delta_{t} \ln R M A_{i}^{U}, X_{i \omega}^{p}, \Delta_{t} n_{i}\right]+\alpha^{n S} E\left[\frac{\partial z_{i \omega, \tau}^{U}}{\partial \Delta_{t} n_{i}} \mid \Delta_{t} \ln R M A_{i}^{U}, X_{i \omega}^{p}\right]
$$

We surmise and confirm empirically that the direct effect $\left(E\left[\frac{\partial z_{i \omega, \tau}^{U}}{\partial \Delta_{t} \ln R M A_{i}^{S}} \mid \Delta_{t} \ln R M A_{i}^{U}, X_{i \omega}^{p}, \Delta_{t} n_{i}\right]\right)$ is equal to zero since, conditional on low-skilled labor demand shocks, high skilled labor demand shocks should have no effect on job opportunities for low-skilled parents. What remains is the effect that runs through neighborhood characteristics $\left(\alpha^{n S} E\left[\frac{\partial z_{i \omega, \tau}^{U}}{\partial \Delta_{t} n_{i}} \mid \Delta_{t} \ln R M A_{i}^{U}, X_{i \omega}^{p}\right]\right)$. This component incorporates both housing wealth or rent effects and changing spillovers from the demographic composition of tract $i$. Thus, given estimates of $\alpha^{p_{U} S}$, we can recover $E\left[\frac{\partial z_{i \omega, \tau}^{U}}{\partial \Delta_{t} n_{i}} \mid \Delta_{t} \ln R M A_{i}^{U}, X_{i \omega}^{p}\right]$ using estimates of $\alpha^{n S}$ from the neighborhood equation. In practice, we estimate $\alpha^{p_{U} S}$ and $\alpha^{p_{S} S}$ to be zero or slightly negative.

As with the neighborhood equation, in the empirical implementation we instrument for $\Delta_{t} \ln R M A_{i}^{S}$ and $\Delta_{t} \ln R M A_{i}^{U}$ when estimating Equations (2) and (3).

\subsection{Children}

Since we only observe outcomes for children after they become teenagers or adults, we examine levels of outcomes $y_{i \omega}^{U}$ or $y_{i \omega}^{S}$ of children of unskilled or skilled parents $\omega$ who lived in tract $i$ in period $t-1$. These outcomes are observed after period $t$. The data generating processes for $y_{i \omega}^{U}$ or $y_{i \omega}^{S}$ are similar to those for the parent outcomes, as follow:

$$
\begin{aligned}
& y_{i \omega}^{U}=\alpha_{0}^{c_{U}}+\alpha^{c_{U} S} \Delta_{t} \ln R M A_{i}^{S}+\alpha^{c_{U} U} \Delta_{t} \ln R M A_{i}^{U}+X_{i \omega}^{c} \phi^{c_{U}}+\nu_{i \omega}^{c_{U}} \\
& y_{i \omega}^{S}=\alpha_{0}^{c_{S}}+\alpha^{c_{S} S} \Delta_{t} \ln R M A_{i}^{S}+\alpha^{c_{S} U} \Delta_{t} \ln R M A_{i}^{U}+X_{i \omega}^{c} \phi^{c_{S}}+\nu_{i \omega}^{c_{S}}
\end{aligned}
$$

Here, we use a similar set of pre-determined household-specific controls, $X_{i \omega}^{c}$ as for the parents. To be consistent with the literature on the effects of youth environment on childrens' human capital accumulation (e.g. Hoynes, Schanzenbach and Almond, 2018), these controls include some observed parental inputs prior to the labor demand shock treatment.

For the children, we have a similar but more complicated interpretation of coefficients on RMA than for the parents. For example, the average effect of skilled RMA growth on children of unskilled parents is:

$$
\begin{aligned}
\alpha^{c_{U} S}= & \alpha^{p_{U} S} E\left[\frac{\partial y_{i \omega}^{U}}{\partial z_{i \omega, \tau}^{U}} \mid \Delta_{t} \ln R M A_{i}^{U}, X_{i \omega}^{c}\right]+E\left[\frac{\partial y_{i \omega}^{U}}{\partial \Delta_{t} \ln R M A_{i}^{S}} \mid \Delta_{t} \ln R M A_{i}^{U}, X_{i \omega}^{c}, \Delta_{t} n_{i}\right] \\
& +\alpha^{n S} E\left[\frac{\partial y_{i \omega}^{U}}{\partial \Delta_{t} n_{i}} \mid \Delta_{t} \ln R M A_{i}^{U}, X_{i \omega}^{c}\right]
\end{aligned}
$$


The first term is the effect of the labor demand shock that runs through parental inputs. Given that we will estimate $\alpha^{p_{U} S}$ from the parents' equation and confirm that it is about zero, we will impose that this first term is zero. The second term is the direct effect of skilled labor demand shocks on children's long-run outcomes, holding neighborhood and parental attributes constant. While it may be difficult to imagine that this term is also not zero, we keep it in explicitly given Charles et al.'s (2016) evidence on the incentive effects of labor demand conditions for teens' human capital accumulation. Finally, the last term includes the direct effect of neighborhood demographic change that we are after. If the parental wealth effect and the direct effect of the skilled labor demand shock are zero, we can directly calculate the neighborhood effect, $E\left[\frac{\partial y_{i \omega}^{U}}{\partial \Delta_{t} n_{i}} \mid \Delta_{t} \ln R M A_{i}^{U}, X_{i \omega}^{c}\right]=$ $\alpha^{C_{U} S} / \alpha^{n S}$. As with the neighborhood and parent analyses, in the empirical implementation we will instrument for $\Delta_{t} \ln R M A_{i}^{S}$ and $\Delta_{t} \ln R M A_{i}^{U}$ when estimating Equations (4) and (5).

In this section, we have laid out the data generating process as a set of reduced form equations that relate changes in labor demand conditions in each neighborhood to outcomes of interest. In principle, one could set this up as a system of equations to be estimated jointly by 3SLS or GMM, allowing for one to recover estimates of neighborhood effects in one step. We do not do so for two reasons. First, this process would not accommodate separate estimation of a potential direct effect of labor demand shocks on children. While we cannot separately identify such an effect, we do not want to assume away its existence. Second, the various identification challenges and specification checks laid out in Section 6 make it more straightforward to estimate parameters in the reduced form hierarchical system and combine them afterwards. This allows for more flexibility in mixing and matching different parameter estimates to recover estimates of neighborhood effects on the children of unskilled parents, $E\left[\frac{\partial y_{i \omega}^{U}}{\partial \Delta_{t} n_{i}} \mid \Delta_{t} \ln R M A_{i}^{U}, X_{i \omega}^{c}\right]$ and neighborhood effects on the children of skilled parents $E\left[\frac{\partial y_{i \omega}^{S}}{\partial \Delta_{t} n_{i}} \mid \Delta_{t} \ln R M A_{i}^{U}, X_{i \omega}^{c}\right]$, our main objects of interest.

\section{Data}

Our analysis makes use of census tract aggregate data from 1970 to 2014, commuting and place of work tabulations from the 1990 and 2000 Census Transportation Planning Packages (CTPP), Decennial Census and American Community Survey (ACS) micro data from 1990 to 2005, LODES commuting and place of work data from 2010, micro data from years 1972 forward from the Panel Study of Income Dynamics (PSID) and micro data from 2000 forward from the Federal Reserve Bank of New York Consumer Credit Panel/Equifax (CCP). We normalize all microgeographic units in these datasets to Census 2000 tract boundaries. 


\subsection{Defining Our Study Areas}

The Census Bureau tabulates the 1990 and 2000 Decennial Census micro data to place of work, place of residence and directional commuting flow to form the Census Transportation Planning Package (CTPP) data sets. The 1990 CTPP geography dictates how we construct our study regions. The $1990 \mathrm{CTPP}$ assigns microgeographic units the size of census tracts or smaller to "regions", which roughly correspond to metropolitan areas. Total commuting flows are reported for each pair of census tracts, traffic analysis zones or block groups within each region, with no information reported on between-region flows. Some regions overlap. Connecticut and surrounding areas and New Jersey and surrounding areas are each defined as one large region. ${ }^{2}$ For Connecticut and New Jersey, we define new regions that each have a minimum $25 \mathrm{~km}$ radius around each central business district (CBD) in each state. Tracts in these CTPP regions that are beyond $25 \mathrm{~km}$ from all CBDs in each state are assigned to the closest CBD. The CTPP reports the mean and median home to work commute times for each pair of microgeographic units with a positive commute flow. Employment in 18 industry groups by place of work are also reported, including the $6 \%$ of the employed workforce who worked at home in 1990. The reported commuting flows do not include those who work at home.

We map the 1990 CTPP geography to 1990 census blocks using Census Bureau reported allocation factors and use the 1990-2000 Census Block Relationship File to convert to Census 2000 tract boundaries. We use land area to form allocation weights in both conversions. We assign one CBD to each region, with its location calculated as the centroid of the set of CBD census tracts reported in the 1982 Economic Census for the region's largest city. Those regions without a CBD in the 1982 Economic Census are assigned one based on a visual assessment of the location of city hall and the oldest bank branches in the city.

Measuring the employment opportunities available in each residential census tract is central to our analysis. As we lay out in the theoretical framework in Section 5, we want to think of each region as a local labor market in isolation in which workers choose residential locations anticipating employment options available in each census tract in the region. Because we do not observe employment locations for region residents who commute beyond region borders in 1990, we organize the data to minimize the potential importance of this type of reverse commute. We measure total 1990 employment in tract $j$ by aggregating over all commute flows to $j$ from both inside and outside the region, with a single assigned residential location outside the region. We measure the number of resident workers in tract $i$ as the aggregate of commute flows from origin $i$ to destinations in the region only. We build all demographic, employment and commuting data described below for the 63,897 Census 2000-definition tracts in 306 regions. $^{3}$

\footnotetext{
${ }^{2}$ In the two cases in which overlapping regions have the same CBD (Portland, OR and Greensboro, NC), we keep only the most expansive region for the analysis.

${ }^{3}$ We have 50,410 unique census tracts in our data, with 41,627 of these appearing in one region only.
} 
Our empirical analysis relies on accurate measures of historical demographic characteristics and viable employment opportunities within commuting range. To this end, our analysis excludes regions without valid 1970 demographic information. In the remaining 254 regions, we focus our analysis on residents of the census tracts that are within $20 \mathrm{~km}$ of the CBD and with valid 1970 demographic information. We further constrain the sample to leave at least $10 \mathrm{~km}$ between each sample census tract and the region's edge, so that we can accurately observe labor market opportunities in all commuting directions. Altogether, the result is 32,515 census tracts $(28,476$ of which are unique) whose residents are counted in the empirical work. However, we emphasize that we incorporate information from all potential commuting destinations outside of this sampled residential area as long as they are within a 1990 definition CTPP region.

\subsection{Post-1990 Commuting and Employment Data}

We use the 2000 CTPP to construct commuting flows, commute times and employment in each of 14 industries for year 2000. Unlike the 1990 version, the 2000 CTPP covers all commutes and employment in the U.S. down to the census tract level or below. We organize it to measure objects of interest within the 1990 definition region geographies described earlier.

For 2010 commuting employment data, we process the LODES aggregation of the Longitudinal Employer Household Dynamics data. This data set has employment by industry and education plus commuting flows for each census block in the U.S. However, it does not include commute times. ${ }^{4}$

\subsection{Demographic Information}

We take census tract aggregates for 1970-2010 from the Decennial Census derived Neighborhood Change Database supplemented with some Summary Tape File 4 variables from 1980, as described in Baum-Snow \& Hartley (2018), and some 2005-2009 and 2012-2016 tract aggregates from the American Community Survey (ACS). We use these data sets to measure aggregate outcomes and to control for pre-treatment trends. We note that because of the smaller ACS samples and the longer time windows the 2005-2009 and 2012-2016 tract aggregate data is noisier than than the 2000 census aggregate data.

Following Aliprantis and Richter (2018), we construct a summary index of neighborhood quality for use throughout the analysis. This index is calculated as the first principal component of the nationwide cumulative distribution functions of fraction high school or more, fraction college or more, the negative of the poverty rate, the employment to population ratio, the negative of the unemployment rate, and the negative of the share of single headed households. The result is a percentile rank for each census tract nationwide. During the 2000-2007 period, tracts in our sample lost 0.9 percentiles in neighborhood quality on average, with a standard deviation of 13.1 percentiles.

\footnotetext{
${ }^{4}$ Since Massachusetts is not included in the 2010 LODES place of work file, we use its 2011 file instead.
} 
The average within-region standard deviation in the 2000-2007 change in neighborhood quality is 12.2 percentiles. These changes in quality are positively correlated with the change in fraction college, which exhibits a within-region standard deviation of 7 percentage points for its 2000-2007 change. This substantial variation in neighborhood change is the key treatment object of interest in this study.

Table 1 Panel A presents summary statistics of relevant census demographic variables.

\subsection{Commute Times}

Our empirical work requires information on commute times between each pair of census tracts in each region in 1990 and 2000. Since the CTPP only uses reports from the roughly one out of every six households who received the Decennial Census long form and flows of fewer than 5 sampled workers are suppressed, many commutes and commute times are not observed in our data. Nevertheless, the CTPP is the most complete historical data on commute times between microgeographic units in a large number of U.S. cities. In particular, we observe this information for 7.4 million tract pairs in 1990 and 6.3 million tract pairs in 2000 in our sample of 254 regions.

So as to limit the influence of outliers, we focus on pairwise median commute times. The 1990 flow-weighted median of median commute time in our sample area is 20 minutes with a standard deviation of 15.1 minutes and a distribution that is skewed to the right. The 2000 median commute time rose to 20.8 minutes with a standard deviation of 19.8 minutes.

To fill in the remaining commute times, we develop an empirical forecasting model based on distances between tract centroids and to the region's CBD. We recognize that observed commutes may be subject to more road congestion than the less common commutes which we must forecast. As such, our prediction model may deliver overestimates of true commute times. However, the headline comparisons in the main empirical work below are for residential locations within CBD distance rings and thus should be subject to similar predicted commute time biases. ${ }^{5}$

After experimenting with a number of flexible forecasting models, we settled on the following simple forecasting equation.

$$
\begin{aligned}
\ln \tau_{i j}^{m}= & \alpha_{d} \ln \text { Distance }_{i j}+\alpha_{r} \ln (\text { Residence CBD Dis })_{i}+\alpha_{w} \ln (\text { Work CBD Dis })_{j} \\
& +v_{m}+u_{i j}^{m}
\end{aligned}
$$

Here, the commute time from tract $i$ to tract $j$ in region $m$ is constant elasticity in distance between $i$ and $j$ plus the CBD distances from home and work. The region fixed effects allow average travel speeds to differ across regions (Couture et al., 2017). Including the two CBD distance terms adds

\footnotetext{
${ }^{5}$ Allen, Arkolakis \& Li (2017) uses travel times calculated using the Fast Marching Method algorithm instead. This also does not account for equilibrium effects due to changes in congestion and would be difficult to implement for 1990 .
} 
about 0.02 to the R-Squared. Adding additional terms to separate out radial from circumferential travel in a flexible way and/or introducing heterogeneity in the estimated elasticities adds less than 0.03 to the R-Squared.

The estimated parameters are reported in Table A1. Our estimated elasticity of travel time with respect to distance is about 0.43. Starting or ending the trip $10 \%$ further from the CBD takes 0.7 percent less time, reflecting faster average travel speeds in the suburbs. The forecasting model fits reasonable well with within R-squared values of 0.53 in 1990 and 0.50 in 2000. Figure A1 shows a graph of the region fixed effects. Travel times in 2000 were highest in the Boston, Chicago, Jersey City, Los Angeles, Newark, New York, Paterson, San Francisco, Trenton, and Washington areas, for a given trip distance and origin and destination CBD distances. ${ }^{6}$ These parameters are used to predict $\widehat{\tau}_{i j}$ for the location pairs between which we do not observe commute times, while incorporating that error terms in each region are drawn from independent normal distributions with different variance parameters. As may be expected, distributions of predicted commute times are typically longer than observed travel times, as short commute times are more likely to attract commuters in equilibrium.

\subsection{Federal Reserve Bank of New York Consumer Credit Panel / Equifax (CCP)}

The CCP has information about block of residence, birth year, loan balances and creditworthiness for a random $5 \%$ nationwide sample of people with a social security number and a credit record. The sample runs from 1999 to the present. We use this data to construct credit histories of children born 1985-1989 and their parents starting in 2000. The observation counts from the CCP indicate that about $85 \%$ of the U.S. population in 2017 had a social secuity number and credit history. This share is stable across the age distribution. ${ }^{7}$ As in Chetty \& Hendren (2018a, b), we identify "parents" as anybody coded to the same address as the child that is $16-45$ years older than them in the first year we observe the child in the sample, typically at age 19-21.

The tracts in our sample area contained about 133 million resdents as measured by the 2000 Census. Five percent of that is 6.55 million people. As of 2000Q1, there were 3.9 million people in our sample area in the CCP. This number is lower than 5 percent of the population primarily due to the fact that not everyone has a credit history, especially children under 18 . This means that in order to determine where young adults in 2017 lived in 2000 when they were children, we must link them to an adult that is also in the 5 percent sample. We can only follow parents' residential locations back in time if they are also sampled, meaning that we have in essence a $5 \%^{2}=0.25 \%$ nationwide random sample that we can use for analysis. We focus on children born from 1985-

\footnotetext{
${ }^{6}$ The New York region geography overlaps with those for Newark, Jersey City and Paterson.

${ }^{7}$ The coverage is also good in earlier years. In $2000 \mathrm{Q} 1$, we observe $78 \%$ of $25-29$ year olds and $85 \%$ of $30-34$ year olds in the CCP, with this share above $81 \%$ for all older age groups.
} 
1989, making them 11-15 years old in 2000 when we observe their parent's residential location, and 28-32 in 2017 at the end of the sample period. This restriction results in a sample size of 10,859 parent-child pairs.

There is a slight complication due to the fact that the CTPP regions can overlap. In these cases, we include any CCP individuals in the sample for for each of the overlapping regions, meaning they appear in the estimation sample multiple times. However, we assign them a weight of one divided by the number of CTPP regions that their tract is in. All of our estimation results use these weights.

While educational attainment is not reported in the CCP, we use the sex-race distribution of the parent's 2000 Census block and the sex-race-educational attainment distribution of their 2000 Census block group to compute weights which represent the probability that each parent is in one of four educational attainment groups: less than a high school degree, high school graduate, some college, and college degree or higher. When we report estimates by educational attainment group for the CCP, we weight by the product of these weights and the weights discussed in the previous paragraph that account for overlapping CTPP regions. When we report observation counts for the CCP results in Tables 8-10 we report the sum of the weights, reflecting the number of unique individuals represented in each specification. Table 1 Panel B presents summary statistics of the CCP data.

\subsection{PSID}

The geocoded PSID follows households over time, allowing us to look at outcomes for children through 2015 living in households hit by labor demand shocks in the 1990s. We focus on the 1,570 children in the PSID that were between the ages of 0 and 18 in 1990, were living with at least one of their parents and lived in our study region described above. Due to siblings and cluster sampling, only 684 census tracts are represented. Table 1 Panel C presents summary statistics for the PSID sample.

\section{Tract Level Analysis}

Our main goal is to estimate causal effects of increases in neighborhood quality on outcomes of incumbent resident children. While our main empirical analysis makes use of the full distribution of employment and population across all census tracts in each region, our fundamental source of identifying variation is in interactions between the 1990 industrial composition of census tract employment and subsequent national industry employment growth rates. In this section we show that tract-level Bartik (1991) type labor demand shocks successfully predict tract-level employment growth. However, separating out skilled and unskilled labor demand shocks at the neighborhood level is only possible for the 2000-2010 period. In Section 6, we explain how we spatially aggregate 
these tract-specific shocks into market access shocks that measure exogenous variation in skillspecific labor demand conditions facing each residential neighborhood and justify the conditions required for their use in building our instruments.

\subsection{Construction of Tract-Level Shocks}

We adapt the widely used Bartik (1991) local labor demand shocks to isolate exogenous variation in 1990-2000 and 2000-2010 tract-specific labor demand and employment growth. ${ }^{8}$ These shocks are constructed by predicting employment growth using 1990 tract industry composition as weights interacted with average national growth rates across industries among college graduates. This type of measure has been widely used to isolate exogenous variation in labor demand in empirical work on local labor markets going back to Blanchard \& Katz (1992). Our implementation has some similarities to that in Diamond (2016), who also uses Bartik shocks for identification while interpreting them as a component of skill group-specific productivity shocks in the context of a general equilibrium model of local labor markets. Unlike Diamond (2016), however, we employ these shocks to isolate variation in labor demand conditions across locations within metropolitan regions (as in Couture \& Handbury, 2017), rather than between metropolitan regions. As a result, the assumptions required for identification, discussed further below, are somewhat different. The key goal is to control for any variation in tract employment growth that may come from differential trends within metro areas in amenities, housing productivity or unobserved initial demographic conditions.

We construct the following two tract-specific Bartik shocks for the 2000-2005 period experienced by census tract $j$, where $k$ indexes industry:

$$
\begin{aligned}
\operatorname{Bartik}_{j}^{S} & =\sum_{k} \frac{\theta_{m^{\prime}(j) k S}^{90} E m p_{j k}^{90}}{\sum_{k} \theta_{m^{\prime}(j) k S}^{90} E m p_{j k}^{90}}\left[\ln E_{m^{\prime}(j) k S}^{05}-\ln E_{m^{\prime}(j) k S}^{00}\right] \\
\operatorname{Bartik}_{j}^{U} & =\sum_{k} \frac{\theta_{m^{\prime}(j) k U}^{90} E m p_{j k}^{90}}{\sum_{k} \theta_{m^{\prime}(j) k U}^{90} E m p_{j k}^{90}}\left[\ln E_{m^{\prime}(j) k U}^{05}-\ln E_{m^{\prime}(j) k U}^{00}\right]
\end{aligned}
$$

In these equations, $E m p_{j k}^{90}$ is the number of workers in tract $j$ and industry $k$ in 1990 taken from the CTPP data. $\theta_{m^{\prime}(j) k S}^{90}$ and $\theta_{m^{\prime}(j) k U}^{90}$ are weights calculated from the census micro data using all states outside of $j$ 's metropolitan area $m$ for the fraction of metropolitan area $m$ workers in industry $k$ in 1990 that are "skilled" and "unskilled" respectively. We count skilled workers as those with a college education or more and unskilled workers as those with any lesser amount of education. $\ln E_{m^{\prime}(j) k S}^{05}$ indicates the log of 2005 skilled employment in industry $k$ in all states excluding those of

\footnotetext{
${ }^{8}$ We use 2000-2005 shocks rather than 2000-2010 shocks in order to improve first stage strength, as we discuss below.
} 
metropolitan area $m$ and $\ln E_{m^{\prime}(j) k S}^{00}$ is the analogous object for 2000. We build analogous versions of these variables for 1990-2000 using the same 1990 employment shares interacted with employment growth rates over this earlier period. Table A2 lists the industry categories that we use to construct these variables with the most and least rapid employment growth rates during the 1990-2000 and 2000-2005 periods. We also construct unified Bartik shocks in which the $\theta$ weights are set to one.

It is straightforward to microfound the use of such Bartik shocks such that they represent the national component of productivity or output price growth as follows. ${ }^{9}$ Suppose firms use skilled labor, unskilled labor and nationally traded capital to produce. This generates the following (reduced form) tract-industry specific aggregate labor demand equation for skill group $S$, where $p_{k}$ is the output price, $w_{j k}^{S}$ is the skilled wage and $w_{j k}^{U}$ is the unskilled wage.

$$
\ln L_{j k}^{S}=f^{S}\left(\ln \alpha_{j k}^{S}, \ln \alpha_{j k}^{U}, \ln p_{k}, \ln w_{j k}^{S}, \ln w_{j k}^{U}\right)
$$

Additionally, decompose productivities $\ln \alpha_{j k}^{S}$ and $\ln \alpha_{j k}^{U}$ to have tract-specific, industry-specific and idiosyncratic components: $\ln \alpha_{j k}^{S}=a_{j}^{S}+b_{k}^{S}+u_{j k}^{S}$. Our goal is to achieve identification from variation in productivity or output demand shocks across industries represented by differential trends in $\ln \alpha_{j k}^{S}, \ln \alpha_{j k}^{U}$ and $\ln p_{k}$. Aggregating across industries at the tract level, we have

$$
\begin{aligned}
d \ln L_{j}^{S}= & \sum_{k} S_{j k}^{S} d \ln L_{j k}^{S} \\
= & \sum_{k} S_{j k}^{S}\left[f_{1}^{S} d b_{k}^{S}+f_{2}^{S} d b_{k}^{U}+f_{3}^{S} d \ln p_{k}\right] \\
& +\sum_{k} S_{j k}^{S}\left[\operatorname{endog}_{j k}^{S}\right],
\end{aligned}
$$

where $S_{j k}^{S}$ is the share of base-year skilled employment in industry $k$, subscripts on $f$ indicate partial derivatives and $e n d o g_{j k}^{S}=f_{4}^{S} d \ln w_{j k}^{S}+f_{5}^{S} d \ln w_{j k}^{U}$.

The idea of Bartik instruments is to use only variation in $d \ln L_{j}^{S}$ from $\sum_{k} S_{j k}^{S}\left[f_{1}^{S} d b_{k}^{S}+f_{2}^{S} d b_{k}^{U}+\right.$ $\left.f_{3}^{S} d \ln p_{k}\right]$ for identification. To achieve power, we need that $\left[f_{1}^{S} d b_{k}^{S}+f_{2}^{S} d b_{k}^{U}+f_{3}^{S} d \ln p_{k}\right]$ is correlated with [ln $\left.E_{m^{\prime}(j) k S}^{05}-\ln E_{m^{\prime}(j) k S}^{00}\right]$, calculated only using locations in states outside of the metro area of tract $j$. We can think of identification as coming either from exogenous components of differences in initial industry shares $S_{j k}^{S}$ across tracts (Goldsmith-Pinkham et al., 2018) or from random shocks to industry growth (Borusyak, Hull \& Jaravel, 2018).

While random industry-specific growth rates would obviate the need for concern about exogeneity of tract-level Bartik instruments, our observation that shocks are correlated across industries leads us to organize our empirical strategy in order to minimize potential concerns that base year

\footnotetext{
${ }^{9}$ Also see Adao, Kolesar, and Morales (2018) for a similar treatment.
} 
industry shares $\frac{\theta_{m^{\prime}(j) k S}^{90} E m p_{j k}^{90}}{\sum_{k} \theta_{m^{\prime}(j) k S}^{90} E m p_{j k}^{90}}$ may be correlated with unobserved labor supply shifters driving local employment growth. For example, areas with a heavy manufacturing presence may have declining amenities due to industrial pollution and plant closures that shift both labor supply and labor demand inwards. In our main empirical work laid out in Section 6, we sidestep this problem by only using Bartik shocks outside tracts of residence for identification and have robustness checks that explicitly control for predicted employment growth near the origin tract. We also present an analysis of pre-treatment trends to further alleviate concerns that unobservables driving outcomes of interest may be correlated with the 1990 industrial composition of employment in commuting destination tracts. Our purpose in this section is only to indicate the sources of Bartik-type variation that are available for identification in our setting.

In our implementation of this Bartik research design, we follow best practices suggested by Goldsmith-Pinkham, Sorkin \& Swift (2018). First, we maintain the same base year shares for Bartik shocks over both the 1990-2000 and 2000-2010 periods. Second, we show robustness to a number of different control sets. Third, we demonstrate that the instruments do not predict pretreatment trends, conditional on these control sets. Anticipating our use of spatial aggregations of tract-level Bartik shocks for identification in the main empirical work, we defer the third test to our main implementation in Sections 6 and 7.

\subsection{Tract Level Empirics}

Since tract-level measures of employment by education are not available in 1990 and 2000, we impute employment by skill using the region-specific distribution of educational attainment by industry and the tract-specific industrial composition. These objects allow us to construct weights which represent the share of skilled and unskilled workers in each tract and year. We build these weights using education shares by industry for all PUMAs in the region of interest using data from the Census PUMS for the year in question. For 2010, we directly observe the fraction of jobs held in each tract by education in the LODES data.

Table 2 shows tract-level regressions of employment growth rates for 2000-2010 (Panel A) or 1990-2000 (Panel B) of all, high skilled and low skilled employment on Bartik shocks Bartik ${ }_{j}^{S}$ and $B_{a r t i k}^{U}$. We control for $2-2.5 \mathrm{~km}$ wide CBD distance ring fixed effects interacted with region fixed effects, a quadratic in CBD distance and 10 and 20 year lags of tract demographic composition in all specifications. ${ }^{10}$

The results in columns 1 and 2 of Panel A show the effects of the Bartik variables on total employment growth. These results show that high-skill Bartik shocks predict total 2000-2010 tract-

\footnotetext{
${ }^{10}$ Accounting for the strong CBD distance-specific trends in employment growth requires our flexible controls for CBD distance. The lagged demographic controls are included to make this specification comparable to those developed below in the main part of the empirical analysis.
} 
level employment growth (column 1), and do so, even conditional on low-skill Bartik shocks. The results in columns 3 and 6 of Panel A show that the skill-specific shocks have impacts on skillspecific employment growth with the expected signs. The results in columns 4 and 7 show that this is true even conditional on the other shock, prefacing our ability to separate out skill-specific 2000-2010 labor demand shocks to residential neighborhoods. However, the results in columns 5 and 8 show that the identifying variation in these skill-specific shocks is quite different for the high and low skilled shocks. In particular, positive high-skill shocks and negative low-skill shocks provide most of the identifying variation, meaning we can only successfully isolate exogenous variation in tract-level skilled employment growth and unskilled employment declines for the 2000-2010 period. We note that analogous regressions using 2000-2010 shocks instead of 2000-2005 shocks have lower power due to the fact that there is little cross-industry shock variation for the $2005-2010$ period. It is for this reason that we use the 2000-2005 period only to construct Bartik shocks. We use 2010 as the terminal year in which we measure employment by skill because this is the first year in which

the LODES coverage is complete and in which we can observe the actual education composition of employment in each tract.

Panel B of Table 2 shows the effects of 1990-2000 Bartik shocks on contemporaneous employment growth. Here, the results in columns 4 and 7 are most informative about our power to separately predict high and low skilled employment growth with their respective shocks. The results in both columns show positive coefficients on the high-skill shock and negative coefficients on the lowskill shock. This means that we cannot separately predict both skilled and unskilled employment growth simultaneously with these two shocks. As such, our analysis for the 1990s necessarily focuses more on simply estimating the effects of unified labor demand shocks on neighborhood change and residents' outcomes. Indeed, we show evidence from the PSID that neighborhood effects are not separately identifiable from parents' wealth effects in Section 7.2.

Taken together, the results in Table 2 show that we can isolate exogenous variation in tractlevel skilled employment growth, while holding unskilled employment growth constant, in the 20002010 period. Since our primary goal is to isolate exogenous variation in skilled worker residential populations across tracts, we use tract-specific skilled Bartik shocks as our main source of identifying variation. The next section shows how we aggregate tract-level labor demand shocks to form the treatment variables hitting each residential tract used in our main empirical analysis.

\section{Conceptual Framework}

In this section, we lay out the application of the urban economic geography model developed in Ahlfeldt et al. (2015) as adapted by Tsivanidis (2018) to generate a measure of "market access" that is readily measured with our data, is conceptually appealing, and has a convenient theoretical interpretation. In addition to facilitating clear thinking about various threats to identification, the 
model delivers treatment measures that incorporate sensible spatial aggregates of labor demand shocks that are relevant to residential locations. The model is used primarily as a vehicle to deliver theoretically grounded treatment variables that capture shifts in labor demand conditions that are oriented toward residential locations and can be constructed from identifying variation across work locations.

We conceptualize each region as starting off in long-run equilibrium in 1990. In this equilibrium, the labor market clears in each work location $j$ and the housing market clears in each residential location $i$. We first develop the simpler case in which there is only one worker type and then show how the environment extends to accommodate both skilled and unskilled workers.

\subsection{Preferences \& Worker Productivity}

Starting from standard Cobb-Douglas preferences, we can write the indirect utility of individual $\omega$ living in tract $i$ commuting to work in tract $j$ and working in industry $k$ as

$$
V_{i j k \omega}=\frac{v_{i \omega} B_{i} z_{i j k \omega} w_{j k}}{Q_{i}^{1-\beta} e^{\kappa \tau_{i j}}}
$$

where $B_{i}$ is a local consumer amenity, $w_{j k}$ is the price of a unit of skill in $j k, Q_{i}$ is the price of a unit of space in $i, 1-e^{-\kappa \tau_{i j}}$ is the fraction of time spent commuting for those living in $i$ and working in $j$ and $1-\beta$ is the housing expenditure share. One component of the local amenity $B_{i}$ may be endogenous and depend on neighborhood demographic composition.

$z_{i j k \omega}$ is a worker-commute-industry specific productivity shock drawn from the Frechet distribution:

$$
F_{z}\left(z_{i j k \omega}\right)=e^{-z_{i j k \omega}^{-\varepsilon}}, \varepsilon>1 .
$$

$v_{i \omega}$ is a preference or amenity shock for living in $i$, also distributed Frechet:

$$
F_{v}\left(v_{i \omega}\right)=e^{-v_{i \omega}^{-\eta}}, \eta>1 .
$$

Workers first see the preference (or amenity) shock for each potential residential location and choose their places of residence to maximize expected utility, anticipating the distribution of wages net of commuting costs associated with each residential location. The productivity shocks are then revealed and individuals choose the highest utility work location-industry combination. If $\eta=\varepsilon$, this formulation reduces to the simpler version of the model in which there are only productivity shocks and no preference shocks, and workers choose commutes to maximize indirect utility in one step. $^{11}$

\footnotetext{
${ }^{11}$ Reformulation of the model to have individuals first choose a work location, based on productivity shocks indexed to $j$ only, and then a commute, with amenity shocks specific to either $i$ or $i j$, generates constant elasticity relationships that are isomorphic to those derived below.
} 


\subsection{Residential Population}

Given this setup, the fraction of residents in $i$ who commute to $j$ is

$$
\pi_{i j \mid i}=\frac{\sum_{k}\left[w_{j k} e^{-\kappa \tau_{i j}}\right]^{\varepsilon}}{\sum_{k} \sum_{j^{\prime}}\left[w_{j^{\prime} k} e^{-\kappa \tau_{i j}}\right]^{\varepsilon}} \equiv \frac{\sum_{k}\left[w_{j k} e^{-\kappa \tau_{i j}}\right]^{\varepsilon}}{R M A_{i}}
$$

where $R M A_{i} \equiv \sum_{k} R M A_{i k} . R M A_{i}$ is our central Resident Market Access variable that is a summary of the strength of job opportunities in and around residential tract $i$. Below we show how we calculate $R M A_{i}$ using information on employment and residential population in each tract. Equation (8) shows that the commuting probability to $j$ is increasing in the wage and decreasing in the commuting cost.

The expected income net of commuting cost from living in tract $i$ is

$$
\bar{y}_{i}=\Gamma\left(1-\frac{1}{\varepsilon}\right)\left(R M A_{i}\right)^{\frac{1}{\varepsilon}}
$$

where $\Gamma(\cdot)$ is the gamma function and comes from taking the expectation over a Frechet distributed random variable. Note that this object is less than the average wage in tract $i$ because the wage does not explicitly include commuting costs. Even though it is not observed directly, $\bar{y}_{i}$ is a useful object to define as it is constant elasticity in $R M A_{i}$, which we can measure with our data.

Anticipating full income $\bar{y}_{i}$ and housing cost $Q_{i}$, preference shocks trace out the residential population supply to tract $i$. The probability that an individual's utility is maximized by living in tract $i$ is:

$$
\pi_{i}=\lambda\left(B_{i} Q_{i}^{\beta-1}\left(R M A_{i}\right)^{\frac{1}{\varepsilon}}\right)^{\eta}
$$

Intuitively, this object is increasing in amenities and labor market opportunities but declining in the housing price. ${ }^{12}$

\subsection{Commuting Gravity and Labor Supply}

In the data, we observe that commute lengths differ markedly across regions. New York has the longest commutes, with an average commute time of 35 minutes in 1990. Bryan-College Station, Texas has the shortest at just 13 minutes. The model can rationalize this discrepancy with different Frechet parameters $\varepsilon$ for each region. Regions in which people are willing to commute longer have more dispersion in their productivity draws (lower values of $\varepsilon$ ). Indeed, a classic explanation for agglomeration economies is that larger cities like New York may exhibit more division of labor and heterogeneity in job types than smaller places like Bryan-College Station (Tian, 2018). Allowing for variation in $\varepsilon$ across regions will be important for our empirical implementation, as tract employment

\footnotetext{
${ }^{12}$ The constant $\lambda$ is $1 / \sum_{i^{\prime}}\left[Q_{i^{\prime}}^{\beta-1} B_{i^{\prime}}\left[R M A_{i^{\prime}}\right]^{\frac{1}{\varepsilon}}\right]$.
} 
growth impacts market access in areas accessible by longer commute times (meaning broader areas) in regions in which $\varepsilon$ is lower.

Combining Equations (8) and (10) allows for the recovery of equilibrium commuting flows $\pi_{i j}=$ $\pi_{i j \mid i} \pi_{i}$. These satisfy the following gravity relationship with commuting times.

$$
\begin{aligned}
\ln \left(\pi_{i j}\right) & =\ln \lambda+\ln \left[\sum_{k}\left[w_{j k}\right]^{\varepsilon}\right]+\ln \left[\left(B_{i} Q_{i}^{\beta-1}\right)^{\eta}\left(R M A_{i}\right)^{\frac{\eta}{\varepsilon}-1}\right]-\kappa \varepsilon \tau_{i j} \\
& =\alpha_{i}+\rho_{j}-(\kappa \varepsilon) \tau_{i j}
\end{aligned}
$$

That is, we can identify $\kappa \varepsilon$ with commuting flow gravity regressions that include origin and destination fixed effects.

We implement the regressions described by Equation (11) by region in 1990 and 2000, weighting by flow (the number of commuters). The resulting estimates of $\kappa \varepsilon$ are depicted in Figure A2. It shows values as low as about 0.02 in large cities including New York and Los Angeles, but also some smaller cities including Tulsa, OK and Mobile, AL. Large values up to about 0.12 are observed in some small cities, including Fargo, ND and Eau Claire, WI. A reasonable calibration of $\kappa$ is 0.005 to 0.01 , implying that a 10 minute commute takes 5-10 percent of the worker's time endowment for working plus commuting. Comparing Panels A and B of Figure A2, the distribution of $\widehat{\kappa \varepsilon}$ across regions is pretty stable between 1990 and 2000, though smaller cities are more likely to move around the distribution than are large cities. The correlation between the 1990 and 2000 region-specific estimates of $\widehat{\kappa \varepsilon}$ is 0.61 .

The labor supply to tract $j$ can be derived by aggregating over commuting flows $L_{j}=\sum_{i} \pi_{i j}$.

$$
L_{j}=\lambda\left[\sum_{k} w_{j k}^{\varepsilon}\right] \sum_{i}\left[e^{-\kappa \varepsilon \tau_{i j}}\left(B_{i} Q_{i}^{\beta-1}\right)^{\eta} R M A_{i}^{\frac{\eta}{\varepsilon}-1}\right]
$$

This object is increasing in the wage opportunities $\left[\sum_{k} w_{j k}^{\varepsilon}\right]$ available in tract $j$ and the residential population in locations that are more accessible to tract $j$. Following Tsivanidis (2018) and Donaldson and Hornbeck (2016), we define the access from each work location $j$ to residential locations of the labor pool as "Firm Market Access"

$$
F M A_{j} \equiv \lambda \sum_{i}\left[e^{-\kappa \varepsilon \tau_{i j}}\left(B_{i} Q_{i}^{\beta-1}\right)^{\eta} R M A_{i}^{\frac{\eta}{\varepsilon}-1}\right]
$$

Intuitively, this object is increasing in nearby residential amenities $B_{i}$ but decreasing in nearby housing costs $Q_{i}$ and commute times to residential locations $\tau_{i j}$. From the perspective of firms in location $j$, the object $e^{-\kappa \varepsilon \tau_{i j}} R M A_{i}^{\frac{\eta}{\varepsilon}-1}$ reflects two forces. On the one hand, higher $R M A_{i}$ in nearby residential locations is a positive labor supply shifter that tends to increase $F M A_{j}$. On the 
other hand, higher $R M A_{i}$ in such locations tends to reflect more competition for workers, thereby reducing $F M A_{i}$. If individuals' elasticity of substitution between neighborhoods in the residential demand system, $\eta$, is higher than the labor supply elasticity to work tracts, $\varepsilon$, then RMA's positive labor supply shifter effect outweighs its competition effect, thereby increasing FMA. ${ }^{13}$

\subsection{Measurement of Market Access}

We combine the expressions above for $R M A_{i}$ and $F M A_{j}$ into a system of recursive equations that can be solved given data on the number of jobs and workers in each tract, tract pair commute times and the parameter cluster $\varepsilon \kappa$. Substitution of Equation (10) into Equation (13) yields an expression for FMA that depends only on RMA in each commuting origin, the parameter cluster $\varepsilon \kappa$ and the residential population of each commuting origin. Using $L_{j}=\left[\sum_{k} w_{j k}^{\varepsilon}\right] F M A_{j}$ from Equation (12) and substituting into the definition of $R M A_{i}=\sum_{j} e^{-\varepsilon \kappa \tau_{i j}} \sum_{k}\left[w_{j k}\right]^{\varepsilon}$ delivers the expression for $R M A_{i}$ below. The resulting system of equations is

$$
\begin{aligned}
F M A_{j} & =\sum_{i} \frac{e^{-\varepsilon \kappa \tau_{i j}} \pi_{i}}{R M A_{i}} \\
R M A_{i} & =\sum_{j} \frac{e^{-\varepsilon \kappa \tau_{i j}} L_{j}}{F M A_{j}} .
\end{aligned}
$$

This system of equations captures the interplay between employment and residential commuting linkages in a metropolitan region. The numerator of Equation (15) reflects that greater employment accessibility must raise available wages net of commuting cost to residential tract $i$. The denominator of Equation (15), $F M A_{j}$, captures the competition effect - that wages become depressed if there are more competing potential workers living nearby. A nice feature of these "market access" objects is that their specification only depends on indifference of people across work and residential locations given some equilibrium wage vector $w_{j k}$. We do not need to specify a structure of labor demand or firm production in order for the empirically observable object $R M A_{i}$ to capture labor demand conditions in tract $i$.

Using data on employment $L_{j}$, residential population $\pi_{i}$ and commute times $\tau_{i j}$ plus estimates of $\kappa \varepsilon$ for each region from the gravity equation (Equation 11), we calculate $F M A_{j}$ and $R M A_{i}$ for each tract and year in our data. We also calculate reduced form analogs to market access "Resident Market Potential" as $R M P_{i}=\sum_{j} e^{-\varepsilon \kappa \tau_{i j}} L_{j}$. In the data, $R M P_{i}$ and $R M A_{i}$ have a correlation coefficient of about 0.95 .

\footnotetext{
${ }^{13}$ Attempts to estimate $\frac{\eta}{\varepsilon}$ in our data yield estimates of about 4, indicating that neighborhoods are highly substitutible in the residential demand system.
} 


\subsection{Model Closure and Equilibrium}

To close the model, we introduce the constant-elasticity housing supply function for each tract.

$$
H_{i}^{s}=\rho_{i} Q_{i}^{\gamma}
$$

We allow each tract to have its own housing productivity but constrain the housing supply elasticity to be the same in all locations. ${ }^{14}$ Our preference specification delivers the following Cobb-Douglas tract housing demand function.

$$
H_{i}^{d}=\frac{(1-\beta)}{Q_{i}} \Gamma\left(1-\frac{1}{\varepsilon}\right)\left(R M A_{i}\right)^{\frac{1}{\varepsilon}} \pi_{i}
$$

For simplicity, we assume that firms do not use space in production.

Equating housing supply (Equation 16) with housing demand (Equation 17) and substituting in for population, we derive the equilibrium relationship between housing price and $R M A_{i}$.

$$
\begin{aligned}
\ln Q_{i}= & \frac{1}{\gamma+1+\eta(1-\beta)} \ln \left[(1-\beta) \Gamma\left(1-\frac{1}{\varepsilon}\right) \lambda\right]+\frac{1+\eta}{\varepsilon} \frac{1}{\gamma+1+\eta(1-\beta)} \ln \left(R M A_{i}\right) \\
& +\frac{\eta}{\gamma+1+\eta(1-\beta)} \ln B_{i}-\frac{1}{\gamma+1+\eta(1-\beta)} \ln \rho_{i}
\end{aligned}
$$

This expression looks like a regression equation, with the error term composed of a linear combination of local amenity $\ln B_{i}$ and housing productivity $\ln \rho_{i}$.

Substituting back into the population supply condition (10), we have $\mathrm{e}^{15}$

$$
\begin{aligned}
\ln \pi_{i}= & K+\frac{\eta}{\varepsilon} \frac{(\gamma+1)+(1-\beta)}{(\gamma+1)+\eta(1-\beta)} \ln \left(R M A_{i}\right) \\
& +\left(\frac{\eta \eta(\beta-1)}{\gamma+1+\eta(1-\beta)}+\eta\right) \ln B_{i}-\frac{\eta(\beta-1)}{\gamma+1+\eta(1-\beta)} \ln \rho_{i}
\end{aligned}
$$

Finally, we calculate the average wage earned by workers in each residential tract. Note that average income net of commuting cost is a constant elasticity function of RMA, but average wage is not. However, if commuting costs are small then the two are close.

$$
\bar{w}_{i}=\left[R M A_{i}\right]^{\frac{1}{\varepsilon}} \Gamma\left(1-\frac{1}{\varepsilon}\right) \sum_{j} \sum_{k} \pi_{i j k \mid i}^{S} e^{\kappa \tau_{i j}}>\left[R M A_{i}\right]^{\frac{1}{\varepsilon}} \Gamma\left(1-\frac{1}{\varepsilon}\right)
$$

In the context of the simple version of the model with one type, the empirical challenge is that $R M A_{i}$ incorporates elements of error terms in Equations (18) and (19). In the following section, we

\footnotetext{
${ }^{14} \mathrm{As} R M A_{i}$ does not depend on housing supply elasticity, this assumption does not materially impact our analysis.

${ }^{15} K=\left(1+\frac{\eta(\beta-1)}{\gamma+1+\eta-\eta \beta}\right) \ln \lambda+\frac{\eta(\beta-1)}{\gamma+1+\eta-\eta \beta} \ln \left[(1-\beta) \Gamma\left(1-\frac{1}{\varepsilon}\right)\right]$
} 
lay out our strategy for using tract-specific Bartik shocks to isolate variation in $\Delta \ln R M A_{i}$ that is orthogonal to trends in local amenities and housing productivity that show up in these error terms.

\subsection{Extension to Multiple Skill Groups}

Incorporating multiple skill types in the model is straightforward. Given observations about residents and workers by skill in each location, we retain the same definitions of $R M A$ and FMA as in Equations (15) and (14) with the addition of superscripts $S$ for skilled or $U$ for unskilled. Note that the introduction of two versions of each of these objects accommodates the possibility that unskilled and skilled wages $w_{j k}^{U}$ and $w_{j k}^{S}$ may both depend on the number of unskilled and skilled workers in tract $j$ and industry $k$. Measurement of equilibrium $R M A_{i}^{S}$ and $R M A_{i}^{U}$ does not require taking a stand on how low and high skilled workers interact in production.

Because the two types of workers compete for housing in each residential location, the housing market clearing condition delivers a housing cost that depends on both $R M A_{i}^{S}$ and $R M A_{i}^{U}$. This feeds through to mean that both objects also predict the equilibrium unskilled and skilled populations of each tract $\pi_{i}^{U}$ and $\pi_{i}^{S}$. In particular, the new equilibrium conditions are

$$
\begin{aligned}
\ln Q_{i} & =q+\frac{1}{\gamma+1+\eta(1-\beta)} \zeta_{i}+\omega^{q}\left(B_{i}, \rho_{i}\right) \\
\ln \pi_{i}^{U} & =P^{u}+\frac{\eta}{\varepsilon} \ln \left(R M A_{i}^{U}\right)+\frac{\eta(\beta-1)}{\gamma+1+\eta(1-\beta)} \zeta_{i}+\eta \ln B_{i}^{U}-\frac{\eta(\beta-1)}{\gamma+1+\eta(1-\beta)} \ln \rho_{i} \\
\ln \pi_{i}^{S} & =P^{s}+\frac{\eta}{\varepsilon} \ln \left(R M A_{i}^{S}\right)+\frac{\eta(\beta-1)}{\gamma+1+\eta(1-\beta)} \zeta_{i}+\eta \ln B_{i}^{S}-\frac{\eta(\beta-1)}{\gamma+1+\eta(1-\beta)} \ln \rho_{i}
\end{aligned}
$$

in which the component of total housing demand in tract $i$ given by $\zeta_{i}$ equally shifts the shares of workers of each type that choose to live in $i$ through its impact on housing cost. ${ }^{16}$

A few observations can be made from these expressions for equilibrium populations that are of particular relevance for our empirical work. First, the college fraction $\frac{\pi_{i}^{S}}{\pi_{i}^{S}+\pi_{i}^{U}}$ is increasing in $\ln \left(R M A_{i}^{S}\right)$ holding $\ln \left(R M A_{i}^{U}\right)$ constant. This justifies our empirical strategy of using exogenous shocks to $\ln \left(R M A_{i}^{S}\right)$ while holding $\ln \left(R M A_{i}^{U}\right)$ constant to deliver variation in $\frac{\pi_{i}^{S}}{\pi_{i}^{S}+\pi_{i}^{U}}$ across residential locations. While analytical expressions for $\ln \left(\frac{\pi_{i}^{S}}{\pi_{i}^{U}}\right)$ are simpler, we prefer to focus on $\frac{\pi_{i}^{S}}{\pi_{i}^{S}+\pi_{i}^{U}}$ as an outcome, as it is both commonly used in the gentrification literature (e.g. Brummet \& Reed, 2019) and is empirically better behaved in tracts with few residents of one skill group. Since our empirical work is done in differences and $d \frac{\pi_{i}^{S}}{\pi_{i}^{S}+\pi_{i}^{U}}=\frac{\pi_{i}^{S}}{\pi_{i}^{S}+\pi_{i}^{U}} \frac{\pi_{i}^{U}}{\pi_{i}^{S}+\pi_{i}^{U}} d \ln \left(\frac{\pi_{i}^{S}}{\pi_{i}^{U}}\right)$, the two measures of neighborhood change are closely related.

Second, $\ln \left(\frac{\pi_{i}^{S}}{\pi_{i}^{U}}\right)$ directly depends on unobserved tract consumer amenities $B_{i}^{U}$ and $B_{i}^{S}$, which will end up in error terms in the empirical work. Moreover, $R M A_{i}^{U}$ and $R M A_{i}^{S}$ themselves are

$$
{ }^{16} \zeta_{i}=\ln \left[\left(B_{i}^{U}\right)^{\eta} \lambda^{U}\left(R M A_{i}^{U}\right)^{\frac{1+\eta}{\varepsilon}}+\left(B_{i}^{S}\right)^{\eta} \lambda^{S}\left(R M A_{i}^{S}\right)^{\frac{1+\eta}{\varepsilon}}\right]
$$


functions of these amenities not only in tract $i$, but in all other tracts as well. This is because $R M A_{i}$ depends on wages in all commuting destinations $j$, which in turn depend on populations in all commuting origins $i^{\prime}$ (including $i$ ), which themselves depend on local amenities $B_{i^{\prime}}$. The existence of neighborhood effects would mean that such local amenities are a function of the tract residential composition $\frac{\pi_{i}^{S}}{\pi_{i}^{S}+\pi_{i}^{U}}$. Therefore, estimation of treatment effects of $R M A_{i}^{S}$ on tract attributes (holding $R M A_{i}^{U}$ constant) requires using variation in $R M A_{i}^{S}$ that is independent of variation in $R M A_{i}^{U}$ and shocks to local amenities. We use these observations in the next section, in which we discuss how we use tract-level Bartik shocks to isolate exogenous variation in $R M A_{i}$ that is oriented toward skilled labor.

Third, we think of the structural parameters $\eta$ and $\varepsilon$ as being heterogeneous across regions and $\gamma$ as potentially heterogeneous across tracts (Baum-Snow \& Han, 2018). Indeed, in Section 5.3 above we showed direct evidence that $\varepsilon \kappa$ is heterogeneous across regions. However, in the empirical work in the next two sections we do not have sufficient statistical power to estimate parameters separately by region. That is, our empirical setting constrains us to estimating average coefficients which do not have straightforward structural interpretations. ${ }^{17}$

Panel A of Table 1 provides summary statistics about log differences in skilled and unskilled RMA measures over our two study periods. In both study periods $R M A_{i}^{S}$ grows more rapidly on average than does $R M A_{i}^{U}$, though the two objects have a similar amount of dispersion. Importantly, most of the dispersion in market access growth comes from comparisons between rather than within commuting regions. The average within region standard deviation of the growth rate of skilled RMA, weighting all tracts in our primary sample equally, is 0.09 for 1990-2000 and 0.02 for 2000-2010. In much of the empirical work, we standardize using the average within region standard deviation across our full sample of census tracts so as to be able to make comparisons of impacts of treatment across tracts within metropolitan regions. ${ }^{18}$

Comparing the mean growth rates of tract market access to tract-level employment growth shows why market access is a useful summary measure of accessible labor market opportunities. In the 1990s, the mean tract-level employment growth rate was 0.17 - much greater than the mean growth rate of market access because of employment booms in areas with little 1990 employment. With the 2007-2009 financial crisis, tracts with only a small amount of 2000 employment disproportionately lost jobs, leading to a mean 2000-2010 tract-level employment growth rate of -0.21. Using the market access aggregation of these tract-level changes captures variation in changes in job accessibility much more smoothly than the simpler tract-level employment growth measure.

\footnotetext{
${ }^{17}$ Moreover, in most of our empirical work, we express RMA in terms of standard deviations, which allows us to make clearer connections with the neighborhood effects literature.

${ }^{18}$ Allen, Arkolakis \& Li (2016) show that a unique equilibrium exists in this type of model as long as agglomerative forces are not too strong, and that there is a unique mapping from the joint spatial distribution of population and employment to tract amenities and productivities. In practice, solving the just-identified system of $2 \mathrm{~J}$ equations in 2J unknowns for RMA and FMA per region is relatively fast. The largest region, New York City, takes only a few minutes.
} 
The left and middle panels of Figure 3 present heat maps of log skilled RMA in 2000 and 2010 for Los Angeles and Orange Counties, the bulk of the Los Angeles region in our data. Here one can see the smoothness of this measure across space. Adjacent tracts are most often in the same quartile (color shade) of each distribution. However, as seen in the right panel, the 2000-2010 change in log skilled RMA for this region is quite heterogeneous across space, with lots of variation across quartiles of its distribution between adjacent census tracts. Our empirical challenge, described in the following section, is to find instruments and controls that allow us to isolate plausibly exogenous variation in the change in log skilled RMA.

\section{Empirical Implementation}

The main goal of our empirical work is to use variation in changes in employment opportunities across census tracts in each metropolitan region to recover long-run effects on children. The neighborhood, parent and child outcome equations ( 1 - 5) laid out in Section 2 are the starting point for our empirical work. Due to various limitations to statistical power hinted at in our tract-level empirical analysis in Section 3, we are constrained from implementing these estimation equations exactly. We discuss these issues in this section along with various other identification challenges to settle on equations that are similar to Equations (1) - (5) but can be feasibly taken to the data.

The model is instructive both in showing how to construct a reasonable measure of labor market opportunities relevant to each location, $R M A_{i}$, and in highlighting various identification challenges. We conceptualize each region as starting off in long-run equilibrium with tract log populations by skill described by Equations (20) and (21). Each tract experiences shocks to local consumer amenities and wages in commuting destinations, which themselves are generated by national sector-specific productivity shocks. These wage shocks indirectly cause additional changes in local amenities $B_{i}^{U}$ and $B_{i}^{S}$ as tract demographic compositions change. The empirical challenge is first to isolate variation in the tract demographic change due to the arrival of new residents that come only because of productivity shocks to industries in nearby commuting destinations and then to estimate the knock-on effects for incumbent resident parents and their children. Through the lens of the model, the key identification challenge is that $B_{i}^{U}$ and $B_{i}^{S}$ may also change for other reasons that are correlated with but not caused by tract demographic change.

\subsection{Instruments}

The model illustrates that $\Delta \ln R M A_{i}^{S}$ and $\Delta \ln R M A_{i}^{U}$ depend on local trends in consumer amenities and housing productivity, both of which are labor and population supply shifters. That is, we are concerned that growing employment and $R M A$ occur in some areas because nearby residential neighborhoods are becoming nicer places to live, not vice-versa. These amenity changes may have 
direct effects on incumbent households and children that have nothing to do with neighborhood effects. More generally, we are concerned that unobserved neighborhood attributes (including demographic characteristics) that are correlated with nearby employment growth may be driving child outcomes rather than demographic change that is caused by this employment growth. To deal with these issues, we require identifying variation that is uncorrelated with local amenity shocks and other unobserved drivers of tract demographic composition that influence child outcomes.

Our primary workhorse instruments are 2000-2005 or 1990-2000 differenced counterfactual versions of RMA, which aggregate tract-level employment predicted with Bartik shocks. We construct the 2000 and 2005 levels of this counterfactual RMA as follows. In each tract, we assume that the 2000 and 2005 employment compositions maintain 1990 shares by industry and skill but get scaled up by the national growth rates for workers in each industry by skill. As with the tract-specific versions described in Equations (6) and (7), we apply industry-specific employment weights by skill from outside the region to construct growth rates of employment by skill. We omit tract $i$ when constructing the instrument in order to reduce the possibility that 1990 industry composition might predict subsequent tract amenity changes. This logic delivers the following expression for counterfactual skilled RMA in 2005:

$$
\widetilde{R M} A_{i}^{S 05}=\sum_{k} \sum_{j \neq i} \frac{e^{-\varepsilon \kappa \tau_{i j}^{90} \theta_{m^{\prime}(j) k S}^{90} E m p_{j k}^{90} \frac{E_{m^{\prime}(j) k S}^{05}}{E_{m^{\prime}(j) k S}}}}{\widetilde{F M} A_{j}^{S 05}}
$$

We maintain 1990 commute times and employment shares by industry and skill to build counterfactual RMA measures for all years. However, we update region-specific decay parameters $\varepsilon \kappa$ to be calculated with the 2000 data for instruments that apply to post-2000 growth in RMA. We construct two counterfactual versions of skilled and unskilled RMA for 2000, one that uses 1990 estimates of $\varepsilon \kappa$ to be differenced with the 1990 data, and one that uses the 2000 estimates of $\varepsilon \kappa$ to be differenced with the 2005 counterfactual RMA. Since $R M A_{i}=\sum_{k} R M A_{i k}$, aggregation over industries is fully consistent with the model.

Since RMA is codetermined with FMA, we must also specify a counterfactual FMA, the commuting time discounted sum of population in commuting origins accessible from tract $j$, divided by RMA in these origins. To construct counterfactual FMA, we assume that the 1990 residential population in each tract changes proportionately, so that the spatial distribution of residences does not change in the counterfactual 2000 or 2005 environment relative to 1990. This rescaling of tract population achieves the required market clearing condition $\sum_{j} \widetilde{F M} A_{j}=\sum_{i} \widetilde{R M} A_{i}$ without imposing any differential labor supply shocks across tracts. The resulting year 2005 measure of 
counterfactual FMA for skilled workers is thus:

$$
\widetilde{F M} A_{j}^{S 05}=\sum_{i \neq j} \frac{e^{-\kappa \varepsilon \tau_{i j}^{90} \pi_{i}^{S 90} \frac{\sum_{j} \sum_{k} \theta_{m^{\prime}(j) k S}^{90} E m p_{j k}^{90} \frac{E_{m^{\prime}}^{05}(j) k S}{E_{m^{\prime}(j) k S}}}{\sum_{j} \sum_{k} \theta_{m^{\prime}(j) k S} E m m_{j}^{90}}}}{\widetilde{R M} A_{i}^{S 05}}
$$

With this specification of counterfactual FMA, counterfactual RMA for any year after 1990 only incorporates changes in skill-specific labor demand conditions. ${ }^{19}$

We use the difference in the log of 2005 counterfactual skilled RMA and the log of 2000 counterfactual skilled RMA ( $\ln \widetilde{R M} A_{i}^{S 05}-\ln \widetilde{R M} A_{i}^{S 00}$ ) as our main instrument for the 2000-2010 change in $\log$ skilled RMA ( $\ln R M A_{i}^{S 10}-\ln R M A_{i}^{S 00}$ ) because the difference in the log of 2010 counterfactual skilled RMA and the $\log$ of 2000 counterfactual skilled RMA $\left(\ln \widetilde{R M} A_{i}^{S 10}-\ln \widetilde{R M} A_{i}^{S 00}\right.$ ) does not have sufficient first stage power. This is consistent with our tract-level empirical results in Section 4.2 .

The left panel of Figure 4 shows a heat map of our main instrument for the 2000-2010 analysis below, $\ln \widetilde{R M} A_{i}^{S 05}-\ln \widetilde{R M} A_{i}^{S 00}$, for Los Angeles and Orange counties. Tracts are shaded by quartile of this variable's distribution within the Los Angeles study region. The right panel of Figure 4 shows the same object after being residualized from a large set of control variables that are used in our primary estimation specifications. CBD distance rings of $10 \mathrm{~km}$ and $20 \mathrm{~km}$ are also indicated in the right panel. Both panels in Figure 4 show considerable variation across quartiles of the distribution conditional on CBD distance.

\subsection{Selection of Empirical Model Specifications}

We develop empirical specifications with the goal of estimating parameters in the tract equation (Equation 1) that describe treatment effects of skilled RMA growth $\left(\Delta \ln R M A_{i}^{S}\right)$ on changes in tract attributes (particularly neighborhood quality and fraction college graduate), while holding unskilled RMA growth $\left(\Delta \ln R M A_{i}^{U}\right)$ constant. We use the tract-level demographic data to select our empirical specifications because this is our only data set that goes back several decades in time and fully covers the regions in our sample. This allows us to determine the set of control variables required to condition out statistically significant relationships between the instruments and pretreatment trends in the dependent variables. After using the tract demographic data set to select our empirical specification, we specify analogous estimation equations which facilitate the recovery of treatment effects of skilled RMA growth $\left(\Delta \ln R M A_{i}^{S}\right)$ on parent and child outcomes.

To get a sense of the main potential biases when attempting to estimate the effects of labor

\footnotetext{
${ }^{19}$ An alternative approach would be to construct a fully simulated instrument in which $Q_{i}, \pi_{i}^{S}, \pi_{i}^{U}, R M A_{i}$ and $F M A_{j}$ are all solved out given a Bartik-based counterfactual employment $L_{j}$ in each tract. However, doing so would require knowledge of all of the structural parameters of the model. We have shown evidence that these parameters likely differ across regions and are difficult to identify empirically as a result.
} 
demand shocks on tract outcomes, we first examine the dynamics of neighborhood change descriptively. Table 3 reports OLS estimates of $a_{1}$ from regressions of the form

$$
\Delta_{t} n_{i m}=a_{0}+a_{1} \Delta_{t-1} n_{i m}+X_{i m} \phi+u_{m r}+\nu_{i m}
$$

where $n_{i m}$ is a tract-level outcome for tract $i$ in region $m$. That is, it shows the extent to which changes in neighborhood quality, fraction college or income growth rates are serially correlated conditional on various control sets. Here, $X_{i m}$ is a vector of base controls which include a quadratic in CBD distance, log 1990 tract employment and 10 and 20 year lags of a house price index, rent index, log population, log family income, share African American, share white, share college graduate, and share without a high school degree, $u_{m r}$ are "region-ring" fixed effects that fully interact region fixed effects with indicators for CBD distance rings of 0-2, 2-4, 4-6, 6-8, 8-10, 10$12.5,12.5-15,15-17.5$ and $17.5-20 \mathrm{~km}$, and $\nu_{i m}$ is an error term. ${ }^{20}$

The descriptive results on the serial correlations of these decadal changes, reported in Table 3 columns 1, 2, 5, 6, 9 and 10, are striking. Conditional on region-ring fixed effects and various combinations of additional controls, changes in our neighborhood quality index, fraction college and $\log$ average household income are all negatively serially correlated. Indeed, this negative serial correlation grows as more pre-determined controls are included in the regressions.

The remaining two columns for each outcome in Table 3 (columns 3, 4, 7, 8, 11 and 12) show how our main endogenous treatment variable $\Delta \ln R M A_{i}^{S}$ for the $2000-2010$ period relates to the lagged change and initial levels of the dependent variables. For example, the dependent variable in column 3 is the change in the share of residents with a college degree or higher from 1990 to 2000 and the dependent variable in column 4 is the share of residents with a college degree or higher in 2000. Here we see that growth in skilled RMA is positively related to prior neighborhood improvements and initial levels of neighborhood quality.

The results for the 1990-2000 period are presented in Appendix Table A3. The 1990-2000 period shows similar mean reversion as the 2000-2010 period. However, the conditional correlations between skilled RMA growth 1990-2000 and the 1980-1990 changes in the dependent variables or 1990 levels of the dependent variables are negative rather than positive, as they are in the later study period. Given the tendency for the growth in neighborhood quality to revert to the mean, one important function of our IV empirical strategy is to help control for the associated differential pre-treatment trends.

Figure 5 shows two diagrams that lay out the fundamental identification challenge and indicate the expected directions of OLS bias. On the vertical axis is tract fraction college and on the horizontal axis is time. The lines show two tracts with different evolutions of fraction college and

\footnotetext{
${ }^{20}$ In each year, the tract-level house price (rent) index is formed from the residuals of a regression of log mean owner occupied home value (log mean gross rent) on housing unit structure characteristics (number of units in building, number of bedrooms in unit, age of building) of the tract and region fixed effects.
} 
how they would evolve differently given two scenarios each for 2000-2010 RMA growth. The diagram on the left side shows the ideal 2000-2010 experiment, in which two tracts with identical levels and histories receive different rates of RMA growth. The red tract gets a positive RMA shock of one standard deviation and the blue tract gets no RMA shock. In an ideal experimental world, the blue tract is a valid counterfactual for the red tract that gets treated. Therefore, we can identifiy the treatment effect of the one standard deviation RMA shock by comparing the 2000-2010 growth in outcome in the red to that in the blue tract. The 1990-2000 pre-trends for these two tracts are identical, meaning they would have the same mean-reverting trend absent a shock to RMA.

The right panel in Figure 5 is closer to our empirical setting for the 2000-2010 period. In this diagram, we see the red tract with the more rapid 1990-2000 growth and higher 2000 level receiving the positive shock relative to the blue tract. We would like to use the blue tract as a counterfactual for the red tract absent a shock, but there is a selection problem. As a result, the simple difference in difference type estimator A-B underestimates the true treatment effect in this setting. A triple difference type estimator (A-A') - (B-B') would exacerbate this problem. Going from OLS to IV makes groups of tracts that receive different employment growth treatments more comparable, as does including demographic controls within IV. Since this is the nature of selection in our 2000-2010 study period, OLS understates the true causal effects of RMA growth on neighborhood quality.

The main role of the instruments is to quasi-randomize the distribution of unobserved neighborhood characteristics so that the treatment is unrelated to pre-treatment trends in neighborhood characteristics. Without such randomization, initial neighborhood attributes rather than changes in neighborhood composition or the labor market environment may drive child outcomes. Moreover, the instruments are useful because they allow us to isolate variation in employment opportunities for college graduates while holding employment opportunities for those without a college degree fixed.

Since all of our instruments are defined using variation in 1990 employment composition near tract $i$, sorting on the industry composition of nearby employment is our main identification concern. While excluding tract $i$ from the calculation of the instruments helps with this problem, employment levels and compositions by industry are likely to be spatially correlated. Our first approach to address this issue is to explicitly control for tract $i 1990$ employment and its skill-specific 2000-2005 Bartik shocks in all regressions. In some specifications, we also control for Bartik shocks hitting 0-10 minute and 10-20 minute commuting time rings from tract $i$, forcing identification to come from Bartik-type demand shocks hitting commuting destinations that are greater than 20 minute commutes away. Since typical commutes are longer in many cities, we can still achieve identification even after excluding variation from locations within 20 minutes when constructing the treatment variables. However, reduced power and larger standard errors arise in this case for some outcomes.

Second, we are concerned that the 1990 employment composition near each tract may respond to the local real estate market and/or demographic trends, which are related to unobserved demo- 
graphic attributes or local amenities that may enter into child investments. As such, we control for 10 and 20 year lags of tract demographic composition and housing costs. We do not control for base year demographic characteristics from the Census because some of our analysis uses these objects as part of the outcome variable (the base year in a time difference).

Third, we must account for secular trends in neighborhood demographics as a function of CBD distance. With the central areas of many cities rebounding after 2000 due to improved local amenities (Baum-Snow \& Hartley, 2018; Couture \& Handbury, 2017), we wish to compare neighborhoods at similar CBD distances. To that end, we control for a quadratic in CBD distance in all specifications. In addition, in most specifications we control for CBD distance ring fixed effects interacted with region fixed effects, capturing potential differing region-specific spatial demographic trends. The heat map in the right panel of Figure 4 highlights the sources of identifying variation we use for the Los Angeles region in the 2000-2005 period. As is evident in the map, there is considerable identifying variation available conditional on most CBD distances, with all four quartiles well-represented.

We select our primary specification for the main empirical work by evaluating which conditioning variables are required to render our instruments uncorrelated with observed pre-treatment trends in tract characteristics. To this end, Table 4 presents IV regressions of pre-treatment trends in fraction college and our neighborhood quality index on $\Delta \ln R M A_{i}^{S}$ for 2000-2010 instrumented with $\Delta \ln \widetilde{R M} A_{i}^{S}$ for the 2000-2005 period, including various sets of controls. We study the sensitivity of our results to including the instrument $\Delta \ln \widetilde{R M} A_{i}^{U}$ as a control. We also study the sensitivity of prediction of pre-trends to the inclusion of controls for skill-specific Bartik shocks aggregated across tracts within 0-10 and 10-20 minutes commuting time from each origin tract (Bartik ring controls).

Including the two Bartik ring controls renders the relationship between the pre-treatment trends and the instruments to be economically and statistically insignificant in all cases studied except for fraction college when we include the $\Delta \ln \widetilde{R M} A_{i}^{U}$ control. However, given the descriptive evidence in Table 3, the logic of Figure 5 suggests that at least for the 2000-2010 study period, the existence of pre-trends will cause us to estimate lower bounds on true causal effects. Consistent with this logic, in our main empirical work below we show that moving from OLS to IV and including additional controls in the IV both increase the estimated treatment effects.

Table A4 presents analogous results for the 1990-2000 study period, in which $\Delta \ln R M A_{i}$ for 1990-2000 is instrumented with $\Delta \ln \widetilde{R M} A_{i}^{S}$. For this earlier period, we do not have sufficient identifying variation to be able to control for $\Delta \ln \widetilde{R M} A_{i}^{U}$. Instead, we examine sensitivity of the inclusion of Bartik controls for $0-10$ and 10-20 minute commute time rings. Here we see that including the Bartik ring controls eliminates differential pre-treatment trends. 


\subsection{First Stage Results}

Table 5 presents the first stage results. Both instruments and endogenous variables are expressed in within-region standard deviation units for the average tract in our census sample. Anticipating the heterogeneity in treatment effects as a function of CBD distance that we show below, we break out coefficients on the instruments by $0-10 \mathrm{~km}$ and 10-20 km CBD distance bands.

Table 5 Columns 1-4 show that 2000-2005 counterfactual skilled RMA growth rates significantly predict actual 2000-2010 skilled RMA growth rates both near and far from CBDs in the full census tract sample. Since the unskilled and skilled counterfactual RMA growth rates $\left(\Delta \ln \widetilde{R M} A_{i}^{U}\right.$ and

$\left.\Delta \ln \widetilde{R M} A_{i}^{S}\right)$ are positively correlated, the coefficients on the skilled counterfactual RMA growth rates $\left(\Delta \ln \widetilde{R M} A_{i}^{S}\right)$ rise when the unskilled counterfactual RMA growth rate $\left(\Delta \ln \widetilde{R M} A_{i}^{U}\right)$ interacted with 0-10 km and 10-20 km CBD distance bands are included as controls. With all controls included (column 4), a one standard deviation increase in the skilled counterfactual RMA growth rate $\left(\Delta \ln \widetilde{R M} A_{i}^{S}\right)$ within $10 \mathrm{~km}$ of a CBD predicts a statistically significant 0.09 standard deviation increase in the actual skilled RMA growth rate $\left(\Delta \ln R M A_{i}^{S}\right)$. In the suburbs, this coefficient is more than twice as large at 0.23 .

In the right block of Table 5, we show analogous results for the CCP sample. Consistent with the analysis to follow, we impose some adjustments to handle the fact that the unit of analysis is now a person rather than a census tract. We inversely weight observations by the number of regions in which the tract appears and cluster standard errors on census tract. Without controls for unskilled RMA shocks in Columns 5 and 6, these first stage estimates exhibit similar patterns as those using the full census tract data set in Columns 1 and 2, though with larger standard errors. However, when such controls are included we lose first stage power, particularly in the inner CBD distance ring (columns 7-8).

In the 1990-2000 study period, we are further constrained by the lack of separate identifying variation in skilled versus unskilled RMA shocks. Moreover, as the first stage coefficients between the two CBD distance bands are much more similar and stable across specifications, we pool them to maximize statistical power. Without the Bartik ring controls, the first stage coefficients are about 0.07 and with these controls they are about 0.04 . These results are reported in Table A5.

\subsection{Main Estimating Equations}

Here we refine the aspirational estimation equations (1)-(5) specified in Section 2 to accommodate the constraints on data, power and identification laid out in this section. In Section 2 we identified both high and low skilled RMA shocks as treatment variables of interest. Constraints on power and available identifying variation in both the 2000-2010 and 1990-2000 study periods lead us to focus on recovering treatment effects of $\Delta_{t} \ln R M A_{i}^{S}$ on neighborhood, household and and individual outcomes. We consider each study period in turn. 
In the 2000-2010 study period, our two instruments $\Delta_{t} \ln \widetilde{R M} A_{i}^{U}$ and $\Delta_{t} \ln \widetilde{R M} A_{i}^{S}$ do provide separate identifying variation. However, as seen in Tables 4 and 5 , we lose precision and introduce pre-trends when including controls for $\Delta_{t} \ln \widetilde{R M} A_{i}^{U}$. To get around this precision problem, we estimate IV regressions of the form

$$
\begin{aligned}
\Delta_{t} n_{i \omega} & =\alpha_{0}^{n}+\alpha_{c}^{n S} \Delta_{t} \ln R M A_{i c}^{S}+\alpha_{s}^{n S} \Delta_{t} \ln R M A_{i s}^{S}+X_{i \omega} \phi^{n}+\widetilde{\nu}_{i \omega}^{n} \\
z_{i \omega, \tau} & =\alpha_{0}^{p}+\alpha_{c}^{p S} \Delta_{t} \ln R M A_{i c}^{S}+\alpha_{s}^{p S} \Delta_{t} \ln R M A_{i s}^{S}+X_{i \omega} \phi^{p}+\widetilde{\nu}_{i \omega}^{p} \\
y_{i \omega} & =\alpha_{0}^{c}+\alpha_{c}^{c S} \Delta_{t} \ln R M A_{i c}^{S}+\alpha_{s}^{c S} \Delta_{t} \ln R M A_{i s}^{S}+X_{i \omega}^{c} \phi^{c}+\widetilde{\nu}_{i \omega}^{c}
\end{aligned}
$$

in which $\Delta_{t} \ln \widetilde{R M} A_{i}^{S}$ enters as the instrument for $\Delta_{t} \ln R M A_{i}^{S}$. Subscripts $c$ and $s$ represent 0 to $10 \mathrm{~km}$ from the $\mathrm{CBD}$ and 10 to $20 \mathrm{~km}$ from the CBD, respectively. The tract equation (22) shows objects indexed by child $\omega$, but is also run for all neighborhoods using census data only. We only have power to include $\Delta_{t} \ln \widetilde{R M} A_{i}^{U}$ as a control in census regressions, not in CCP regressions. Because we cannot hold $\Delta_{t} \ln \widetilde{R M} A_{i}^{U}$ constant, below we confirm directly that $\widehat{\alpha}_{c}^{p S}=\widehat{\alpha}_{s}^{p S}=0$, obviating the need to control for the unskilled RMA growth shocks. In our initial treatment of this hierarchical empirical setup in Section 2, we indexed the second and third equations by the skill group of the parents. We do report coefficients for different parent skill groups below but also show unified results given our evidence that the shocks have no effect on parental finanical health $\left(\widehat{\alpha}^{p S}=0\right)$ for both skilled and unskilled parents.

There are two main considerations that shape our choices of control variables $X_{i \omega}$. First, we choose our control set to minimize any pre-treatment trends in the data. This justifies the inclusion of region-ring fixed effects, $1990 \log$ tract $i$ employment, skilled and unskilled Bartik shocks for tract $i$ (used as instruments in Table 2) and 10 and 20 year lags of a host of tract demographic variables and housing costs. We control for Bartik shocks aggregated to 0-10 minute and 10-20 minute commute time rings (henceforth, "Bartik ring controls") in robustness checks. Consistent with our discussion of selection biases in the context of Figure 5, all neighborhood effects estimates grow larger with the inclusion of these controls. Second, we endeavor to control for variables that reduce the variances in error terms, thereby reducing standard errors of our coefficient estimates. As such, we additionally control for parents' credit score and an indicator of whether they had any home loans in 2000.

For the 1990-2000 study period, we are constrained to estimating a set of equations that include only one RMA variable. We use the following specifications.

$$
\begin{aligned}
\Delta_{t} n_{i \omega} & =b_{0}^{n}+b^{n} \Delta_{t} \ln R M A_{i}+X_{i \omega} \rho^{n}+\bar{v}_{i \omega}^{n} \\
\Delta_{t} z_{i \omega} & =b_{0}^{p}+b^{p} \Delta_{t} \ln R M A_{i}+X_{i \omega} \rho^{p}+\bar{v}_{i \omega}^{p} \\
y_{i \omega} & =b_{0}^{c}+b^{c} \Delta_{t} \ln R M A_{i}+X_{i \omega} \rho^{c}+\bar{v}_{i \omega}^{c}
\end{aligned}
$$


We estimate these equations by IV, instrumenting for $\Delta_{t} \ln R M A_{i}$ with $\Delta_{t} \ln \widetilde{R M} A_{i}^{S}$. Note that rather than using long-run outcomes in the parent equation, we instead use changes in outcomes. This choice comes because the structure of the PSID data does not allow us to measure parent outcomes in a way that parallels the timing structure of the child outcomes. For this earlier period, our set of controls in $X_{i \omega}$ are analogous to those in the later period, except that instead of parents' credit score and home loan information for 2000 we include a rich set of controls for 1990 parent and household characteristics.

\section{$7 \quad$ Results}

In this section, we first examine how shocks to $R M A_{i}^{S}$ causally affect neighborhood demographics in the 2000-2014 period using the census data, corresponding to estimates of $\alpha^{n S}$ in Equation (22). Next, we report estimates of $\alpha^{p S}$ and $\alpha^{c S}$ from Equations (23) and (24) using the CCP data. We combine these estimates to recover estimates of neighborhood effects. Finally, we perform the analogous analysis for the 1990-2015 period using the census and PSID data instead.

\section{$7.1 \quad 2000-2017$ Period}

\subsubsection{Neighborhoods}

Table 6 reports estimates from Equation (22). The top block shows OLS results, with four specifications for each outcome, and the bottom block shows IV results. The treatment variable, the decadal change in skilled RMA growth $\left(\ln R M A_{i}^{S}\right)$, is scaled by its average within-region standard deviation in our sample. The dependent variables are measured as 2000-2007 changes so as to focus on the period in which sampled children are still mostly living with their parents. ${ }^{21}$

Our estimates indicate that a one standard deviation increase in skilled RMA growth increases the neighborhood fraction college by 1.6-2.6 percentage points (23 to 38 percent of one withinregion standard deviation) for the 2000-2007 period, depending on the specification. Once controls for aggregate skill-specific Bartik shocks for 0-10 minute and 10-20 minute commutes (Bartik ring controls) are included, the estimates are not affected by conditioning on the growth in counterfactual

unskilled RMA $\left(\Delta_{2010} \ln \widetilde{R M} A_{i}^{U}\right)$. The estimated effects on the neighborhood quality index are a bit smaller, at between a 1.7 and 3.4 percentile points increase (14 to 28 percent of a within-region standard deviation) per standard deviation increase in skilled RMA growth. The estimates are quantitatively similar for central areas and suburbs. For the 2000-2014 period (not reported), the estimated effects on suburban fraction college are about one percentage point greater and those for

\footnotetext{
${ }^{21}$ Our 2007 measures of college fraction and neighborhood quality are actually the 2005-2009 5 year ACS aggregates. This is the earliest range of years for which tract-level tabulations are available after the 2000 Census.
} 
suburban neighborhood quality are about twice as large as those for the 2000-2007 period, though those for central areas are little changed.

We have various pieces of evidence that the IV estimates in Table 6 are well identified. The clearest potential threat to identification is that neighborhoods with positive unobserved shocks to neighborhood amenities were nearby areas with a 1990 employment mix that was both skilled and experienced strong national growth in the 2000-2005 period. That is, unobserved neighborhood amenity shocks like municipal investments in improved schools and parks could be correlated with the instrument and drive growth in both college fraction and neighborhood amenities. We think this sort of threat to identification is unlikely for two reasons. First, the evidence discussed in Section 6 indicates that the dynamics of neighborhood change generate endogeneity bias that would lead us to underestimate the true causal effects if left uncorrected. Second, eliminating region-ring controls and/or lagged demographic controls from the specifications reported in Table 6 Columns 1, 3, 5 and 7 always reduces the estimated IV coefficients (unreported). Third, the IV estimates are greater than the OLS estimates. That is, as we include more controls for selection and instrument, the estimated coefficients of interest increase, consistent with moving from the observed correlations depicted in the right graph in Figure 5 to the more ideal experiment depicted in the left graph in Figure 5. More complete controls for selection of high skilled employment growth to areas that already have many skilled workers living nearby always increases our estimates.

One important mechanism for neighborhood effects that we examine below is school quality. Credible evaluation of this mechanism requires exogenous variation in neighborhood attributes within school districts. The evidence in Table 7 shows that we can isolate such exogenous variation. The results in columns 1 and 4 show that growth in skilled RMA increases the educational attainment of the neighborhood and the neighborhood quality index using variation only within public school districts. The results in columns 2 and 5 show that looking between districts, the coefficients on interactions between RMA and school district quality are positive for fraction college and essentially zero for neighborhood quality, weakly indicating that skilled labor demand shocks to better school districts bring in even more college graduate households in these areas. Finally, the results in columns 3 and 6 show that using only within district variation, in better school districts the same labor demand shock has a smaller effect on neighborhood demographic composition. ${ }^{22}$ However, shocks to skilled RMA still induce variation in neighborhood change within school districts in about the bottom two-thirds of the school quality distribution.

\footnotetext{
${ }^{22}$ We measure school district quality using the sum of standardized elementary and math scores for fourth grade, as compiled in the Stanford Education Data Archive (Reardon et al., 2018). This measure has mean 0 and standard deviation 1 across students nationwide. In our sample, the mean is -0.23 and the standard deviation is 0.99 across tracts.
} 


\subsubsection{Parents and Children}

We first look at the exposure to neighborhood change experienced by the sampled families in the CCP. Table 8 presents estimates of the coefficients on standardized skilled RMA growth in the IV regressions described by Equations (23) and (24). The set of controls is the same as in Column 1 of Table 6 , with the addition of controls for the parent's credit score and a mortgage loan indicator for 2000 (pre-treatment). The standard errors are clustered by census tract of resdence in 2000 . Columns 1-3 report the estimated effects on the 2000-2007 change in tract college fraction in the 2000 tract of residence by the parent's imputed educational attainment. Columns 4-6 report the estimated effects on 2007 college fraction in the 2017 tract of residence minus 2000 college fraction for the year 2000 tract of residence. Therefore, the differences indicate how 2000-2017 migration that was induced by neighborhood change after year 2000 resulted in long-run differences in exposure to college educated neighbors.

Consistent with the census results, the evidence in columns 1-3 of Table 8 indicates that, on average, one standard deviation of skilled RMA growth caused a 0.9 to 1.3 percentage point increase in fraction college from 2000 to 2007, in the suburban tracts where CCP sample parents and children resided in 2000. These estimates are different only due to sampling variation. ${ }^{23}$ The estimates for the city tracts are positive but not statistically significant. The results in columns 4-6 of Panel A show that skilled RMA shocks are estimated to cause parents to move in a way that offsets the causal effect of skilled RMA growth on fraction college in their 2000 tracts of residence. However, in Panel B we see that suburban children, in the least educated neighborhoods in particular, react quite differently to neighborhood shocks than their parents. Experiencing a one standard deviation better labor demand shock as a teenager growing up in the suburbs results in living in a tract that has about 2-3 percentage points higher college fraction by age $28-33$, relative to not moving. The largest effects are for children of parents that rent in the suburbs. That is, the results in Table 8 indicate that if measured in terms of neighborhood profile, children in the suburbs benefit from nearby skilled labor demand shocks while their parents experience no significant effects. Moreover, because the effects are larger for renters, our evidence is not consistent with parents using housing equity to contribute to this improvement for their children. The results for those living less than 10 $\mathrm{km}$ from a CBD in 2000 do not exhibit sufficient statistical power to draw firm conclusions, though the point estimates for this region are near zero.

Panels A and B of Figure 6 present dynamic versions of the estimates that are reported in columns 3-6 of Table 8 for 2017. The outcome is measured as the 2007 fraction college in the tract of residence in the year indicated on the horizontal axis minus the 2000 fraction college in the 2000 tract of residence. We do not observe credit records for children and infer that the youngest cohort

\footnotetext{
${ }^{23}$ The difference in sample size between Panel A and Panel B is due to attrition in the parent sample between 2000 and 2017. We restrict the sample in columns 1-3 to parents that are still in the CCP in 2017 so that the sample is the same as is used in columns 4-6 of Panel A.
} 
experiences 2000-2007 residential locations that are the same as the parents', thus the graphs for children start in 2008.

The thick black line in Panel A shows that suburban families' average exposure to gentrification slowly declined over time due to migration out of more heavily treated tracts. The long-dashed line shows that roughly the same is true for families living in less educated suburban neighborhoods in 2000. This is the key treatment exposure to neighborhood change in which we are interested. As in Table 8, we see essentially zero average long-run improvement in neighborhood fraction college for the parents in Panel A of Figure 6. However, in Panel B, we do see such long-run improvements for the children. This positive effect begins in 2015, after a period of no effect.

Figure 7 presents the central results of the paper. The thick black lines in this figure show the estimated dynamic effects of skilled RMA shocks to tracts of year 2000 residence on suburban children's credit score, aggregate credit card limits, 30 day loan delinquency and mortgage holding in Panels A-D, respectively. These are estimated separately for each indicated year, where Equation (24) is the estimation equation. The specifications match those in column 1 of Table 6 Panel A, with additional controls the for parent's credit score and whether the parent had a mortgage in 2000. We exclude the low skilled RMA shock and Bartik ring controls from our specification as they only increase the estimated coefficients; by excluding these controls we estimate lower bounds on the true coefficients of interest. Moreover, since we directly show no evidence of wealth effects of $\Delta_{2010} \ln R M A_{i}^{S}$ for parents below, which was the motivation for conditioning on $\Delta_{2010} \ln R M A_{i}^{U}$, in practice the inclusion of this extra control variable is unnecessary to recover credible estimates of neighborhood effects.

The credit score results in Panel A show essentially no effect in 2008, when sample children were 19-23 years old. However, the estimates rise monotonically over the following 5 years to a statistically significant 23 points, or 21 percent of a standard deviation. Over the following 9 years, the estimates bounce around with little trend from a minimum of 18 points to a maximum of 28 points. The results for the sum of credit card limits (Panel B) and mortgage holding (Panel D) exhibit similar qualitative patterns, though their increases begin after 2011. By 2017, the estimated effect on the sum of credit card limits for residents of the suburbs in 2000 rises to $\$ 1978$, or 16 percent of a standard deviation. The estimated effect on holding a mortgage rises to 9.9 percentage points in 2016, before dipping back down to 7.3 percentage points - 24 percent and 18 percent of a standard deviation, respectively. The results for loan delinquency in Panel $\mathrm{C}$ are qualitatively similar, though noisier and with a bigger decline from 2016 to 2017. The fact that we see no effect in 2008 for any of these outcomes and that the responses rise monotonically over time is consistent with the results reflecting causal relationships. Were they not causal, the unobservables driving the estimated effects would have to both be correlated with counterfactual skilled RMA shocks and growing only while sampled individuals are in their late 20s and early 30s. All four of these primary outcomes except the sum of credit card limits exhibit statistically significant estimates in at least 
one year.

Having established our headline result that a standard deviation higher growth in skilled RMA increases children's outcomes by about 20 percent of a standard deviation, we examine heterogeneity of the treatment effects in three dimensions. First, city residents experience essentially zero estimated effects of neighborhood change. Second, for credit score and loan delinquency, the estimated effects in some years are slightly greater in absolute value for those growing up in less educated neighborhoods. These are seen in the short-dashed lines in Panels A and C of Figure 7. Finally, we compare the effects for children of owners versus renters, with tenure proxied by whether the parent had a mortgage in 2000. Panel B of Table 9 reports the full set of results for children in 2017, with standard errors clustered by census tract of residence in 2000 . Here we see somewhat larger effects on credit score and credit card limits for children of owners and somewhat larger effects on holding a mortgage for children of renters. However, none of these differences are statistically significant.

None of the estimated effects on children reported in Table 9 Panel B and Figure 7 can be explained by parental wealth effects. The analogous regressions for the parents, described by Equation (23), are reported in Table 9 Panel A and Figure 8. Here we see point estimates that are consistently closer to zero and not statistically distinguisable from zero. Moreover, we see no statistically significant or coherent difference in the parent estimates for urban versus suburban areas.

To examine the extent to which school quality or other factors correlated with school quality drive our estimated neighborhood effects, we include school district fixed effects rather than regionring fixed effects in estimation equations like Equation (24). Recall from the tract-level results that even within school districts there is still identifying variation for the effects of skilled RMA growth on the share of tract residents with a college degree. The analogous CCP-based results are reported in Table 10. They show insignificant and small (sometimes negative) coefficients for all outcomes of interest when school district fixed effects are included (columns 1, 4, 7 and 10). This indicates that variation in neighborhood fraction college within school district has no estimated effect on long run outcomes for resident children. As a result, we conclude that our estimated neighborhood effects must run through the schools in some way.

The remaining results in Table 10 indicate two additional instructive facts about mechanisms. The results in Columns 2, 4, 6 and 8 have region-ring fixed effects but interact the RMA treatment with school quality. The positive coefficients on these interactions indicate that higher quality schools impart larger impacts on children than do lower quality schools. If college graduates are more likely to send their children to public schools if they are of higher quality, these results are consistent with the idea that schools mediate our estimated effects in Table 9. However, these positive interactions disappear when controlling for school district fixed effects, as seen in Columns $3,6,9$ and 12. In better school districts, variation in neighborhood quality is not estimated to 
effect long-run outcomes of children. We caution, however, that these interacted specifications are under-powered.

Overall, our analysis of the CCP provides compelling quantitative evidence on the existence of neighborhood effects that operate through schools. Quantifying these neighborhood effects indicates that a shock that causes neighborhood quality to improve by 25-38 percent of a standard deviation causes suburban children's long-run outcomes to increase by 13-17 percent of a standard deviation but their parents' outcomes to not change. Dividing the estimate of the effect on children by the estimate of the effect on the neighborhood, implies a neighborhood effect that can be summarized as a one standard deviation improvement in neighborhood quality leading to about a half of a standard deviation improvement in children's long-run outcomes.

A set of robustness checks presented in Appedix Tables A7-A9 reveal that adding controls for skill-specific Bartik shocks amongst commuting destinations 0-10 minutes and 10-20 minutes away (Bartik ring controls) to the specifications in Tables 8-10 show somewhat larger effects of skilled RMA growth on long-run outcomes for the children and smaller effects of skilled RMA growth on neighborhood educational attainment. These estimates imply larger neighborhood effects than those reported in the previous paragraph as they have a larger numerator and smaller denominator. However, they also have slightly larger standard errors. For this reason, we view the results presented in Tables 8-10 as more conservative estimates.

\subsection{0-2000 Period}

As we discussed earlier, the 1990-2000 period presents some additional challenges for identifying neighborhood effects. First, the skilled and unskilled RMA shocks are more highly correlated during this period, making econometric identification more difficult. Second, the identifying variation during this period produces parental wealth effects which complicate the recovery of neighborhood effects. Finally, the PSID's smaller sample size generates lower statistical power. Despite these issues, the evidence shown here is fully consistent with the CCP results, shown above. So as to maintain statistical power, we focus on results from specifications where we do not interact growth in RMA with urban/suburban status.

The census tract results in Appendix Table A6 indicate that shocks to RMA growth significantly increase the tract-level fraction college and neighborhood quality, but only without controls for aggregated commute time ring Bartik shocks (Bartik ring controls). For this period, a one standard deviation increase in unified RMA growth, with identifying variation from counterfactual skilled RMA growth $\left(\Delta_{2000} \ln \widetilde{R M} A_{i}^{S}\right.$ ), generates 1990-2000 increases in college fraction of 1 to 3 percentage points and contemporaneous increases in neighborhood quality of 1.3 to 4.0 percentiles.

Table 11 presents estimates of the effects of RMA growth on family outcomes in the PSID. Panel A shows the effects on outcomes relevant to families and children while they still reside with 
their parents and Panel B shows long-run effects on children. We present IV regressions with region fixed effects and the full set of demographic controls and tract-level controls, with standard errors clustered by 1990 census tract of residence. The smaller sample size of the PSID means that there is not enough variation within region-rings for estimation.

The results in Panel A show that RMA growth is estimated to effect growth in family incomes in the 1990 tract of residence. Each standard deviation in RMA growth is estimated to lead to $32 \%$ higher family income growth during the 1990s. The results is driven by parents that are college graduates. As expected, shocks to RMA growth are estimated to have caused the fraction college in tract of 1990 residence to grow, with estimates in line with our Census results in Table A6. Scores on an applied problem test taken in the teenage years are $26 \%$ of a standard deviation higher for each additional standard deviation of RMA growth. Point estimates of the effect of RMA growth on scores on a number of other tests (not shown) are also strongly positive, but they are not statistically significant.

We have two strong results for children's long-run outcomes. Their 2015 family income is about $27 \mathrm{log}$ points larger (30 percent of a standard deviation) for a one standard deviation greater RMA shock in youth and their 2015 employment rate is 13 percentage pionts higher, though only marginally significant.

Because we find measurable effects on both children and parents, the PSID data do not allow us to distinguish between the effects of improved labor market opportunities increasing parental investment versus neighborhood effects that affect children directly. However, the PSID does provide evidence that the sum of these objects is positive for the children.

\section{Conclusions}

Using quasi-random variation in 1990-2000 and 2000-2005 skilled labor demand shocks for each urban census tract in the U.S. as a source of identifying variation, this paper investigates the effects of neighborhood change on incumbent residents. Our estimates indicate that skilled labor demand shocks to areas within commuting distance raise neighborhood quality, fraction college and incomes in these neighborhoods. Our evidence from the PSID on the effects of 1990-2000 growth in accessible employment opportunities shows that it results in increases in parental income, child test scores for teenagers and family income at age 25 to 43 . Our evidence on 2000-2005 growth in employment opportunities from the CCP shows resulting improvements in a number of credit outcomes for those who were 11-15 at the beginning of exposure to treatment and living in the suburbs, but little or negative effects for their parents. These estimated positive impacts for the children only manifest themselves once the children are at least age 19, and increase monotonically with age before levelling

off. Taken together, the evidence in this paper indicates that a one standard deviation shock to neighborhood quality improves suburban children's long-run outcomes by 40 to 70 percent of a 
standard deviation, with these neighborhood effects more pronounced for children growing up in less educated neighborhoods. Schools appear to represent the primary channel through which these neighborhood spillovers operate.

Our analysis is one of the first attempts to look at the effects of neighborhoods that change around people rather than children's exposure to neighborhood change through the migration choices of their parents. Nevertheless, while different empirical settings make the results somewhat hard to compare, we find evidence that is broadly consistent with that from the literature using household moves. For example, Chetty and Hendren (2018a) and Laliberté (2018) find that one additional year of exposure to a neighborhood promotes convergence of about 4.4 percent between new arrivals up to age 23 and incumbent residents for various long-run labor market outcomes. Someone who is moved at age 13, the midpoint of our cohort, to a neighborhood that is one standard deviation higher quality would thus end up 44 percent of a standard deviation higher in the distribution of outcomes by age 23. This estimate is at the lower end of our range of estimates for the suburbs, but is consistent with an average of our city and suburb effects.

The compendium of evidence on neighborhood effects suggests two fruitful avenues for future research. First, while it seems that schools matter as an important causal mechanism, it is not clear why schools matter. That schools matter more in better quality districts and mostly in the suburbs, where higher educated families are more likely to send their children to public schools, suggests that it is not simply a consequence of improvements in the tax base. But whether the effects we find are truly from peer interactions, more active engagement from parents in schools, or more political support for expanding resources to public schools seems important. Second, the existing research on neighborhood effects has not had the statistical power to establish the extent to which neighborhood effects operate nonlinearly as functions of attributes of the treatment and/or the treated. If spillovers are linear, no aggregate gain is available from reallocating people across neighborhoods. In contrast, knowing details about the nature of any potential nonlinear relationships would allow for improving the efficacy of inclusionary and low income housing policies. 


\section{References}

Adao, Rodrigo, Michal Kolesar and Eduardo Morales (2018) "Shift-Share Designs: Theory and Inference," NBER Working Paper No. 24944.

Ahlfeldt, Gabriel, Stephen Redding, Daniel Sturm, Nikolaus Wolf (2015) "The Economics of Density: Evidence from the Berlin Wall," Econometrica 83(6): 2127-2189.

Aliprantis, Dionissi and F. G.-C. Richter (2018) "Evidence of Neighborhood Effects from Moving to Opportunity: LATEs of Neighborhood Quality," manuscript.

Altonji, J.G. \& R.K. Mansfield (2018) "Estimating Group Effects Using Averages of Observables

to Control for Sorting on Unobservables: School and Neighborhood Effects," American Economic Review, 108(10): 2902-2946.

Allen, Treb, C. Arkolakis \& Li (2016) "Optimal City Structure," manuscript.

Andersson, F., J. Haltiwanger, M. Kutzbach, G. Palloni, H. Pollakowski, and D. H. Weinberg (2016). "Childhood housing and adult earnings: A between-siblings analysis of housing vouchers and public housing." NBER Working Paper No. 22721.

Åslund, O., Edin, P.-A., Fredriksson, P. and H. Grönqvist (2011), "Peers, neighborhoods, and immigrant student achievement: Evidence from a placement policy," American Economic Journal: Applied Economics 3, 67-95.

Bartik, Timothy (1991) Who Benefits from State and Local Economic Development Policies? Kalamazoo, MI: W.E. Upjohn Institute for Employment Research.

Baum-Snow, Nathaniel \& Lu Han (2018) "The Microgeography of Housing Supply," manuscript.

Baum-Snow, Nathaniel \& Daniel Hartley (2018) "Accounting for Central Neighborhood Change," manuscript.

Bayer, P., Ross, S.L. and G. Topa (2008), "Place of work and place of residence: Informal hiring networks and labor market outcomes," Journal of Political Economy 116, 1150-1196.

Beaman, L. (2012), "Social networks and the dynamics of labor market outcomes:Evidence from refugees resettled in the U.S.," Review of Economic Studies 79, 128-161.

Blanchard, Olivier Jean and Lawrence F. Katz. (1992) "Regional Evolutions," Brookings Papers on Economic Activity, 23(1): 1-76.

Borusyak, K. and X. Jaravel. (2018) "Consistency and Inference in Bartik Research Designs," manuscript.

Brummet, Quentin and Davin Reed (2019) "Gentrification and the Location and Well-Being of Original Neighborhood Residents," manuscript.

Charles, Kerwin Kofi, Erik Hurst and M. J. Notowidigdo. (2018) "Housing Boom and Busts, Labor Market Opportunities, and College Attendance," American Economic Review, 108(10): 29472994.

Chetty, Raj, John N. Friedman, Nathaniel Hendren, Maggie R. Jones and Sonya R. Porter. (2018) "The Opportunity Atlas: Mapping the Childhood Roots of Social Mobility," manuscript. 
Chetty, Raj, Nathaniel Hendren, Patrick Kline, and Emmanuel Saez (2014) "Where is the Land of Opportunity: The Geography of Intergenerational Mobility in the United States," Quarterly Journal of Economics 129: 1553-1623.

Chetty, Raj, Nathaniel Hendren, and Lawrence Katz (2016) "The Effects of Exposure to Better Neighborhoods on Children: New Evidence from the Moving to Opportunity Experiment," American Economic Review 106(4): 855-902.

Chetty, Raj and Nathaniel Hendren (2018a) "The Impacts of Neighborhoods on Intergenerational Mobility I: Childhood Exposure Effects," Quarterly Journal of Economics, forthcoming.

Chetty, Raj and Nathaniel Hendren (2018b) "The Impacts of Neighborhoods on Intergenerational Mobility II: County Level Estimates," Quarterly Journal of Economics, forthcoming.

Couture, Victor and Jessie Handbury (2016) "Urban Revival in America, 2000 to 2010," manuscript.

Couture, Victor, G. Duranton \& M. Turner (2017) "Speed," Review of Economics and Statistics, forthcoming.

Chyn, Eric (2016) "Moved to Opportunity: The Long-Run Effect of Public Housing Demolition on Labor Market Outcomes of Children," manuscript.

Currie, Janet, Lucas Davis, Michael Greenstone, and Reed Walker (2015) "Environmental Health Risks and Housing Values: Evidence from 1,600 Toxic Plant Openings and Closings," American Economic Review, 105:2.

Damm, A.P. (2009) "Ethnic enclaves and immigrant labor market outcomes: Quasi-experimental evidence," Journal of Labor Economics 27, 281-314.

Damm, A.P. and C. Dustmann (2014) "Does growing up in a high crime neighborhood affect youth criminal behavior?" American Economic Review 104, 1806-1832.

Davis, Steve \& Till von Wachter (2012) "Recessions and the Costs of Job Loss" Brookings Papers on Economic Activity.

Donaldson, Dave and Richard Hornbeck (2016) "Railroads and American economic growth: A "market access" approach." The Quarterly Journal of Economics 131(2): 799-858.

Edin, P.-A., Fredriksson, P. and O. Aslund (2003) "Ethnic enclaves and the economic success of immigrants: Evidence from a natural experiment," Quarterly Journal of Economics 118, 329-357.

Reardon, S. F., Ho, A. D., Shear, B. R., Fahle, E. M., Kalogrides, D., \& DiSalvo, R. (2018). Stanford Education Data Archive (Version 2.1). Retrieved from http://purl.stanford.edu/db586ns4974.

Fogli, Alessandra and Veronica Guerrieri (2018) "The End of the American Dream? Inequality and Segregation in US Cities," manuscript.

Goldsmith-Pinkham, Paul, Isaac Sorkin \& Henry Swift (2018) "Bartik Instruments: What, When, Why and How?" manuscript.

Gould, E.D., Lavy, V. and D. Paserman (2011) "Sixty years after the magic carpet ride: The long-run effect of the early childhood environment on social and economic outcomes," Review of 
Ecoconomic Studies 78, 938-973.

Gould, E.D., Simhon, A. and B.A. Weinberg (2015) "Does Parental Quality Matter? Evidence on the Transmission of Human Capital Using Variation in Parental Influence from Death, Divorce, and Family Size," manuscript.

Graham, B.S. (2018) "Identifying and Estimating Neighborhood Effects," Journal of Economic Literature 56(2): 450-500.

Hellerstein, J.K., M.P. McInerney and D. Neumark (2011) "Neighbors and co-workers: The importance of residential labor market networks," Journal of Labor Economics 29, 659-695.

Hellerstein, J.K., Kutzbach, M.J. and D. Neumark (2014) "Do labor market networks have an important spatial dimension?" Journal of Urban Economics 79, 39-58.

Hoynes, H.W., D.W. Schanzenbach and D. Almond (2018) "Long Run Impacts of Childhood Access to the Safety Net," American Economic Review, forthcoming.

Laliberté, J-W.P. (2018) "Long-term Contextual Effects in Education: Schools and Neighborhoods," manuscript.

Meltzer, R. and P. Ghorbani (2017) "Does gentrification increase employment opportunities in low-income neighborhoods?," Regional Science and Urban Economics 66, 52-73.

Monte, Ferdinando, Steven Redding \& Esteban Rossi-Hansberg (2016) "Commuting, Migration and Local Employment Elasticities," American Economic Review

Oreopoulous, P. (2003) "The long-run consequences of living in a poor neighborhood," Quarterly Journal of Economics 118, 1533-1575.

Sampson, R. J. (2008) Moving to inequality: neighborhood effects and experiments meet social structure. American Journal of Sociology 114(1), 189-231.

Severen, C. (2019) "Commuting, Labor, and Housing Market Effects of Mass Transportation: Welfare and Identification," manuscript

Tian, L. (2018) "Division of Labor and Productivity Advantage of Cities: Theory and Evidence from Brazil," manuscript.

Tsivanidis, N. (2018) "The Aggregate And Distributional Effects Of Urban Transit Infrastructure: Evidence From Bogotá's TransMilenio," manuscript. 
Table 1: Summary Statistics

Residents of Sample Census Tracts in 254 Regions

Panel A: Census Tract Sample (32,515 Tracts)

Growth Rates

Fraction College

Neighborhood Quality (Pctiles)

Employment in Tract

Unified RMA

Skilled RMA

Unskilled RMA

Shocks

Tract Bartik Shock, Skilled

Tract Bartik Shock, Unskilled

Simulated RMA, Skilled

Simulated RMA, Unskilled

Migration Since 2000

Fraction College (2000 or 2007)

Equifax Risk Score ${ }^{\mathrm{TM}}$

Sum of Credit Card Limits

Any Loan 30 Days Past Due

Mortgage Indicator

$\begin{array}{cccccc}\text { Mean } & \begin{array}{c}\text { St Dev. } \\ \text { 2000-2007/10 }\end{array} & \text { In Rgn Stdev. } & \text { Mean } & \begin{array}{c}\text { St Dev. } \\ \mathbf{1 9 9 0 - 2 0 0 0}\end{array} & \text { In Rgn Stdev. } \\ 0.035 & 0.073 & 0.069 & 0.026 & 0.051 & 0.048 \\ -0.9 & 13.1 & 12.2 & -2.7 & 12.5 & 12.0 \\ -0.21 & 0.88 & 0.86 & 0.17 & 0.85 & 0.76 \\ 0.05 & 0.05 & 0.015 & 0.03 & 0.16 & 0.08 \\ 0.09 & 0.07 & 0.018 & 0.13 & 0.17 & 0.09 \\ 0.03 & 0.07 & 0.015 & -0.02 & 0.17 & 0.08 \\ & \mathbf{2 0 0 0 - 2 0 0 5} & & & \mathbf{1 9 9 0 - 2 0 0 0} & \\ 0.14 & 0.03 & 0.02 & 0.28 & 0.05 & 0.04 \\ 0.03 & 0.04 & 0.04 & 0.07 & 0.04 & 0.04 \\ 0.07 & 0.003 & 0.001 & 0.15 & 0.009 & 0.002 \\ 0.01 & 0.006 & 0.001 & 0.03 & 0.010 & 0.002\end{array}$

Panel B: CCP Samples (Children Born 1985-1989, 9,083 Tracts in 2000)

\begin{tabular}{lcccccccc}
\multicolumn{3}{c}{ Parents, 2000} & Parents, 2017 & \multicolumn{3}{c}{ Children, 2017} \\
Mean & St Dev. & Obs & Mean & St Dev. & Obs & Mean & St Dev. & Obs \\
0.00 & 0.00 & 10,859 & 0.69 & 0.46 & 10,433 & 0.85 & 0.36 & 10,859 \\
0.26 & 0.18 & 10,858 & 0.30 & 0.18 & 10,397 & 0.30 & 0.18 & 10,794 \\
655 & 108 & 10,352 & 703 & 108 & 9,408 & 653 & 109 & 10,277 \\
1,224 & 16,571 & 10,333 & 19,862 & 26,227 & 9,394 & 8,408 & 10,962 & 10,279 \\
0.23 & 0.42 & 10,333 & 0.18 & 0.38 & 9,394 & 0.25 & 0.43 & 10,279 \\
0.45 & 0.50 & 10,333 & 0.43 & 0.49 & 9,394 & 0.22 & 0.41 & 10,279
\end{tabular}

In (2015 Family Income)

Employed in 2015

Max Years of Education

Age Adjusted Applied Problem Score

Migration Probability, 1990-2001

$\Delta$ In (Parent Family Income), 1990-2001

Avg Annual $\Delta$ In Rent, 1990 Tract

$\Delta$ In (Parent Rent), 1990-2001

Panel C: PSID Sample (1,519 Children born 1972-1990, 684 Tracts in 1990)

$\begin{array}{cc}\text { Mean } & \text { Standard Dev. } \\ 10.3 & 1.1 \\ 0.79 & 0.41 \\ 13.8 & 2.4 \\ 0.02 & 0.39 \\ 0.67 & 0.47 \\ 0.32 & 0.87 \\ 0.00 & 0.02 \\ 0.27 & 1.00\end{array}$


Table 2: Effects of Tract Level Bartik Shocks on Tract Level Employment Growth Rate by Education

(1) Total

(1)
College
(4)

\author{
(5)
}

$<$ HS to Some College

(6) (7) (8)

\section{Panel A: 2000-2010}

\begin{tabular}{|c|c|c|c|c|c|c|c|c|}
\hline Skilled Shock & $1.600 * * *$ & $1.463^{* * *}$ & $0.726 * * *$ & \multirow{2}{*}{\multicolumn{2}{|c|}{$\begin{array}{c}1.618^{* * *} \\
(0.303)\end{array}$}} & \multicolumn{3}{|c|}{$1.385^{* * *}$} \\
\hline Bartik $_{j}^{S}$ & $(0.230)$ & $(0.278)$ & $(0.251)$ & & & & $(0.273)$ & \\
\hline Unskilled Shock & & 0.129 & & $-0.838 * * *$ & & $0.962 * * *$ & $0.550 * * *$ & \\
\hline Bartik $_{j}^{U}$ & & $(0.147)$ & & $(0.160)$ & & (0.119) & $(0.144)$ & \\
\hline Skilled Shock & & & & & 120.5 & & & 66.21 \\
\hline Bartik $_{j}^{\mathrm{s}}$ if neg., 0 o/w & & & & & $(85.34)$ & & & $(77.01)$ \\
\hline Skilled Shock & & & & & $1.604 * * *$ & & & $1.379 * * *$ \\
\hline Bartik $_{j}^{\mathrm{s}}$ if pos., 0 o/w & & & & & $(0.304)$ & & & $(0.273)$ \\
\hline Unskilled Shock & & & & & $-0.816 * * *$ & & & $0.545^{* * *}$ \\
\hline Bartik $_{j}^{u}$ if neg., 0 o/w & & & & & $(0.164)$ & & & $(0.147)$ \\
\hline Unskilled Shock & & & & & -2.173 & & & 0.765 \\
\hline Bartik $_{\mathrm{j}}^{\mathrm{U}}$ if pos., $0 \mathrm{o} / \mathrm{w}$ & & & & & $(1.762)$ & & & $(1.589)$ \\
\hline Observations & 32,459 & 32,459 & 32,362 & 32,362 & 32,362 & 32,449 & 32,449 & 32,449 \\
\hline (Within) R-Squared & 0.030 & 0.030 & 0.041 & 0.042 & 0.042 & 0.032 & 0.032 & 0.032 \\
\hline & & & & Panel B: & $990-2000$ & & & \\
\hline Skilled Shock & $0.977^{* * *}$ & $1.933 * * *$ & $1.259 * * *$ & $3.392 * * *$ & & & $1.323 * * *$ & \\
\hline Bartik $_{j}^{S}$ & $(0.108)$ & $(0.168)$ & $(0.113)$ & $(0.174)$ & & & $(0.169)$ & \\
\hline Unskilled Shock & & $-1.254 * * *$ & & $-2.796 * * *$ & & $0.269 * *$ & $-0.745 * * *$ & \\
\hline Bartik $_{j}^{U}$ & & (0.168) & & $(0.174)$ & & (0.109) & $(0.169)$ & \\
\hline Skilled Shock & & & & & $-9.212 * * *$ & & & $-10.34 * * *$ \\
\hline Bartik $_{\mathrm{j}}^{\mathrm{S}}$ if neg., 0 o/w & & & & & $(2.044)$ & & & $(1.981)$ \\
\hline Skilled Shock & & & & & $3.478 * * *$ & & & $1.400 * * *$ \\
\hline Bartik $_{j}^{\mathrm{S}}$ if pos., 0 o/w & & & & & $(0.175)$ & & & $(0.169)$ \\
\hline Unskilled Shock & & & & & $-1.941 * * *$ & & & 0.118 \\
\hline Bartik $_{j}^{U}$ if neg., 0 o/w & & & & & $(0.388)$ & & & $(0.376)$ \\
\hline Unskilled Shock & & & & & $-2.910 * * *$ & & & $-0.866 * * *$ \\
\hline Bartik $_{j}^{u}$ if pos., 0 o/w & & & & & $(0.188)$ & & & $(0.183)$ \\
\hline Observations & 32,016 & 32,016 & 32,016 & 32,016 & 32,016 & 32,016 & 32,016 & 32,016 \\
\hline (Within) R-Squared & 0.194 & 0.196 & 0.169 & 0.176 & 0.177 & 0.197 & 0.199 & 0.200 \\
\hline
\end{tabular}

Notes: Each column in each panel reports the results from a separate regression of change in log tract employment for the group indicated at top on the indicated tract level labor demand shocks, region-ring fixed effects and our base set of controls. Bartik shocks in Panel A are for 2000-2005 whereas those in Panel B are for 1990-2000. The full sample in each panel includes all tracts within $20 \mathrm{~km}$ of a CBD and with positive employment in the base and terminal years. Base controls are a quadratic in CBD distance, log 1990 tract employment and 10 and 20 year lags of the house price index, rent index, log population, log family income, share African American, share White, share college graduate, and share with less than high school. There are 2,060 inluded region-ring fixed effects. Heteroskedasticity robust standard errors are reported. Standard errors constructed using Adao, Kolesar \& Morales' (2018) approach are about twice as large. 
Table 3: Descriptive OLS Regressions About Neighborhood Change and Relationships With RMA, 2000-2010

\begin{tabular}{|c|c|c|c|c|c|c|c|c|c|c|c|c|}
\hline & \multicolumn{4}{|c|}{ Fraction College Graduate } & \multicolumn{4}{|c|}{ Neighborhood Quality Index } & \multicolumn{4}{|c|}{ log Average HH Income } \\
\hline & \multicolumn{2}{|c|}{ 2000-2007 Change } & \multirow{2}{*}{$\begin{array}{c}90-00 \text { Chg } \\
\text { (3) }\end{array}$} & \multirow{2}{*}{$\begin{array}{l}2000 \text { Level } \\
\text { (4) }\end{array}$} & \multicolumn{2}{|c|}{ 2000-2007 Change } & \multirow{2}{*}{$\begin{array}{l}90-00 \mathrm{Chg} \\
\text { (7) }\end{array}$} & \multirow{2}{*}{$\begin{array}{c}2000 \text { Level } \\
\text { (8) }\end{array}$} & \multicolumn{2}{|c|}{ 2000-2007 Change } & \multirow{2}{*}{$\begin{array}{l}90-00 \text { Chg } \\
\text { (11) }\end{array}$} & \multirow{2}{*}{$\begin{array}{l}2000 \text { Level } \\
\text { (12) }\end{array}$} \\
\hline & $(1)$ & $(2)$ & & & $(5)$ & (6) & & & (9) & $(10)$ & & \\
\hline $\begin{array}{l}\text { 1990-2000 Change in } \\
\text { Dependent Variable }\end{array}$ & $\begin{array}{l}-0.124^{* * *} \\
(0.00641)\end{array}$ & $\begin{array}{l}-0.168^{* * *} \\
(0.00667)\end{array}$ & & & $\begin{array}{l}-0.255^{* * *} \\
(0.00562)\end{array}$ & $\begin{array}{l}-0.288^{* * *} \\
(0.00572)\end{array}$ & & & $\begin{array}{l}-0.301^{* * *} \\
(0.00610)\end{array}$ & $\begin{array}{l}-0.379 * * * \\
(0.00625)\end{array}$ & & \\
\hline $\begin{array}{l}\Delta \text { In Skilled RMA, } \\
2000-2010\end{array}$ & & & $\begin{array}{l}0.00205^{* * *} \\
(0.000324)\end{array}$ & $\begin{array}{r}0.00209 * * * \\
(0.000326)\end{array}$ & & & $\begin{array}{c}0.0772 \\
(0.0604)\end{array}$ & $\begin{array}{c}0.390 * * * \\
(0.0667)\end{array}$ & & & $\begin{array}{l}0.00229 * * \\
(0.000911)\end{array}$ & $\begin{array}{l}0.00233^{* *} \\
(0.000921)\end{array}$ \\
\hline Obs & 32,413 & 32,413 & 32,430 & 32,460 & 32,510 & 32,510 & 32,515 & 32,515 & 32,286 & 32,286 & 32,342 & 32,395 \\
\hline (Within) R-Squared & 0.012 & 0.053 & 0.115 & 0.870 & 0.063 & 0.114 & 0.079 & 0.745 & 0.075 & 0.155 & 0.135 & 0.783 \\
\hline Region-Ring Fixed Effects & Yes & Yes & Yes & Yes & Yes & Yes & Yes & Yes & Yes & Yes & Yes & Yes \\
\hline Base Controls & No & Yes & Yes & Yes & No & Yes & Yes & Yes & No & Yes & Yes & Yes \\
\hline
\end{tabular}

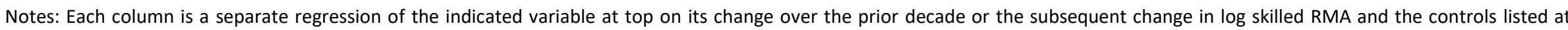

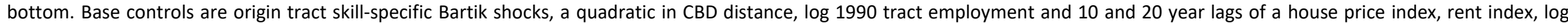

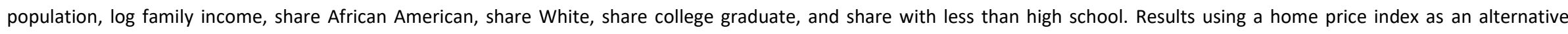
outcome show the same qualitative pattern as that seen for the three outcomes shown. 
Table 4: Examination of Differential Pre-2000 Trends, IV Regressions

\begin{tabular}{|c|c|c|c|c|c|c|c|c|}
\hline & \multicolumn{4}{|c|}{ Fraction College Graduate } & \multicolumn{4}{|c|}{ Neighborhood Quality Index } \\
\hline & $(1)$ & $(2)$ & (3) & $(4)$ & $(5)$ & $(6)$ & (7) & $(8)$ \\
\hline \multirow[t]{2}{*}{$\Delta$ In Skilled RMA } & $0.0253 * * *$ & -0.00265 & $0.0143 * * *$ & $0.0111 * *$ & $3.146 * * *$ & -0.809 & $1.982 * * *$ & 0.749 \\
\hline & $(0.00510)$ & $(0.00752)$ & $(0.00348)$ & $(0.00482)$ & $(0.918)$ & $(1.406)$ & $(0.644)$ & $(0.887)$ \\
\hline Obs & 32,294 & 32,294 & 32,294 & 32,294 & 32,379 & 32,379 & 32,379 & 32,379 \\
\hline First Stage F & 143.6 & 57.05 & 277.0 & 142.1 & 143.2 & 56.98 & 278.3 & 143.2 \\
\hline Unskilled Simul. RMA Controls & No & No & Yes & Yes & No & No & Yes & Yes \\
\hline Bartik Ring Controls & No & Yes & No & Yes & No & Yes & No & Yes \\
\hline Region-Ring Fixed Effects & Yes & Yes & Yes & Yes & Yes & Yes & Yes & Yes \\
\hline Base Controls & Yes & Yes & Yes & Yes & Yes & Yes & Yes & Yes \\
\hline
\end{tabular}

Notes: Each column reports coefficients from a separate IV regression of the 1990-2000 change in the variable listed at top on the change in log skilled RMA in the following decade, instrumented with the change in counterfactual log skilled RMA. See the notes to Table 3 for the base controls. The instrument is built using employment in all tracts excluding the origin tract. 
Table 5: First Stage Results - Resident Market Access

\begin{tabular}{|c|c|c|c|c|c|c|c|c|}
\hline & \multicolumn{4}{|c|}{ Census Sample } & \multicolumn{4}{|c|}{ CCP Child Sample } \\
\hline & $(1)$ & $(2)$ & (3) & (4) & (5) & $(6)$ & $(7)$ & $(8)$ \\
\hline $\begin{array}{l}\text { Change in Cntrfctl. log Skill. RMA, } \\
\quad<10 \mathrm{~km} \text { from CBD }\end{array}$ & $\begin{array}{l}0.0573 * * * \\
(0.00686)\end{array}$ & $\begin{array}{l}0.0440 * * * \\
(0.00719)\end{array}$ & $\begin{array}{l}0.122 * * * \\
(0.0164)\end{array}$ & $\begin{array}{c}0.0893 * * * \\
(0.0166)\end{array}$ & $\begin{array}{l}0.100 * * * \\
(0.0319)\end{array}$ & $\begin{array}{c}0.0923 * * * \\
(0.0326)\end{array}$ & $\begin{array}{c}0.0256 \\
(0.0701)\end{array}$ & $\begin{array}{l}-0.0286 \\
(0.0700)\end{array}$ \\
\hline $\begin{array}{l}\text { Change in Cntrfctl. log Skill. RMA, } \\
\quad>10 \mathrm{~km} \text { from CBD }\end{array}$ & $\begin{array}{c}0.0643 * * * \\
(0.00740)\end{array}$ & $\begin{array}{c}0.0429 * * * \\
(0.00821)\end{array}$ & $\begin{array}{l}0.300 * * * \\
(0.0181)\end{array}$ & $\begin{array}{c}0.233 * * * \\
(0.0189)\end{array}$ & $\begin{array}{l}0.142 * * * \\
(0.0372)\end{array}$ & $\begin{array}{l}0.129 * * * \\
(0.0439)\end{array}$ & $\begin{array}{l}0.177^{* *} \\
(0.0694)\end{array}$ & $\begin{array}{c}0.0705 \\
(0.0704)\end{array}$ \\
\hline Observations & 32,515 & 32,515 & 32,515 & 32,515 & 10,251 & 10,251 & 10,251 & 10,251 \\
\hline (Within) R-Squared / R-Squared & 0.031 & 0.040 & 0.038 & 0.044 & 0.956 & 0.957 & 0.956 & 0.957 \\
\hline Cntrfctl. log Unskill. RMA Controls & No & No & Yes & Yes & No & No & Yes & Yes \\
\hline Bartik Ring Controls & No & Yes & No & Yes & No & Yes & No & Yes \\
\hline Region-Ring FE & Yes & Yes & Yes & Yes & Yes & Yes & Yes & Yes \\
\hline Base Controls & Yes & Yes & Yes & Yes & Yes & Yes & Yes & Yes \\
\hline
\end{tabular}

Notes: All RMA measures are expressed in standard deviation units. Base controls are listed in the notes to Table 3. Testing whether the coefficients are jointly equal to zero in columns (5) - (8) yields F-statistics of 12.1, 6.9, 3.3 and 0.6, respectively. 
Table 6: Effects of Skilled RMA on Census Tract Outcomes, 2000-2007

\begin{tabular}{|c|c|c|c|c|c|c|c|c|}
\hline & \multicolumn{4}{|c|}{ Fraction College Graduate } & \multicolumn{4}{|c|}{ Neighborhood Quality Index } \\
\hline & (1) & (2) & (3) & (4) & (5) & (6) & (7) & (8) \\
\hline \multicolumn{9}{|l|}{ OLS, 1st Diff. } \\
\hline$\Delta$ Skilled RMA, & 0.000166 & 0.000123 & 0.000112 & 0.000100 & 0.0256 & 0.0267 & 0.0206 & 0.0255 \\
\hline$<10 \mathrm{~km}$ from CBD & $(0.000471)$ & $(0.000471)$ & $(0.000472)$ & $(0.000472)$ & $(0.0795)$ & $(0.0795)$ & $(0.0795)$ & $(0.0795)$ \\
\hline$\Delta$ Skilled RMA, & $0.00178 * * *$ & $0.00157^{* * *}$ & $0.00175^{* * *}$ & $0.00158 * * *$ & -0.0295 & 0.00749 & -0.0329 & 0.00837 \\
\hline$>10$ km from CBD & $(0.000597)$ & $(0.000603)$ & $(0.000597)$ & $(0.000603)$ & $(0.101)$ & $(0.102)$ & $(0.101)$ & $(0.102)$ \\
\hline \multicolumn{9}{|l|}{ IV, 1st Diff. } \\
\hline$\Delta$ Skilled RMA, & $0.0249 * * *$ & $0.0206 * *$ & $0.0167 * *$ & $0.0210 * *$ & $2.405^{*}$ & 2.047 & 1.739 & $3.387 * *$ \\
\hline$<10$ km from CBD & $(0.00774)$ & $(0.00931)$ & $(0.00845)$ & $(0.00965)$ & $(1.253)$ & $(1.535)$ & $(1.408)$ & $(1.634)$ \\
\hline$\Delta$ Skilled RMA, & $0.0261 * * *$ & $0.0194 *$ & $0.0161^{* * *}$ & $0.0181 * * *$ & $2.624^{* *}$ & 2.145 & $1.729 * * *$ & $2.878^{* * *}$ \\
\hline$>10$ km from CBD & $(0.00687)$ & $(0.0101)$ & $(0.00380)$ & $(0.00508)$ & $(1.101)$ & $(1.646)$ & $(0.627)$ & $(0.851)$ \\
\hline Observations & 32,283 & 32,283 & 32,283 & 32,283 & 32,375 & 32,375 & 32,375 & 32,375 \\
\hline First Stage F & 63.31 & 33.09 & 50.04 & 38.44 & 63.46 & 33.20 & 49.76 & 38.11 \\
\hline Unskilled Simul. RMA Controls & No & No & Yes & Yes & No & No & Yes & Yes \\
\hline Bartik Ring Controls & No & Yes & No & Yes & No & Yes & No & Yes \\
\hline Region-Ring FE & Yes & Yes & Yes & Yes & Yes & Yes & Yes & Yes \\
\hline Base Controls & Yes & Yes & Yes & Yes & Yes & Yes & Yes & Yes \\
\hline
\end{tabular}

Notes: Entries show OLS or IV coefficients and standard errors. RMA measures are expressed in standard deviation units. Analogous results for the CCP sample are about half the magnitudes reported above, reflecting the larger first stage coefficients reported in Table 5 . 
Table 7: Effects of Standardized Skilled RMA on 2000-2007 Tract Outcomes - School District Analysis

\begin{tabular}{|c|c|c|c|c|c|c|}
\hline & \multicolumn{3}{|c|}{ College Graduate Share } & \multicolumn{3}{|c|}{ Neighborhood Quality Index } \\
\hline & $(1)$ & (2) & (3) & (4) & (5) & (6) \\
\hline \multicolumn{7}{|l|}{ IV, 1st Diff. } \\
\hline $\begin{array}{l}\triangle \mathrm{RMA},<10 \mathrm{~km} \\
\text { from CBD }\end{array}$ & $\begin{array}{c}0.0159 * * * \\
(0.00257)\end{array}$ & $\begin{array}{c}0.0257 * * * \\
(0.00778)\end{array}$ & $\begin{array}{c}0.0181 * * * \\
(0.00288)\end{array}$ & $\begin{array}{l}0.736 * \\
(0.411)\end{array}$ & $\begin{array}{c}2.561^{* *} \\
(1.264)\end{array}$ & $\begin{array}{l}1.088^{* *} \\
(0.455)\end{array}$ \\
\hline $\begin{array}{c}\triangle \mathrm{RMA},>10 \mathrm{~km} \\
\text { from CBD }\end{array}$ & $\begin{array}{l}0.0160 * * * \\
(0.00260)\end{array}$ & $\begin{array}{c}0.0202 * * * \\
(0.00509)\end{array}$ & $\begin{array}{c}0.0182 * * * \\
(0.00291)\end{array}$ & $\begin{array}{c}0.830 * * \\
(0.416)\end{array}$ & $\begin{array}{c}2.387^{* * *} \\
(0.822)\end{array}$ & $\begin{array}{c}1.222^{* * *} \\
(0.460)\end{array}$ \\
\hline$\triangle \mathrm{RMA},<10 \mathrm{~km}$ from $\mathrm{CBD}$ & & $0.000740 * * *$ & $-0.0153^{* * *}$ & & -0.0464 & $-1.670 * *$ \\
\hline X School Quality Pctile & & $(0.000253)$ & (0.00409) & & $(0.0410)$ & (0.649) \\
\hline$\triangle \mathrm{RMA},>10 \mathrm{~km}$ from $\mathrm{CBD}$ & & $0.000926 * * *$ & $-0.0153 * * *$ & & 0.0198 & $-1.503^{* *}$ \\
\hline X School Quality Pctile & & $(0.000190)$ & $(0.00420)$ & & $(0.0307)$ & $(0.666)$ \\
\hline Observations & 32,015 & 31,373 & 31,131 & 32,107 & 31,436 & 31,194 \\
\hline First Stage F & 283.7 & 30.91 & 51.57 & 293.7 & 30.85 & 51.33 \\
\hline Region-Ring FE & No & Yes & No & No & Yes & No \\
\hline Base Controls & Yes & Yes & Yes & Yes & Yes & Yes \\
\hline School District FE & Yes & No & Yes & Yes & No & Yes \\
\hline Region-Ring FE & No & Yes & No & No & Yes & No \\
\hline
\end{tabular}

Notes: Each column reports one IV regression that includes the set of controls listed at bottom. College-oriented simulated $\triangle$ InRMA interacted with the two indicated CBD distance bands enters as instruments, as in Table 5. CCP sample results are similar, though with larger standard errors. Analogous regressions including additional controls for low and high skilled shocks in 0-10 and 10-20 minute commute time rings show similar results. 
Table 8: Impacts of RMA on Neighborhood Exposure and Migration

Region-Ring Fixed Effects and Full Set of Controls

2000-2007 Change in Fraction College in

Tract of 2000 Residence

Fraction College in 2017 Tract of Residence Fraction College in 2000 Tract of Residence

\begin{abstract}
:ducational Attainment Weight
\end{abstract}
None

$<$ HS

College +

None

$<\mathrm{HS}$

College +

\title{
Panel A: Parents
}

\begin{tabular}{|c|c|c|c|c|c|c|}
\hline All, 0-10 km from CBD & $\begin{array}{c}0.00722 \\
(0.00697)\end{array}$ & $\begin{array}{c}0.00459 \\
(0.00784)\end{array}$ & $\begin{array}{l}0.000163 \\
(0.00651)\end{array}$ & $\begin{array}{c}-0.0102 \\
(0.0163)\end{array}$ & $\begin{array}{l}-0.0206 \\
(0.0213)\end{array}$ & $\begin{array}{c}-0.0222 \\
(0.0186)\end{array}$ \\
\hline All, $10-20$ km from CBD & $\begin{array}{c}0.00872^{* *} \\
(0.00420)\end{array}$ & $\begin{array}{l}0.00832 * \\
(0.00489)\end{array}$ & $\begin{array}{l}0.0124^{* *} \\
(0.00507)\end{array}$ & $\begin{array}{r}-0.000407 \\
(0.00939)\end{array}$ & $\begin{array}{l}0.00843 \\
(0.0121)\end{array}$ & $\begin{array}{r}-0.00470 \\
(0.0119)\end{array}$ \\
\hline Observations & 9,848 & 1,769 & 3,163 & 9,826 & 1,765 & 3,156 \\
\hline \multicolumn{7}{|c|}{ Panel B: Children (Born 1985-1989) } \\
\hline All, 0-10 km from CBD & $\begin{array}{c}0.00628 \\
(0.00663)\end{array}$ & $\begin{array}{c}0.00429 \\
(0.00706)\end{array}$ & $\begin{array}{l}0.000926 \\
(0.00652)\end{array}$ & $\begin{array}{r}-0.00174 \\
(0.0187)\end{array}$ & $\begin{array}{l}-0.00690 \\
(0.0208)\end{array}$ & $\begin{array}{l}0.00185 \\
(0.0216)\end{array}$ \\
\hline All, $10-20$ km from CBD & $\begin{array}{l}0.0101^{* *} \\
(0.00428)\end{array}$ & $\begin{array}{l}0.0123^{* *} \\
(0.00539)\end{array}$ & $\begin{array}{c}0.0134^{* * *} \\
(0.00513)\end{array}$ & $\begin{array}{l}0.0210^{*} \\
(0.0116)\end{array}$ & $\begin{array}{c}0.0348^{* *} \\
(0.0142)\end{array}$ & $\begin{array}{c}0.0205 \\
(0.0144)\end{array}$ \\
\hline Observations & 10,246 & 1,853 & 3,278 & 10,188 & 1,845 & 3,258 \\
\hline Renters, 0-10 km from CBD & $\begin{array}{c}0.00871 \\
(0.00692)\end{array}$ & $\begin{array}{c}0.00670 \\
(0.00734)\end{array}$ & $\begin{array}{c}0.00301 \\
(0.00681)\end{array}$ & $\begin{array}{l}0.00132 \\
(0.0189)\end{array}$ & $\begin{array}{l}0.00155 \\
(0.0218)\end{array}$ & $\begin{array}{l}-0.00530 \\
(0.0228)\end{array}$ \\
\hline Owners, 0-10 km from CBD & $\begin{array}{c}0.00595 \\
(0.00684)\end{array}$ & $\begin{array}{c}0.00388 \\
(0.00726)\end{array}$ & $\begin{array}{l}0.000256 \\
(0.00663)\end{array}$ & $\begin{array}{r}-0.00188 \\
(0.0188)\end{array}$ & $\begin{array}{l}-0.00891 \\
(0.0218)\end{array}$ & $\begin{array}{l}0.00405 \\
(0.0221)\end{array}$ \\
\hline Renters, $10-20 \mathrm{~km}$ from CBD & $\begin{array}{c}0.0113 * * * \\
(0.00436)\end{array}$ & $\begin{array}{l}0.0138^{* *} \\
(0.00554)\end{array}$ & $\begin{array}{c}0.0143 * * * \\
(0.00524)\end{array}$ & $\begin{array}{l}0.0230^{*} \\
(0.0120)\end{array}$ & $\begin{array}{c}0.0412^{* * *} \\
(0.0148)\end{array}$ & $\begin{array}{c}0.0174 \\
(0.0154)\end{array}$ \\
\hline Owners, $10-20 \mathrm{~km}$ from CBD & $\begin{array}{c}0.00815^{* *} \\
(0.00410)\end{array}$ & $\begin{array}{l}0.0106^{* *} \\
(0.00528)\end{array}$ & $\begin{array}{l}0.0112^{* *} \\
(0.00494)\end{array}$ & $\begin{array}{c}0.0184 \\
(0.0116)\end{array}$ & $\begin{array}{l}0.0273^{*} \\
(0.0142)\end{array}$ & $\begin{array}{l}0.0255^{*} \\
(0.0148)\end{array}$ \\
\hline $\begin{array}{l}\text { Observations } \\
\text { Notes: Each block of results is }\end{array}$ & $\begin{array}{l}10,246 \\
\text { m a separa }\end{array}$ & $\begin{array}{l}1,853 \\
\text { regressior }\end{array}$ & $\begin{array}{l}3,278 \\
\text { the outcom }\end{array}$ & $\begin{array}{l}10,188 \\
\text { t top on req }\end{array}$ & $\begin{array}{l}1,845 \\
\text {-ring tixed et }\end{array}$ & $\begin{array}{l}3,258 \\
\text { s, the tract's }\end{array}$ \\
\hline $\begin{array}{l}2000-2005 \text { Bartik shock, } 1990 \\
\text { variables listed at left. Each } \\
\text { with the objects listed at left. } \\
\text { of residence in } 2000 \text {. }\end{array}$ & $\begin{array}{l}\text { ct employm } \\
\text { A variable is } \\
\text { presentative }\end{array}$ & $\begin{array}{l}10 \text { and } 20 \\
\text { trumented } \\
\text { t stage resu }\end{array}$ & $\begin{array}{l}\text { r lags of dem } \\
\mathrm{h} \text { the growt } \\
\text { are in Table }\end{array}$ & $\begin{array}{l}\text { aphic cont } \\
\text { te in coun }\end{array}$ & $\begin{array}{l}\text { nd RMA int } \\
\text { ctual skilled }\end{array}$ & $\begin{array}{l}\text { ted with the } \\
\text { A interacted }\end{array}$ \\
\hline
\end{tabular}

Panel B: Children (Born 1985-1989) 
Table 9: Consumer Credit Panel Results - Impacts of Standardized RMA

Region-Ring Fixed Effects and Full Set of Controls

\begin{tabular}{|c|c|c|c|c|c|c|c|c|c|c|c|c|}
\hline \multirow{2}{*}{$\begin{array}{r}\text { Outcome } \\
\text { Educational Attainment Weight }\end{array}$} & \multicolumn{3}{|c|}{ Equifax Risk Score ${ }^{\mathrm{TM}}$} & \multicolumn{3}{|c|}{ Sum of Credit Card Limits } & \multicolumn{3}{|c|}{ Any Loan 30 Days Past Due } & \multicolumn{3}{|c|}{ Mortgage Dummy } \\
\hline & None & $<\mathrm{HS}$ & College + & None & $<\mathrm{HS}$ & College + & None & $<\mathrm{HS}$ & College + & None & $<\mathrm{HS}$ & College + \\
\hline \multicolumn{13}{|c|}{ Panel A: Parent Outcomes, 2017} \\
\hline \multirow[t]{2}{*}{ All, 0-10 km from CBD } & 3.297 & 18.77 & -10.17 & 2,967 & 3,977 & 2,228 & -0.00776 & -0.0788 & 0.0208 & 0.0583 & 0.0984 & 0.0272 \\
\hline & $(9.082)$ & $(13.23)$ & $(9.387)$ & $(2,656)$ & $(3,401)$ & $(2,843)$ & $(0.0411)$ & $(0.0627)$ & $(0.0395)$ & $(0.0584)$ & $(0.0853)$ & $(0.0554)$ \\
\hline \multirow[t]{2}{*}{ All, $10-20 \mathrm{~km}$ from CBD } & -5.010 & -9.943 & -8.433 & 456.5 & -335.5 & $-2,615$ & -0.0181 & 0.00764 & -0.0137 & 0.0288 & 0.0504 & 0.00535 \\
\hline & (5.079) & (7.398) & $(5.538)$ & $(2,625)$ & $(2,922)$ & $(2,372)$ & $(0.0201)$ & $(0.0304)$ & $(0.0228)$ & $(0.0316)$ & $(0.0433)$ & $(0.0364)$ \\
\hline \multirow[t]{2}{*}{ Observations } & 8,995 & 1,594 & 2,924 & 8,984 & 1,589 & 2,924 & 8,984 & 1,589 & 2,924 & 8,984 & 1,589 & 2,924 \\
\hline & \multicolumn{9}{|c|}{ Panel B: Child Outcomes, 2017} & & & \\
\hline \multirow[t]{2}{*}{ All, 0-10 km from CBD } & -0.203 & 5.014 & 6.393 & -45.50 & 904.3 & $-1,040$ & -0.0794 & -0.126 & -0.0447 & 0.0633 & 0.0906 & 0.0464 \\
\hline & $(11.97)$ & (13.99) & $(12.00)$ & $(1,147)$ & $(1,383)$ & $(1,395)$ & $(0.0577)$ & $(0.0813)$ & $(0.0512)$ & $(0.0532)$ & $(0.0638)$ & $(0.0546)$ \\
\hline \multirow[t]{2}{*}{ All, $10-20$ km from CBD } & $18.28 * *$ & 18.91 & 14.86 & $1,978^{*}$ & $2,634 * *$ & $1,767^{*}$ & -0.0205 & 0.0130 & 0.00637 & $0.0728^{*}$ & $0.0825^{*}$ & 0.0639 \\
\hline & $(9.184)$ & $(12.01)$ & $(9.320)$ & $(1,028)$ & $(1,306)$ & $(1,063)$ & $(0.0343)$ & $(0.0463)$ & $(0.0361)$ & $(0.0392)$ & $(0.0496)$ & $(0.0397)$ \\
\hline \multirow[t]{2}{*}{ Renters, $0-10 \mathrm{~km}$ from CBD } & -1.150 & 3.069 & 4.044 & -184.3 & 963.5 & $-1,562$ & -0.0529 & -0.0954 & -0.0192 & 0.0792 & 0.0878 & 0.0685 \\
\hline & (11.96) & (14.04) & $(12.16)$ & $(1,148)$ & $(1,373)$ & $(1,476)$ & $(0.0552)$ & $(0.0755)$ & $(0.0518)$ & $(0.0551)$ & $(0.0626)$ & $(0.0570)$ \\
\hline \multirow[t]{2}{*}{ Owners, $0-10 \mathrm{~km}$ from CBD } & -0.160 & 5.399 & 7.147 & 4.265 & 848.7 & -773.7 & -0.0884 & $-0.143^{*}$ & -0.0579 & 0.0585 & 0.0942 & 0.0359 \\
\hline & $(12.06)$ & $(14.27)$ & $(12.12)$ & $(1,159)$ & $(1,405)$ & $(1,451)$ & $(0.0562)$ & $(0.0781)$ & $(0.0517)$ & $(0.0560)$ & $(0.0645)$ & $(0.0568)$ \\
\hline \multirow[t]{2}{*}{ Renters, $10-20 \mathrm{~km}$ from CBD } & $17.77^{*}$ & 17.71 & 13.78 & $1,926^{*}$ & $2,662^{* *}$ & 1,571 & -0.0103 & 0.0320 & 0.0158 & $0.0794 * *$ & 0.0816 & $0.0726^{*}$ \\
\hline & $(9.456)$ & $(12.40)$ & (9.593) & $(1,061)$ & $(1,331)$ & $(1,123)$ & $(0.0352)$ & $(0.0485)$ & $(0.0359)$ & $(0.0394)$ & $(0.0507)$ & $(0.0413)$ \\
\hline \multirow[t]{2}{*}{ Owners, $10-20 \mathrm{~km}$ from CBD } & $19.76 * *$ & $21.59^{*}$ & $17.88^{*}$ & $2,129 * *$ & $2,607^{* *}$ & $2,416 * *$ & -0.0508 & -0.0226 & -0.0248 & 0.0530 & $0.0821 *$ & 0.0354 \\
\hline & $(9.200)$ & (12.14) & (9.234) & $(1,030)$ & $(1,296)$ & $(1,083)$ & $(0.0353)$ & $(0.0476)$ & $(0.0356)$ & $(0.0385)$ & $(0.0491)$ & $(0.0404)$ \\
\hline Observations & 9,736 & 1,737 & 3,151 & 9,736 & 1,737 & 3,146 & 9,736 & 1,737 & 3,146 & 9,736 & 1,737 & 3,146 \\
\hline
\end{tabular}

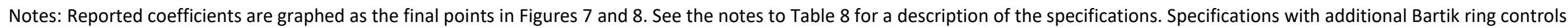
generate coefficients that are 30-50 percent larger and standard errors that are 10-30 percent larger. Standard errors are clustered by census tract of residence in 2000. 
Table 10: Consumer Credit Panel Results for Children - School District Fixed Effects

\begin{tabular}{|c|c|c|c|c|c|c|c|c|c|c|c|c|}
\hline \multirow[b]{2}{*}{$\begin{array}{l}\triangle \mathrm{RMA},<10 \mathrm{~km} \\
\text { from } \mathrm{CBD}\end{array}$} & \multicolumn{3}{|c|}{ Equifax Risk Score ${ }^{\mathrm{TM}}$} & \multicolumn{3}{|c|}{ Sum of Credit Card Limits } & \multicolumn{3}{|c|}{ Any Loan 30 Days Past Due } & \multicolumn{3}{|c|}{ Mortgage Indicator } \\
\hline & $\begin{array}{l}-2.708 \\
(7.594)\end{array}$ & $\begin{array}{l}-3.034 \\
(12.63)\end{array}$ & $\begin{array}{l}-0.118 \\
(8.965)\end{array}$ & $\begin{array}{l}-748.3 \\
(690.5)\end{array}$ & $\begin{array}{l}-581.7 \\
(1,211)\end{array}$ & $\begin{array}{l}-658.6 \\
(765.5)\end{array}$ & $\begin{array}{c}0.0243 \\
(0.0340)\end{array}$ & $\begin{array}{l}-0.0621 \\
(0.0582)\end{array}$ & $\begin{array}{l}0.00713 \\
(0.0406)\end{array}$ & $\begin{array}{l}-0.00102 \\
(0.0286)\end{array}$ & $\begin{array}{c}0.0568 \\
(0.0548)\end{array}$ & $\begin{array}{l}0.00304 \\
(0.0317)\end{array}$ \\
\hline $\begin{array}{l}\triangle \mathrm{RMA},>10 \mathrm{~km} \\
\text { from } \mathrm{CBD}\end{array}$ & $\begin{array}{l}-3.430 \\
(7.698)\end{array}$ & $\begin{array}{l}18.11 * \\
(9.493)\end{array}$ & $\begin{array}{l}-0.818 \\
(9.111)\end{array}$ & $\begin{array}{l}-741.2 \\
(702.2)\end{array}$ & $\begin{array}{l}1,883^{*} \\
(1,057)\end{array}$ & $\begin{array}{l}-672.9 \\
(779.9)\end{array}$ & $\begin{array}{c}0.0233 \\
(0.0344)\end{array}$ & $\begin{array}{l}-0.0173 \\
(0.0353)\end{array}$ & $\begin{array}{l}0.00555 \\
(0.0411)\end{array}$ & $\begin{array}{r}-0.00626 \\
(0.0290)\end{array}$ & $\begin{array}{l}0.0678 * \\
(0.0399)\end{array}$ & $\begin{array}{l}-0.00292 \\
(0.0322)\end{array}$ \\
\hline $\begin{array}{c}\triangle \mathrm{RMA},<10 \mathrm{~km} \text { from CBD } \\
\text { X School Quality Pctile }\end{array}$ & & $\begin{array}{c}0.247 \\
(0.599)\end{array}$ & $\begin{array}{l}-12.45 \\
(12.43)\end{array}$ & & $\begin{array}{l}143.0 * * \\
(67.96)\end{array}$ & $\begin{array}{l}-301.9 \\
(1,092)\end{array}$ & & $\begin{array}{c}0.00115 \\
(0.00261)\end{array}$ & $\begin{array}{c}0.0755 \\
(0.0531)\end{array}$ & & $\begin{array}{c}0.00128 \\
(0.00271)\end{array}$ & $\begin{array}{l}-0.0126 \\
(0.0427)\end{array}$ \\
\hline $\begin{array}{c}\triangle \mathrm{RMA},>10 \text { km from CBD } \\
\text { X School Quality Pctile }\end{array}$ & & $\begin{array}{l}0.995^{* *} \\
(0.444)\end{array}$ & $\begin{array}{l}-11.17 \\
(12.68)\end{array}$ & & $\begin{array}{l}135.7^{* *} \\
(53.86)\end{array}$ & $\begin{array}{l}-301.7 \\
(1,111)\end{array}$ & & $\begin{array}{l}-0.00294^{*} \\
(0.00178)\end{array}$ & $\begin{array}{c}0.0711 \\
(0.0539)\end{array}$ & & $\begin{array}{c}0.00133 \\
(0.00185)\end{array}$ & $\begin{array}{l}-0.0135 \\
(0.0434)\end{array}$ \\
\hline Observations & 9,736 & 9,374 & 9,374 & 9,736 & 9,372 & 9,372 & 9,736 & 9,372 & 9,372 & 9,736 & 9,372 & 9,372 \\
\hline School District FE & Yes & No & Yes & Yes & No & Yes & Yes & No & Yes & Yes & No & Yes \\
\hline Region-Ring FE & No & Yes & No & No & Yes & No & No & Yes & No & No & Yes & No \\
\hline
\end{tabular}

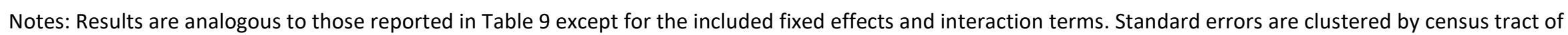
residence in 2000 . 
Table 11: PSID Results, All Tracts 0-20 km from CBDs

Panel A: Outcomes When Children and Parents Live Together

\begin{tabular}{cc|c|c} 
& $\begin{array}{c}\Delta \ln (\text { Family Income), } \\
1990-2001\end{array}$ & $\begin{array}{c}1990-2000 \Delta \text { Fraction } \\
\text { College, 1990 Tract }\end{array}$ & $\begin{array}{c}\text { Children's Applied } \\
\text { Problem Score }\end{array}$ \\
\cline { 2 - 4 }$\Delta$ In (RMA) & $0.315^{*}$ & $0.0285^{* *}$ & $0.255^{* *}$ \\
& $(0.185)$ & $(0.0132)$ & $(0.127)$ \\
First Stage F & 11.87 & 12.45 & 6.831 \\
& & & \\
$\Delta$ In (RMA) & $0.455^{* *}$ & $0.0289^{* *}$ & $0.256^{* *}$ \\
X Parent $>=$ Coll & $(0.198)$ & $(0.0129)$ & $(0.123)$ \\
$\Delta$ In (RMA) & 0.102 & $0.0280^{*}$ & 0.251 \\
X Parent < Coll & $(0.221)$ & $(0.0144)$ & $(0.156)$ \\
First Stage F & 5.415 & 5.614 & 3.099 \\
& & & \\
$\Delta$ In (RMA) & 0.280 & $0.0286^{* *}$ & $0.266^{* *}$ \\
X own & $(0.204)$ & $(0.0122)$ & $(0.128)$ \\
$\Delta$ In (RMA) & 0.202 & $0.0287^{*}$ & 0.310 \\
X rent & $(0.303)$ & $(0.0172)$ & $(0.397)$ \\
First Stage F & 3.078 & 2.977 & 0.203 \\
Observations & 1,371 & 1,416 & 696
\end{tabular}

Panel B: Long-run Child Outcomes

\begin{tabular}{|c|c|c|c|}
\hline & Max Years of Education & Employed in 2015 & In (2015 Family \\
\hline \multirow[t]{2}{*}{$\Delta \ln (\mathrm{RMA})$} & -0.175 & $0.133^{*}$ & $0.274 * *$ \\
\hline & $(0.471)$ & $(0.0767)$ & $(0.113)$ \\
\hline First Stage F & 13.92 & 12.56 & 12.33 \\
\hline$\Delta \ln (\mathrm{RMA})$ & 0.419 & $0.159 * *$ & $0.308 * * *$ \\
\hline X Parent $>=$ Coll & (0.639) & $(0.0773)$ & $(0.111)$ \\
\hline$\Delta \ln (\mathrm{RMA})$ & -0.818 & 0.0876 & 0.169 \\
\hline X Parent $<$ Coll & $(0.662)$ & $(0.0877)$ & $(0.139)$ \\
\hline First Stage F & 6.689 & 5.871 & 5.264 \\
\hline$\Delta \ln (\mathrm{RMA})$ & -0.188 & 0.116 & $0.278 * *$ \\
\hline X own & $(0.509)$ & $(0.0830)$ & $(0.116)$ \\
\hline$\Delta \ln (\mathrm{RMA})$ & -0.228 & -0.0158 & 0.303 \\
\hline $\mathrm{X}$ rent & $(0.816)$ & $(0.187)$ & $(0.207)$ \\
\hline First Stage F & 2.196 & 1.967 & 2.966 \\
\hline Observations & 1,374 & 1,057 & 945 \\
\hline
\end{tabular}

Notes: Estimates are from IV regressions that include controls for region fixed effects, a quadratic in CBD distance, 1990 household income, child age in 1990, child sex, number of family members in 1990, household head's race in 1990, mother's age in 1990, single parent indicator as of 1990, parent divorce indicator as of 1990, and living with father and mother indicator for 1990. Tract-level controls include log 1990 employment, 1990-2000 skill-specific Bartik shocks, and 1980 and 1970 levels of the following variables: house price index, rent index, log population, log family income, share African American, share White, share college graduate, and share with less than high school. Standard errors are clustered by census tract of residence in 1990. 

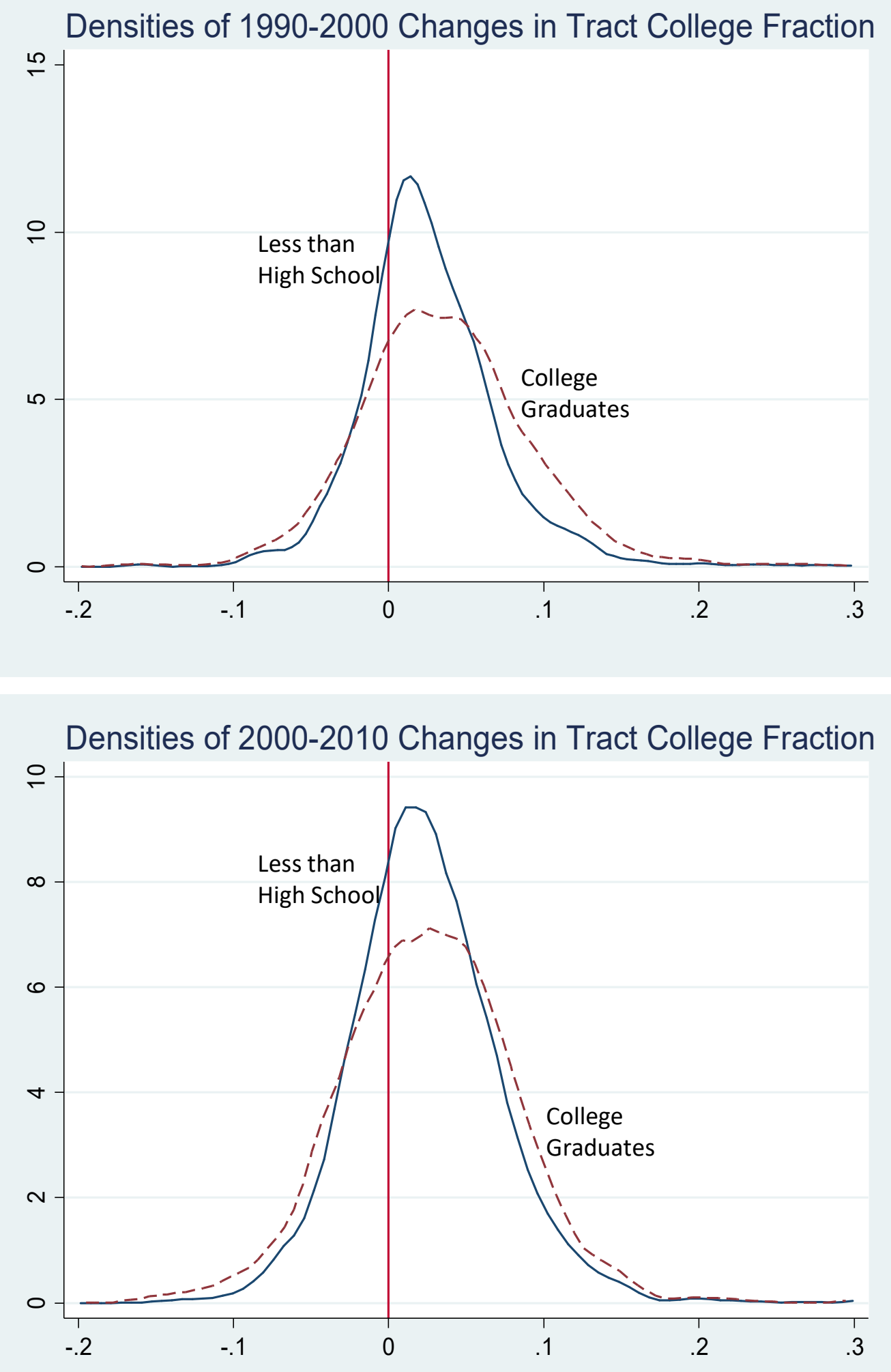

Notes: Figures show densities of childrens' exposure to change in neighborhood fraction college in the 1990s and 2000s by parents' education. These are calculated by taking the number of children ages 0-19 in each census tract and assigning parents' education based on the fraction of those 25 and older in the tract in the indicated education groups. 
Figure 2: Neighborhood Attributes for Movers and Stayers, Consumer Credit Panel

Panel A: 2000 Tract Fraction College
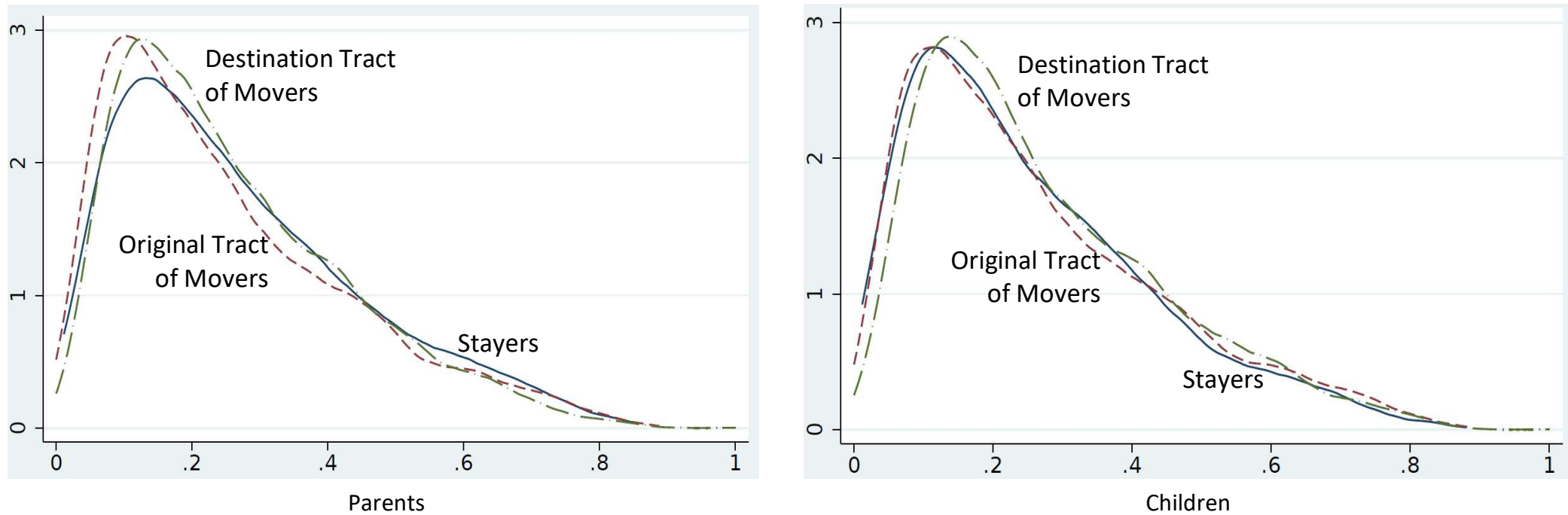

Panel B: 2000-2007 Changes in Tract Fraction College
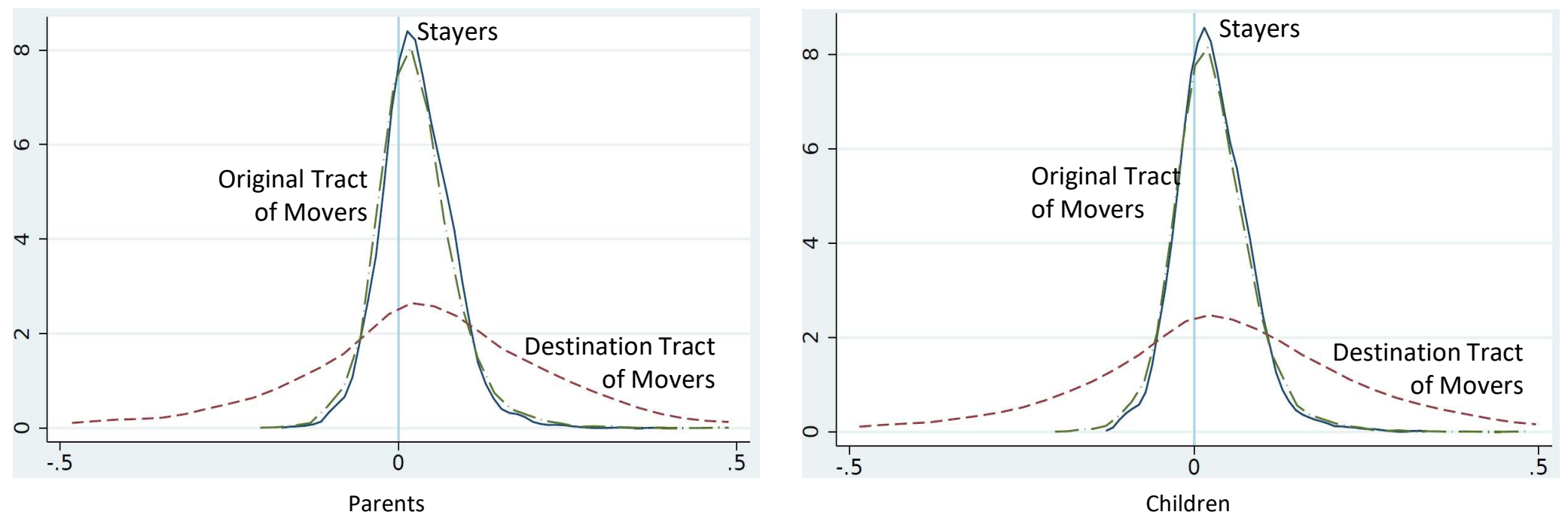

Notes: Panel A shows distributions of year 2000 college fraction of the neighborhoods of parents and their children by whether they moved by year 2017. Panel B shows distributions of 2000-2007 change in college fraction for stayers and the original tracts of movers. Red lines show distributions of college fraction measured in 2007 of movers' 2017 tracts of residence minus 2000 college fraction in year 2000 tract of residence. 
Figure 3: Skilled Resident Market Access for Los Angeles and Orange Counties

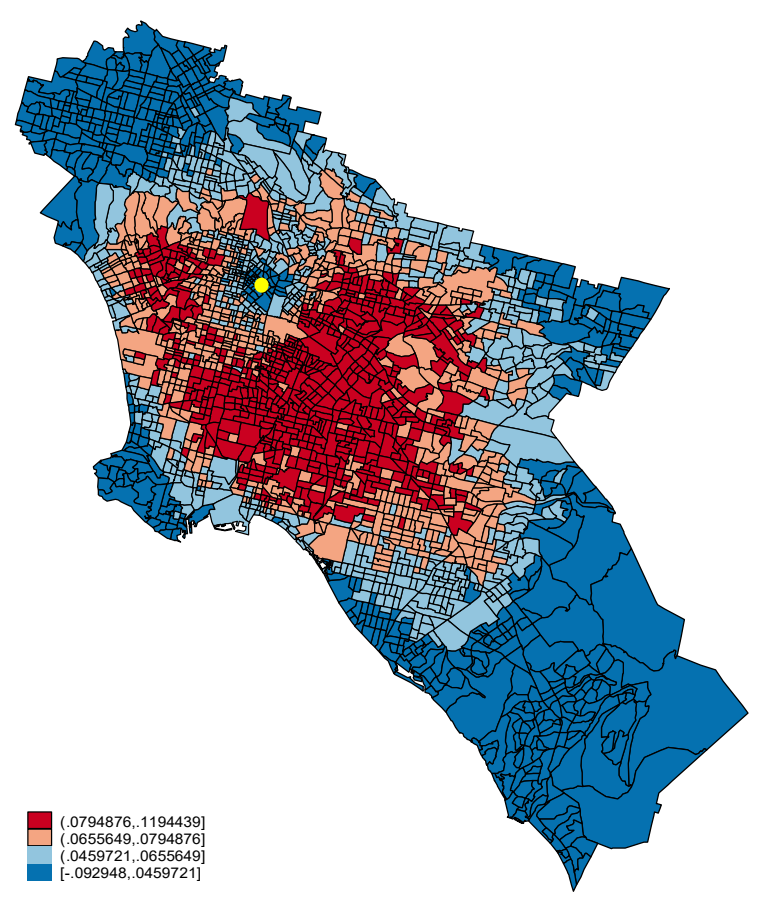

log College RMA, 2000

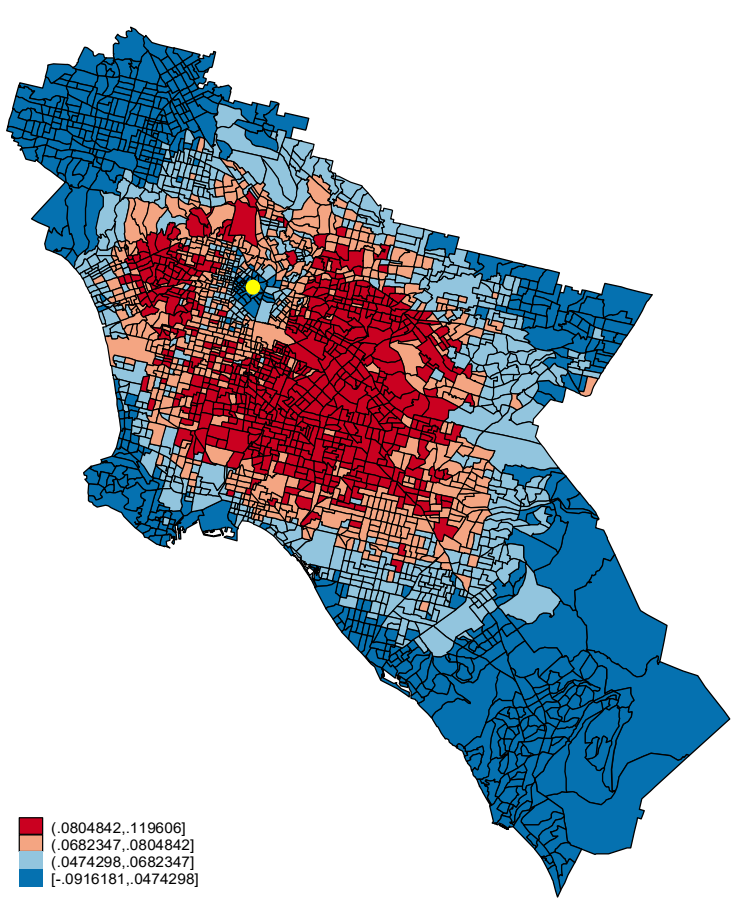

log College RMA, 2010

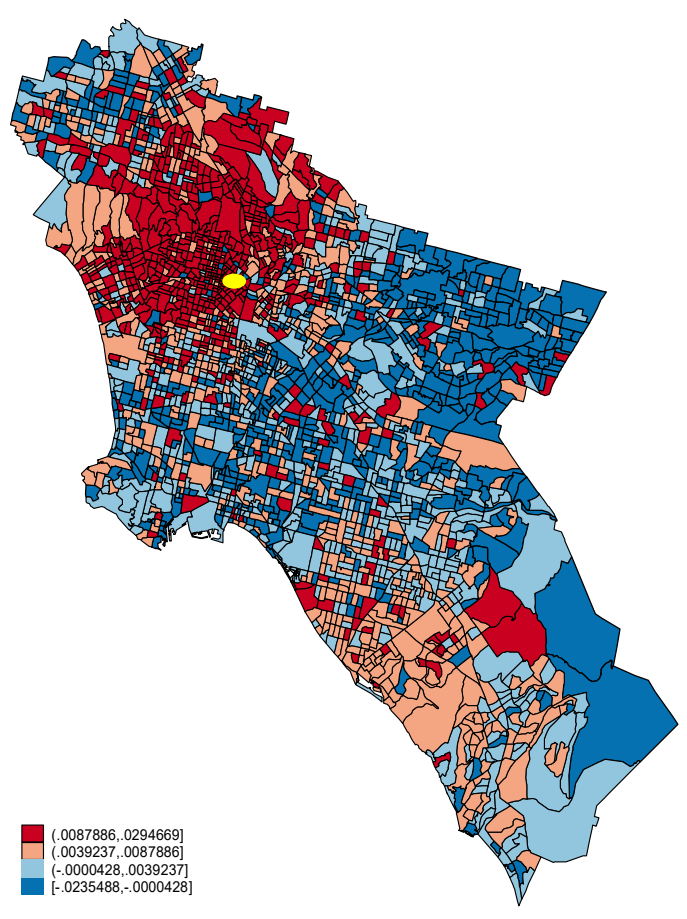

2000-2010 Change in log College RMA 
Figure 4: Change in Simulated RMA for College Workers, Los Angeles and Orange Counties
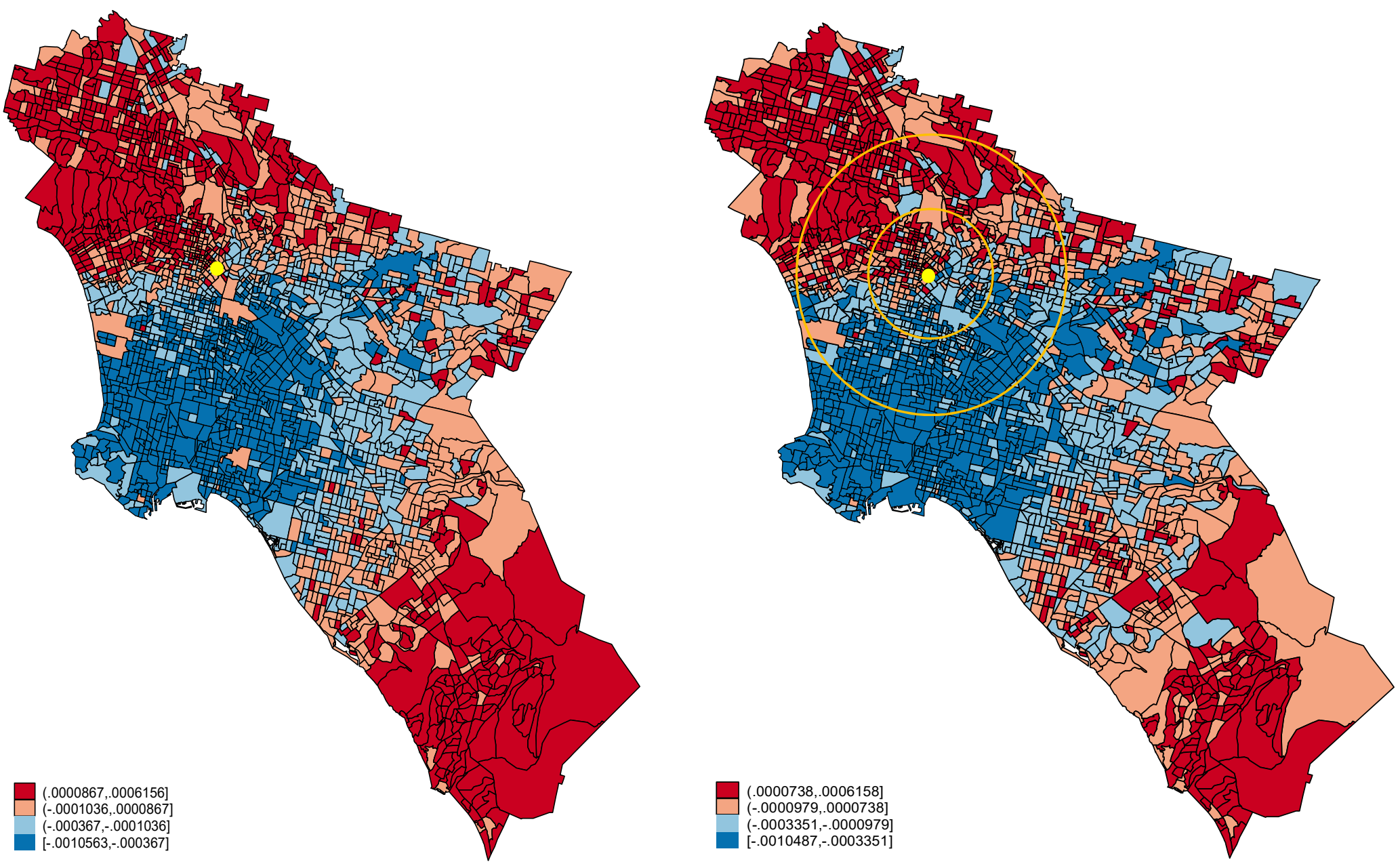

Notes: The left panel depicts our main instrumental variable for the 2000-2010 analysis and the right panel shows the same object after being residualized. Residuals are taken from regressions of the instrument on region-ring fixed effects, origin tract Bartik shocks, origin tract 1990 employment, a quadratic in CBD distance and two decades of lagged demographic characteristics. CBD distance rings of $10 \mathrm{~km}$ and $20 \mathrm{~km}$ are also shown. 
Figure 5: Schematic Diagram of the Identification Challenge for the 2000-2010 Period

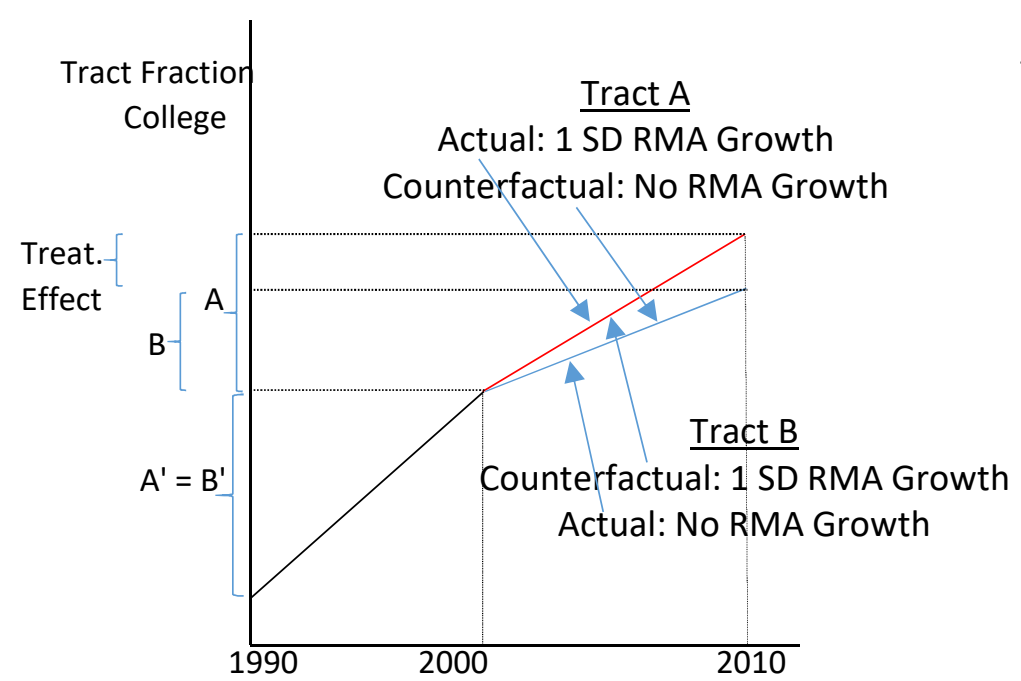

Ideal Experiment: Two identical tracts w/ diff. post-2000 experiences

Treatment Effect $=\mathrm{A}-\mathrm{B}$

Relative Pre-Trend $=A^{\prime}-B^{\prime}=0$

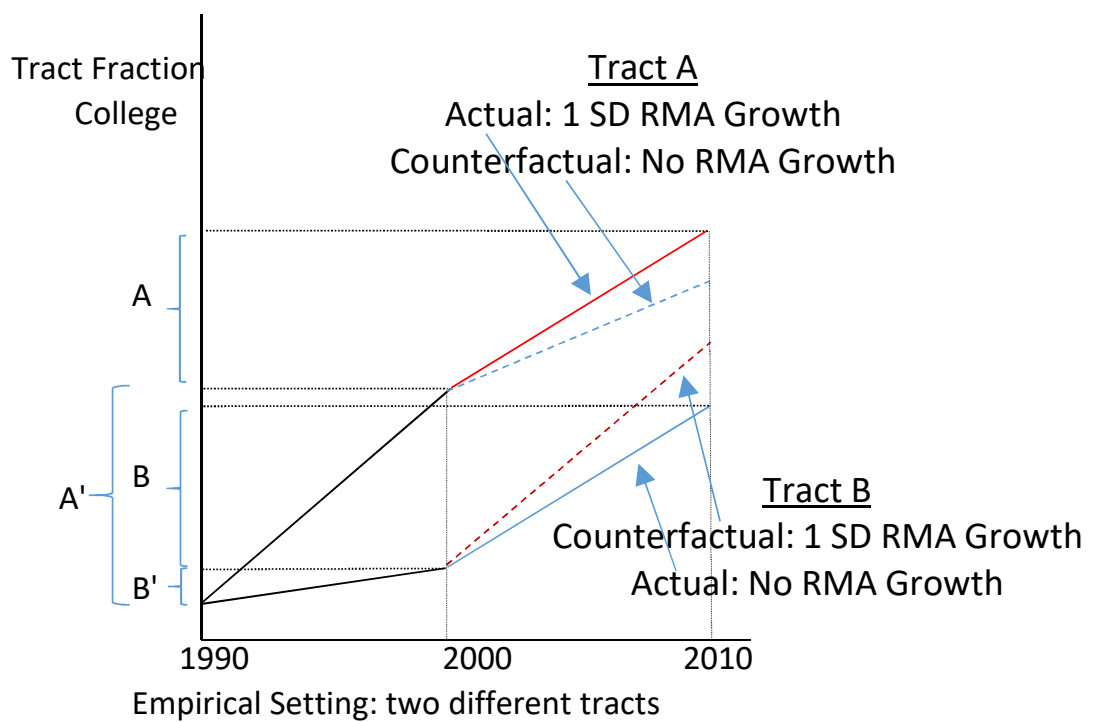

Estimated Diff in Diff $=\mathrm{A}-\mathrm{B}<$ Treatment Effect Relative Pre-Trend $=A^{\prime}-B^{\prime}>0$ 
Figure 6: Dynamic Treatment Effects on Neighborhood Attributes Accounting for Migration
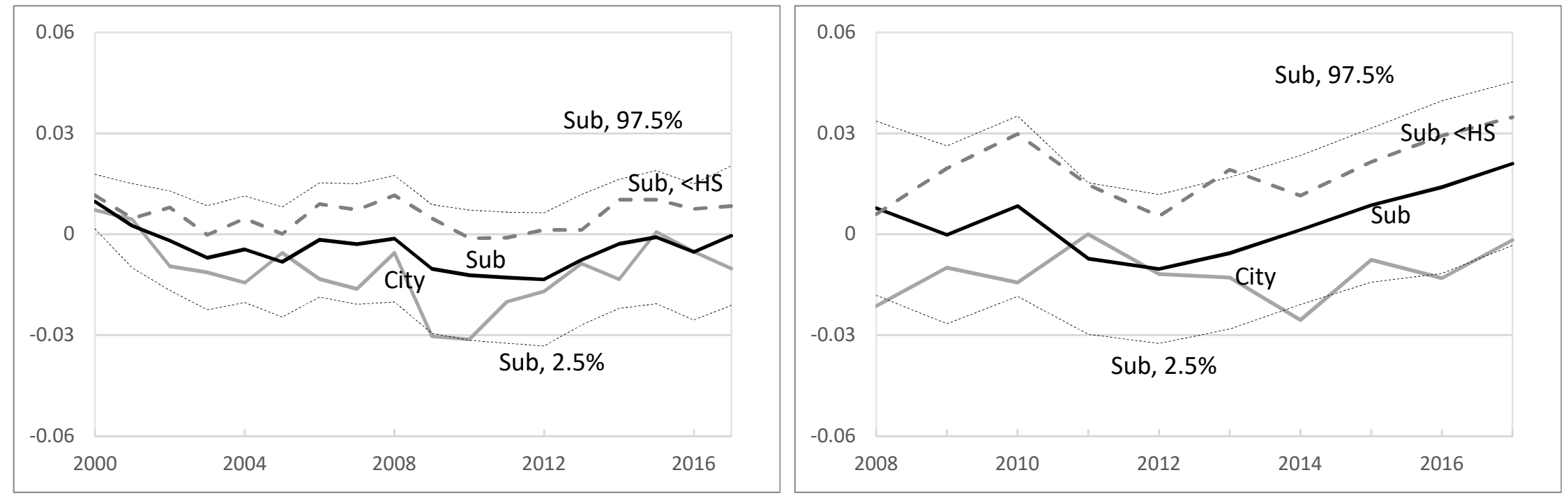

Panel A: Parents' 2000-2007 Change in Fraction College in Tract of Residence Panel B: Children's 2000-2007 Change in Fraction College in Tract of Residence

Notes: Each panel graphs coefficients from separate IV regressions of the indicated outcome applying to the indicated area and education group in the indicated year on base controls and region fixed effects. Graphs exclude plots for education groups with similar results as those for everyone pooled. Indicated confidence intervals use robust standard errors. Change in fraction college is measured for the tract of residence in the indicated year measured as of 2005-2009 minus tract of residence in 2000 measured as of 2000. 
Figure 7: Dynamic Treatment Effects on CCP Children

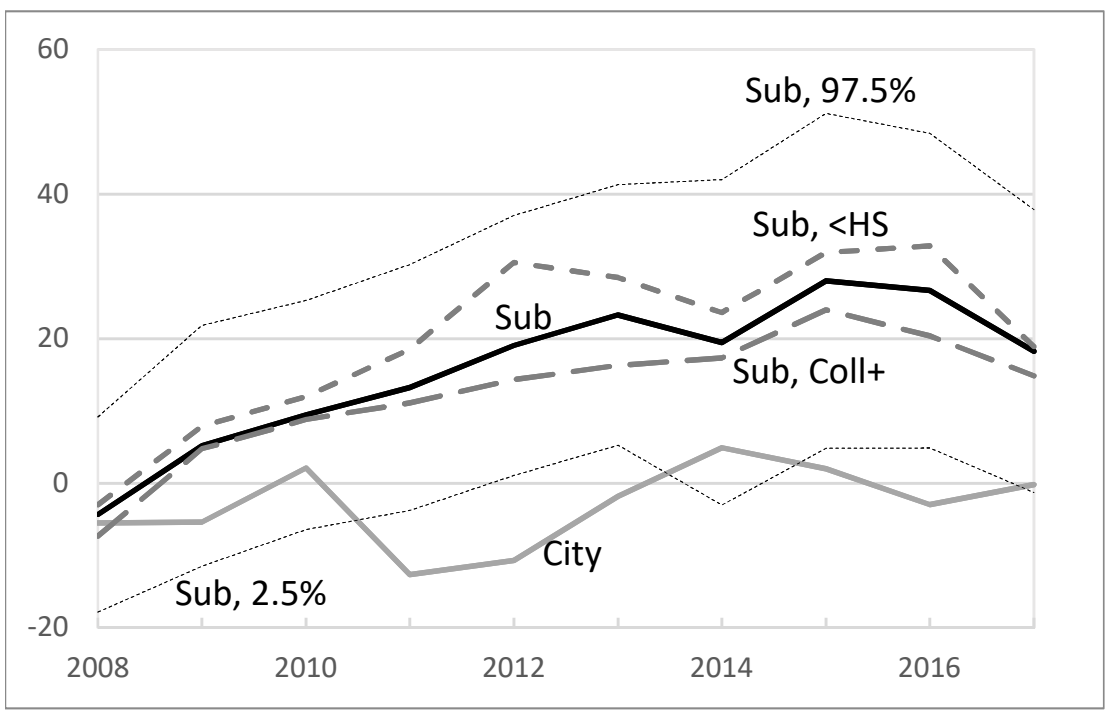

Panel A: Credit Score

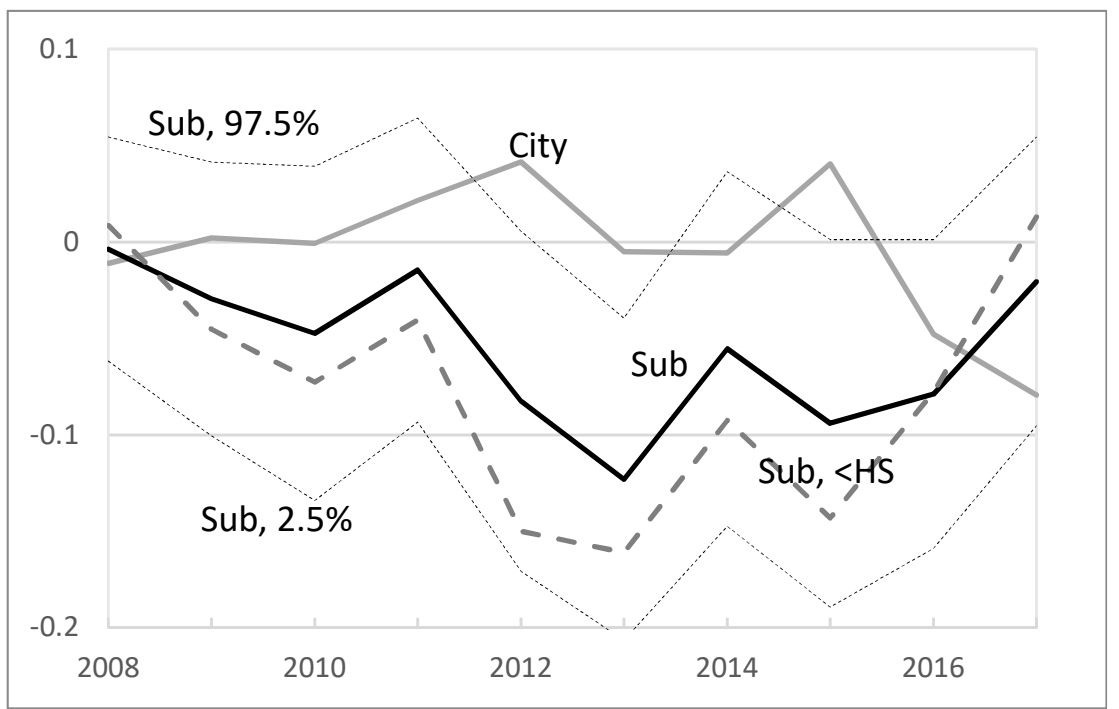

Panel C: Probability 30 Days Past Due

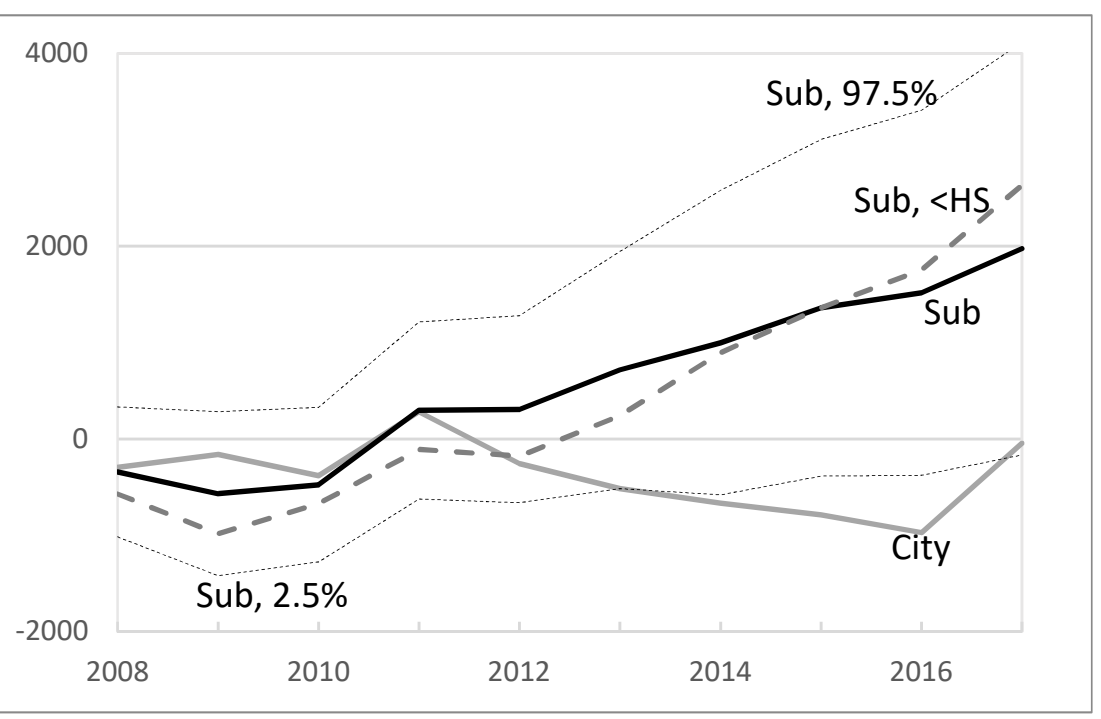

Panel B: Sum of Credit Card Limits

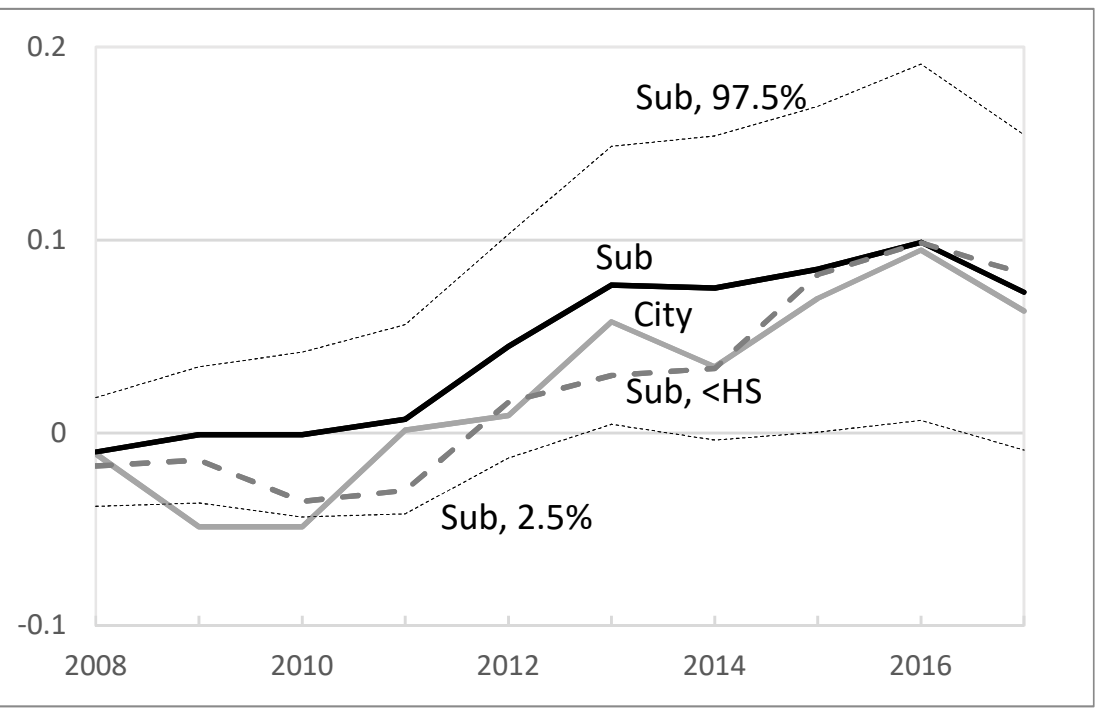

Panel D: Probability of Having a Mortgage

Notes: See the notes to Figure 6 for an explanation of the plots. Table 9 Panel B presents detailed results for 2017. 
Figure 8: Dynamic Treatment Effects on CCP Parents

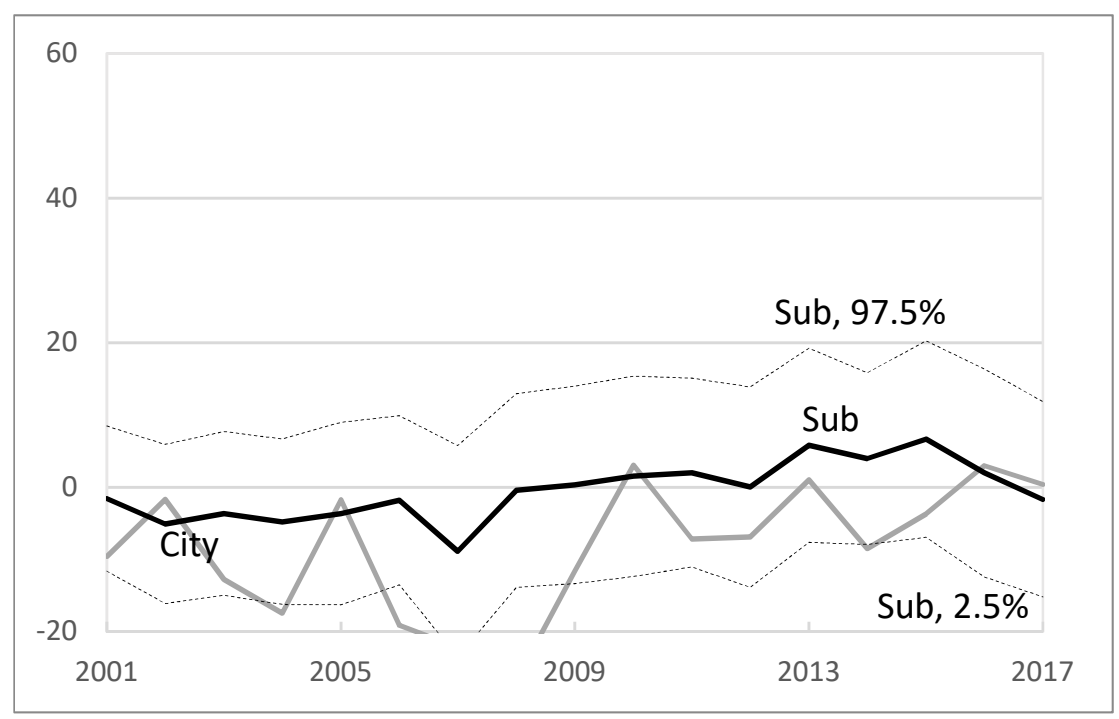

Panel A: Credit Score

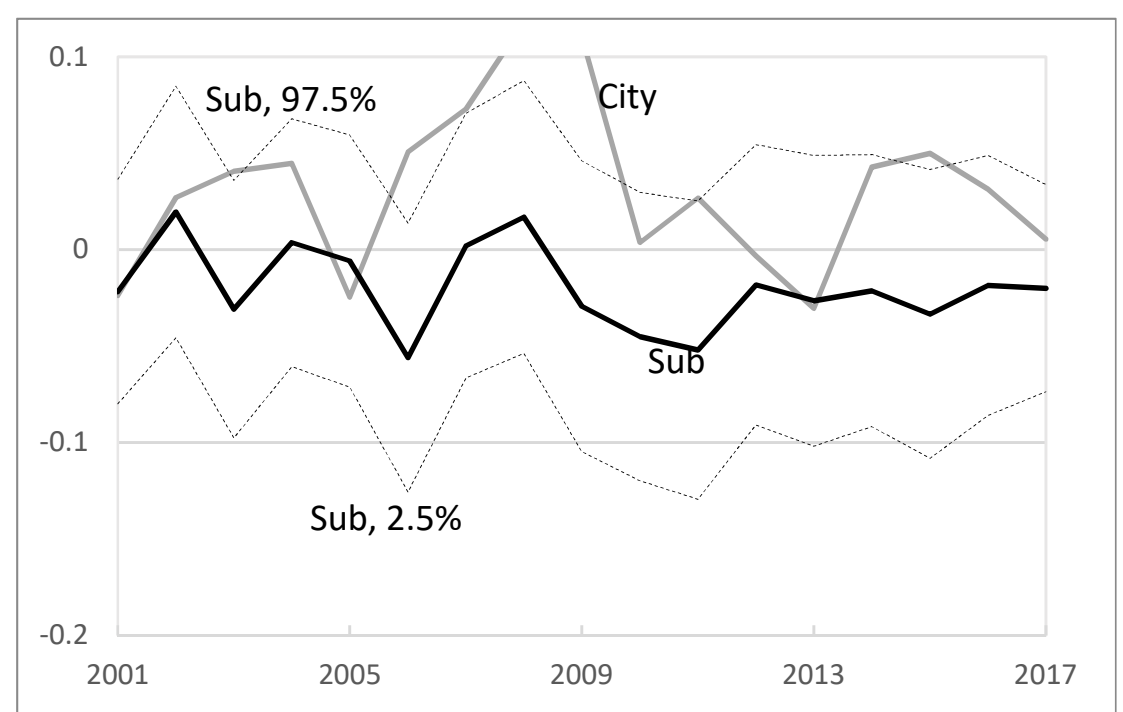

Panel C: Probability 30 Days Past Due

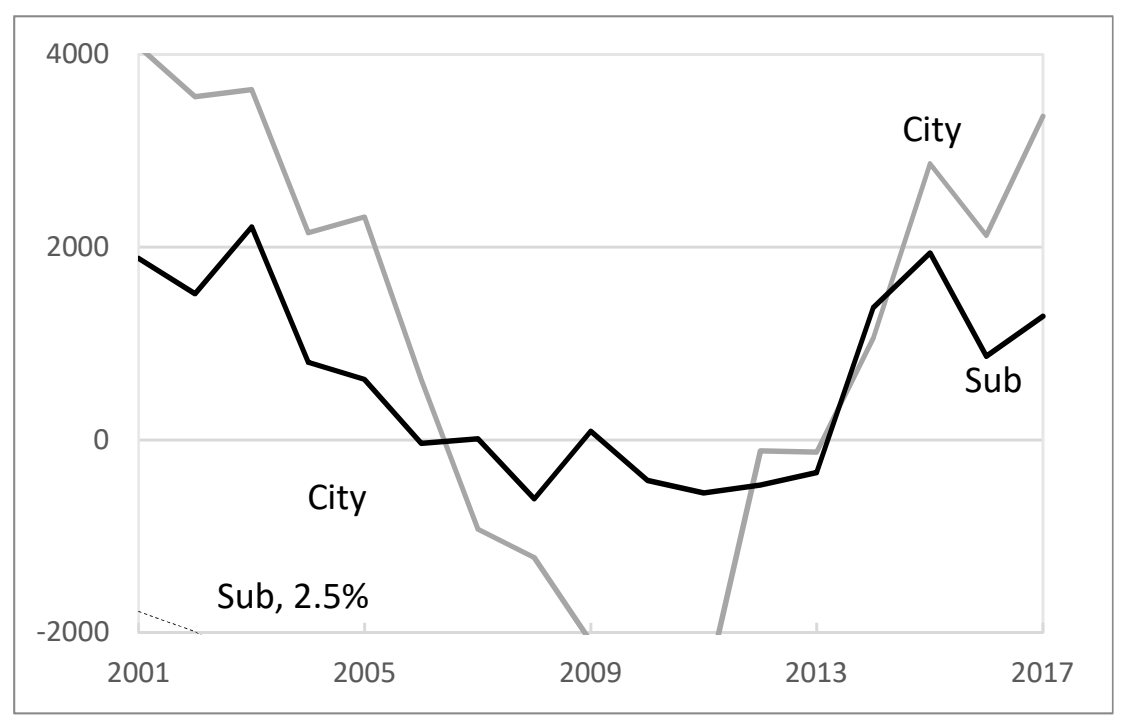

Panel B: Sum of Credit Card Limits

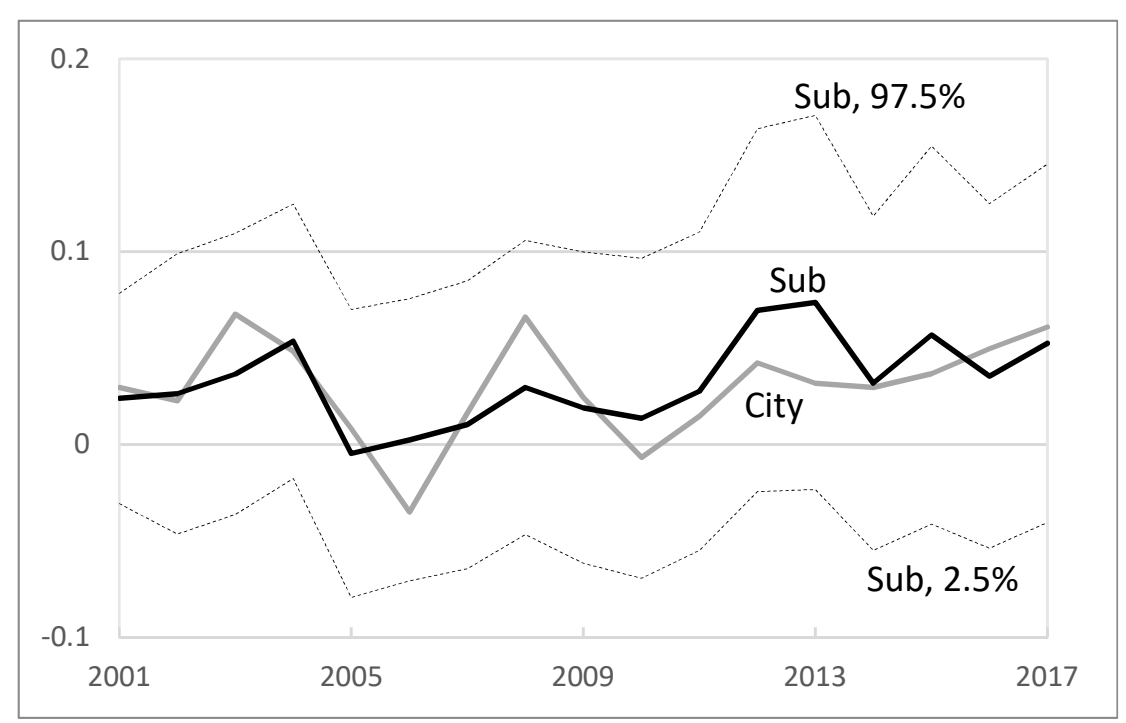

Panel D: Probability of Having a Mortgage

Notes: See the notes to Figure 6 for an explanation of the plots. Table 9 Panel A presents detailed results for 2017. 
Table A1: Coefficients from Commute Time Regressions

\begin{tabular}{lcc} 
& $\mathbf{1 9 9 0}$ & $\mathbf{2 0 0 0}$ \\
\hline log Distance between i and j & 0.427 & 0.434 \\
& $(0.000)$ & $-0.000)$ \\
log Distance from CBD to Residence i & -0.068 & $(0.000)$ \\
log Distance from CBD to Work j & $(0.000)$ & -0.072 \\
& -0.068 & $(0.000)$ \\
R-Squared & $(0.000)$ & 0.504
\end{tabular}

Notes: Regressions are of log one-way commute time on the variables listed at left and region fixed effects. Both regressions have contemporaneous commuting flow weights. 
Table A2: Ranking of Industry Growth Rates for College Bartik Shocks

Industry Employment Growth Rate

Panel A: $1990-2000$

\begin{tabular}{|c|c|c|}
\hline \multirow[t]{9}{*}{ Top .... } & Business and repair services & 0.71 \\
\hline & Other professional and related services & 0.41 \\
\hline & Communications and other public utilities & 0.39 \\
\hline & Personal services & 0.37 \\
\hline & Health services & 0.33 \\
\hline & Construction & 0.10 \\
\hline & Agriculture, forestry, and fisheries & 0.06 \\
\hline & Wholesale trade & 0.02 \\
\hline & Armed Forces & -0.22 \\
\hline ... Bottom & Mining & -0.41 \\
\hline
\end{tabular}

Panel B: 2000-2005

\begin{tabular}{|c|c|c|}
\hline \multirow[t]{9}{*}{ Top .... } & Construction & 0.23 \\
\hline & Retail Trade & 0.20 \\
\hline & Finance, Insurance and Real Estate & 0.20 \\
\hline & Personal Services & 0.19 \\
\hline & Wholesale Trade & 0.18 \\
\hline & Business and Repair Services & 0.07 \\
\hline & Communications and Public Utilities & 0.07 \\
\hline & Manufacturing, Nondurable & 0.03 \\
\hline & Manufacturing, Durable & 0.01 \\
\hline ... Bottom & Armed Forces & -0.02 \\
\hline
\end{tabular}

Notes: Since Bartik shocks exclude the origin metro area, they are slightly different across metro areas. Here we report industry-specific employment growth rates used for shocks in Bismark, ND. 
Table A3: Descriptive OLS Regressions About Neighborhood Change and Relationships With RMA for the 1990-2000 Period

\begin{tabular}{|c|c|c|c|c|c|c|c|c|c|c|c|c|}
\hline & \multicolumn{4}{|c|}{ Fraction College Graduate } & \multicolumn{4}{|c|}{ Neighborhood Quality Index } & \multicolumn{4}{|c|}{ log Average HH Income } \\
\hline & $\begin{array}{l}1990-20 \\
(1)\end{array}$ & $\begin{array}{r}\text { Change } \\
\text { (2) }\end{array}$ & $\begin{array}{c}1980-1990 \text { Chg } \\
\text { (3) }\end{array}$ & $\begin{array}{c}1990 \text { Level } \\
\text { (4) }\end{array}$ & $\begin{array}{l}1990-200 \\
(5)\end{array}$ & $\begin{array}{c}\text { Change } \\
(6) \\
\end{array}$ & $\begin{array}{c}1980-1990 \text { Chg } \\
(7)\end{array}$ & $\begin{array}{c}1990 \text { Level } \\
(8)\end{array}$ & $\begin{array}{l}1990-200 \\
(9)\end{array}$ & $\begin{array}{r}\text { Change } \\
(10) \\
\end{array}$ & $\begin{array}{c}\text { 1980-1990 Chg } \\
\text { (11) }\end{array}$ & $\begin{array}{c}1990 \text { Level } \\
(12)\end{array}$ \\
\hline $\begin{array}{l}\text { 1980-1990 Growth in } \\
\text { Dependent Variable }\end{array}$ & $\begin{array}{r}-0.000340 \\
(0.00491)\end{array}$ & $\begin{array}{c}-0.0483^{* * *} \\
(0.00617)\end{array}$ & & & $\begin{array}{l}-0.213^{* * *} \\
(0.00532)\end{array}$ & $\begin{array}{l}-0.248^{* * *} \\
(0.00526)\end{array}$ & & & $\begin{array}{c}-0.00204 * * * \\
(0.000733)\end{array}$ & $\begin{array}{l}-0.264^{* * *} \\
(0.00555)\end{array}$ & & \\
\hline $\begin{array}{l}\Delta \text { In Unified RMA } \\
1990-2000\end{array}$ & & & $\begin{array}{c}-0.00145 * * * \\
(0.000267)\end{array}$ & $\begin{array}{c}-0.00145^{* * *} \\
(0.000267)\end{array}$ & & & $\begin{array}{c}-0.308^{* * *} \\
(0.0739)\end{array}$ & $\begin{array}{c}-0.221 * * * \\
(0.0770)\end{array}$ & & & $\begin{array}{c}-0.00419 * * * \\
(0.00114)\end{array}$ & $\begin{array}{c}-0.00419 * * * \\
(0.00114)\end{array}$ \\
\hline Obs & 32,457 & 32,457 & 32,478 & 32,478 & 32,515 & 32,515 & 32,515 & 32,515 & 32,342 & 32,342 & 32,394 & 32,394 \\
\hline (Within) R-Squared & 0.000 & 0.079 & 0.471 & 0.845 & 0.050 & 0.116 & 0.050 & 0.732 & 0.000 & 0.110 & 0.984 & 0.748 \\
\hline Region-Ring Fixed Effects & Yes & Yes & Yes & Yes & Yes & Yes & Yes & Yes & Yes & Yes & Yes & Yes \\
\hline Base Controls & No & Yes & Yes & Yes & No & Yes & Yes & Yes & No & Yes & Yes & Yes \\
\hline
\end{tabular}

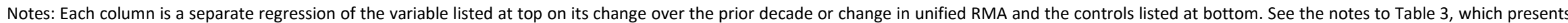
analogous regressions for the 2000-2010 period, for more details. 
Table A4: Examination of Differential Pre-1990 Trends

\begin{tabular}{lcc|cc} 
& \multicolumn{2}{c}{ Fraction College Graduate } & \multicolumn{2}{c}{ Neighborhood Quality Index } \\
& $(1)$ & $(2)$ & $(3)$ & $(4)$ \\
\hline$\Delta$ In Unified RMA, 1990-2000 & $0.0299^{* * *}$ & 0.0125 & $3.955^{* * *}$ & $4.653^{* *}$ \\
& $(0.00439)$ & $(0.00830)$ & $(0.861)$ & $(1.816)$ \\
& & & & \\
Obs & 32,342 & 32,342 & 32,379 & 32,379 \\
First Stage F & 65.31 & 26.54 & 65.28 & 26.51 \\
\hline & & & & \\
Region-Ring Fixed Effects & Yes & Yes & Yes & Yes \\
Base Controls & Yes & Yes & Yes & Yes \\
Bartik Ring Controls & No & Yes & No & Yes
\end{tabular}

Notes: Each column reports coefficients from a separate IV regression of the 1980-1990 change in the variable listed at top on the change in log unified RMA, instrumented with the change in counterfactual log skilled RMA. See the notes to Table 3 for the base controls. The instrument is built using employment in all tracts excluding the origin tract. Regressions do not control for the change in counterfactual log unskilled RMA, as these are not separately identified from the skilled shocks for the 1990-2000 period. 


\section{Table A5: First Stage Results - 1990-2000 Period}

\begin{tabular}{lcc|cc} 
& \multicolumn{2}{c}{ Census Sample } & \multicolumn{2}{c}{ Tracts in PSID Sample } \\
\cline { 2 - 5 } Change in Cntrfctl. log Skill. RMA & $(1)$ & $(2)$ & $(3)$ & $(4)$ \\
\cline { 2 - 5 } & $\begin{array}{c}0.0698^{* * *} \\
(0.00440)\end{array}$ & $\begin{array}{c}0.0397^{* * *} \\
(0.00507)\end{array}$ & $\begin{array}{c}0.0701^{* *} \\
(0.0294)\end{array}$ & $\begin{array}{c}0.0604 \\
(0.0404)\end{array}$ \\
Observations & & & & \\
(Within) R-Squared & 32,515 & 32,515 & 1,519 & 1,519 \\
\hline & 0.065 & 0.118 & 0.906 & 0.914 \\
Region-Ring FE & & & & \\
Base Controls & Yes & Yes & Yes & Yes \\
Bartik Ring Controls & Yes & Yes & Yes & Yes \\
& No & Yes & No & Yes
\end{tabular}

Notes: All RMA measures are expressed in standard deviation units. 
Table A6: Effects of RMA on Census Tract Outcomes, 1990-2000

\begin{tabular}{lcc|cc} 
& \multicolumn{2}{c}{ Fraction College Graduate } & \multicolumn{2}{c}{ Neighborhood Quality } \\
& $(1)$ & $(2)$ & $(3)$ & $(4)$ \\
\hline OLS, 1st Diff. & 0.000400 & 0.000246 & $0.288^{* * *}$ & $0.313^{* * *}$ \\
$\Delta$ Unified RMA & $(0.000382)$ & $(0.000394)$ & $(0.0704)$ & $(0.0727)$ \\
& & & & \\
IV, 1st Diff. & $0.0299 * * *$ & 0.0101 & $4.003 * * *$ & 1.269 \\
$\Delta$ Unified RMA & $(0.00459)$ & $(0.00878)$ & $(0.813)$ & $(1.624)$ \\
Observations & 32,294 & 32,294 & 32,379 & 32,379 \\
First Stage F & 253.3 & 62.31 & 251.0 & 61.28 \\
\hline & & & & \\
Region-Ring FE & Yes & Yes & Yes & Yes \\
Base Controls & Yes & Yes & Yes & Yes \\
Bartik Ring Controls & No & Yes & No & Yes
\end{tabular}

Notes: Entries show OLS or IV coefficients and standard errors. All RMA measures are expressed in standard deviation units. 
Table A7: Impacts of RMA on Neighborhood Exposure and Migration

Region-Ring Fixed Effects, Full Set of Controls and Bartik Ring Controls

2000-2007 Change in Fraction College in

Tract of 2000 Residence

Fraction College in 2017 Tract of Residence Fraction College in 2000 Tract of Residence

:ducational Attainment Weight None $<\mathrm{HS}$ College + None $<\mathrm{HS}$

College +

\section{Panel A: Parents}

\begin{tabular}{|c|c|c|c|c|c|c|}
\hline \multirow[t]{2}{*}{ All, 0-10 km from CBD } & 0.00336 & -0.00272 & -0.00102 & -0.0231 & -0.0364 & -0.0316 \\
\hline & $(0.00721)$ & (0.00789) & $(0.00730)$ & $(0.0183)$ & $(0.0257)$ & $(0.0218)$ \\
\hline \multirow[t]{2}{*}{ All, $10-20$ km from CBD } & 0.00439 & $1.11 \mathrm{e}-05$ & 0.0109* & -0.0124 & -0.00546 & -0.0170 \\
\hline & $(0.00463)$ & $(0.00537)$ & $(0.00611)$ & $(0.0110)$ & $(0.0137)$ & $(0.0153)$ \\
\hline \multirow[t]{2}{*}{ Observations } & 9,848 & 1,769 & 3,163 & 9,826 & 1,765 & 3,156 \\
\hline & \multicolumn{4}{|c|}{ Panel B: Children (Born 1985-1989) } & & \\
\hline \multirow[t]{2}{*}{ All, 0-10 km from CBD } & 0.00157 & -0.00452 & -0.000871 & -0.00676 & -0.0214 & 0.00133 \\
\hline & $(0.00688)$ & (0.00709) & $(0.00734)$ & $(0.0209)$ & $(0.0236)$ & (0.0244) \\
\hline \multirow[t]{2}{*}{ All, $10-20$ km from CBD } & 0.00472 & 0.00181 & $0.0109^{*}$ & 0.0165 & 0.0199 & 0.0209 \\
\hline & $(0.00468)$ & $(0.00564)$ & $(0.00621)$ & $(0.0140)$ & $(0.0160)$ & $(0.0180)$ \\
\hline \multirow[t]{2}{*}{ Renters, 0-10 km from CBD } & 0.00444 & -0.00210 & 0.00225 & -0.00297 & -0.0114 & -0.00832 \\
\hline & $(0.00726)$ & $(0.00726)$ & (0.00789) & $(0.0213)$ & $(0.0242)$ & $(0.0267)$ \\
\hline \multirow[t]{2}{*}{ Owners, 0-10 km from CBD } & 0.00184 & -0.00445 & -0.000831 & -0.00617 & -0.0219 & 0.00121 \\
\hline & (0.00709) & $(0.00717)$ & $(0.00745)$ & $(0.0209)$ & $(0.0242)$ & $(0.0252)$ \\
\hline \multirow[t]{2}{*}{ Renters, $10-20 \mathrm{~km}$ from CBD } & 0.00640 & 0.00351 & $0.0128^{*}$ & 0.0192 & $0.0278^{*}$ & 0.0150 \\
\hline & (0.00495) & $(0.00588)$ & $(0.00663)$ & $(0.0147)$ & $(0.0167)$ & (0.0198) \\
\hline \multirow[t]{2}{*}{ Owners, $10-20 \mathrm{~km}$ from CBD } & 0.00345 & 0.000671 & 0.00942 & 0.0145 & 0.0137 & 0.0233 \\
\hline & $(0.00455)$ & $(0.00557)$ & $(0.00600)$ & $(0.0137)$ & (0.0159) & $(0.0180)$ \\
\hline Observations & 10,246 & 1,853 & 3,278 & 10,188 & 1,845 & 3,258 \\
\hline
\end{tabular}

Notes: These estimates show robustness of Table 8 estimates to the inclusion Bartik ring controls. Standard errors are clustered by census tract of residence in 2000 . 
Table A8: Consumer Credit Panel Results - Impacts of Standardized RMA

Region-Ring Fixed Effects, Full Set of Controls and Bartik Ring Controls

\begin{tabular}{|c|c|c|c|c|c|c|c|c|c|c|c|c|}
\hline \multirow{2}{*}{$\begin{array}{r}\text { Outcome } \\
\text { Educational Attainment Weight }\end{array}$} & \multicolumn{3}{|c|}{ Equifax Risk Score ${ }^{\mathrm{TM}}$} & \multicolumn{3}{|c|}{ Sum of Credit Card Limits } & \multicolumn{3}{|c|}{ Any Loan 30 Days Past Due } & \multicolumn{3}{|c|}{ Mortgage Dummy } \\
\hline & None & $<\mathrm{HS}$ & College + & None & $<\mathrm{HS}$ & College + & None & $<\mathrm{HS}$ & College + & None & $<\mathrm{HS}$ & College + \\
\hline \multicolumn{13}{|c|}{ Panel A: Parent Outcomes, 2017} \\
\hline \multirow[t]{2}{*}{ All, 0-10 km from CBD } & 12.59 & $28.20^{*}$ & -1.020 & 3,208 & 3,962 & 2,717 & -0.0146 & -0.0676 & 0.0102 & 0.0956 & 0.117 & 0.0702 \\
\hline & $(10.94)$ & $(16.10)$ & (11.53) & $(2,999)$ & $(3,540)$ & $(3,231)$ & $(0.0441)$ & $(0.0643)$ & $(0.0443)$ & $(0.0681)$ & $(0.0904)$ & $(0.0673)$ \\
\hline \multirow[t]{2}{*}{ All, $10-20 \mathrm{~km}$ from CBD } & 4.048 & 0.239 & 2.924 & 477.1 & -756.6 & $-1,861$ & -0.0279 & 0.0151 & -0.0315 & 0.0656 & 0.0807 & 0.0522 \\
\hline & (6.548) & $(8.483)$ & (6.933) & $(3,221)$ & $(3,187)$ & $(2,960)$ & $(0.0243)$ & $(0.0357)$ & $(0.0279)$ & $(0.0411)$ & $(0.0503)$ & $(0.0459)$ \\
\hline Observations & 8,995 & 1,594 & 2,924 & 8,984 & 1,589 & 2,924 & 8,984 & 1,589 & 2,924 & 8,984 & 1,589 & 2,924 \\
\hline \multicolumn{13}{|c|}{ Panel B: Child Outcomes, 2017} \\
\hline \multirow[t]{2}{*}{ All, 0-10 km from CBD } & 2.907 & 12.67 & 10.84 & -154.8 & 651.2 & $-1,167$ & -0.112 & $-0.181^{*}$ & -0.0794 & 0.0839 & 0.106 & 0.0635 \\
\hline & $(13.39)$ & $(15.82)$ & $(13.86)$ & $(1,304)$ & $(1,549)$ & $(1,605)$ & $(0.0683)$ & $(0.0971)$ & $(0.0616)$ & $(0.0603)$ & $(0.0709)$ & $(0.0610)$ \\
\hline \multirow[t]{2}{*}{ All, $10-20$ km from CBD } & $24.15^{* *}$ & $29.72^{*}$ & $22.20^{*}$ & 1,890 & 2,272 & 1,712 & -0.0488 & -0.0393 & -0.0229 & $0.108 * *$ & $0.112^{*}$ & $0.102 * *$ \\
\hline & $(11.83)$ & $(15.97)$ & $(12.01)$ & $(1,228)$ & $(1,544)$ & $(1,307)$ & $(0.0436)$ & $(0.0586)$ & $(0.0457)$ & $(0.0530)$ & $(0.0632)$ & $(0.0518)$ \\
\hline \multirow[t]{2}{*}{ Renters, $0-10 \mathrm{~km}$ from CBD } & 2.213 & 10.59 & 8.170 & -321.8 & 749.9 & $-1,930$ & -0.0769 & -0.140 & -0.0437 & $0.107^{*}$ & 0.101 & 0.0987 \\
\hline & $(13.50)$ & $(15.71)$ & $(14.31)$ & $(1,325)$ & $(1,542)$ & $(1,775)$ & $(0.0639)$ & $(0.0881)$ & $(0.0613)$ & $(0.0645)$ & $(0.0696)$ & $(0.0675)$ \\
\hline \multirow[t]{2}{*}{ Owners, 0-10 km from CBD } & 2.747 & 12.70 & 10.57 & -153.0 & 627.7 & $-1,136$ & $-0.112^{*}$ & $-0.189 * *$ & -0.0812 & 0.0841 & 0.107 & 0.0628 \\
\hline & $(13.38)$ & $(15.91)$ & $(13.74)$ & $(1,308)$ & $(1,561)$ & $(1,685)$ & $(0.0641)$ & $(0.0909)$ & $(0.0594)$ & $(0.0639)$ & $(0.0707)$ & $(0.0643)$ \\
\hline \multirow[t]{2}{*}{ Renters, $10-20 \mathrm{~km}$ from CBD } & $23.66^{*}$ & $28.32 *$ & 20.40 & 1,800 & 2,337 & 1,239 & -0.0297 & -0.0104 & -0.000800 & $0.120 * *$ & $0.109 *$ & $0.124 * *$ \\
\hline & $(12.36)$ & $(16.51)$ & $(12.88)$ & $(1,282)$ & $(1,587)$ & $(1,435)$ & $(0.0454)$ & $(0.0615)$ & $(0.0472)$ & $(0.0537)$ & $(0.0646)$ & $(0.0559)$ \\
\hline \multirow[t]{2}{*}{ Owners, $10-20 \mathrm{~km}$ from CBD } & $25.17^{* *}$ & $31.97 * *$ & $23.77^{* *}$ & 1,984 & 2,270 & 2,095 & -0.0698 & -0.0662 & -0.0403 & $0.0920^{*}$ & $0.109 *$ & 0.0831 \\
\hline & $(11.73)$ & $(16.11)$ & $(11.73)$ & $(1,214)$ & $(1,533)$ & $(1,297)$ & $(0.0443)$ & $(0.0604)$ & $(0.0442)$ & $(0.0510)$ & $(0.0620)$ & $(0.0506)$ \\
\hline Observations & 9,736 & 1,737 & 3,151 & 9,736 & 1,737 & 3,146 & 9,736 & 1,737 & 3,146 & 9,736 & 1,737 & 3,146 \\
\hline
\end{tabular}

Notes: These estimates show robustness of Table 9 estimates to the inclusion Bartik ring controls. Standard errors are clustered by census tract of residence in 2000. 


\section{Table A9: Consumer Credit Panel Results for Children - School District Fixed Effects - Full Controls and Bartik Ring Controls}

\begin{tabular}{|c|c|c|c|c|c|c|c|c|c|c|c|c|}
\hline \multirow[b]{2}{*}{$\begin{array}{l}\triangle \mathrm{RMA},<10 \mathrm{~km} \\
\text { from CBD }\end{array}$} & \multicolumn{3}{|c|}{ Equifax Risk Score $^{\mathrm{TM}}$} & \multicolumn{3}{|c|}{ Sum of Credit Card Limits } & \multicolumn{3}{|c|}{ Any Loan 30 Days Past Due } & \multicolumn{3}{|c|}{ Mortgage Indicator } \\
\hline & $\begin{array}{l}-3.369 \\
(10.09)\end{array}$ & $\begin{array}{l}-0.0177 \\
(13.76)\end{array}$ & $\begin{array}{c}1.058 \\
(12.66)\end{array}$ & $\begin{array}{l}-1,291 \\
(963.3)\end{array}$ & $\begin{array}{l}-627.2 \\
(1,344)\end{array}$ & $\begin{array}{l}-1,256 \\
(1,133)\end{array}$ & $\begin{array}{c}-0.000608 \\
(0.0405)\end{array}$ & $\begin{array}{c}-0.102 \\
(0.0685)\end{array}$ & $\begin{array}{l}-0.0406 \\
(0.0558)\end{array}$ & $\begin{array}{l}-0.0184 \\
(0.0381)\end{array}$ & $\begin{array}{c}0.0723 \\
(0.0599)\end{array}$ & $\begin{array}{l}-0.0222 \\
(0.0458)\end{array}$ \\
\hline $\begin{array}{l}\triangle \mathrm{RMA},>10 \mathrm{~km} \\
\text { from CBD }\end{array}$ & $\begin{array}{l}-4.125 \\
(10.20)\end{array}$ & $\begin{array}{l}24.16 * * \\
(11.88)\end{array}$ & $\begin{array}{c}0.352 \\
(12.84)\end{array}$ & $\begin{array}{l}-1,285 \\
(975.7)\end{array}$ & $\begin{array}{c}1,870 \\
(1,232)\end{array}$ & $\begin{array}{l}-1,274 \\
(1,149)\end{array}$ & $\begin{array}{l}-0.00172 \\
(0.0410)\end{array}$ & $\begin{array}{l}-0.0565 \\
(0.0436)\end{array}$ & $\begin{array}{l}-0.0426 \\
(0.0565)\end{array}$ & $\begin{array}{l}-0.0237 \\
(0.0385)\end{array}$ & $\begin{array}{c}0.100 * \\
(0.0515)\end{array}$ & $\begin{array}{l}-0.0285 \\
(0.0464)\end{array}$ \\
\hline $\begin{array}{c}\triangle \mathrm{RMA},<10 \mathrm{~km} \text { from } \mathrm{CBD} \\
\mathrm{X} \text { School Quality Pctile }\end{array}$ & & $\begin{array}{c}0.293 \\
(0.601)\end{array}$ & $\begin{array}{l}-12.92 \\
(14.37)\end{array}$ & & $\begin{array}{l}146.3^{* *} \\
(68.06)\end{array}$ & $\begin{array}{l}151.8 \\
(1.232)\end{array}$ & & $\begin{array}{c}0.00125 \\
(0.00268)\end{array}$ & $\begin{array}{c}0.108 \\
(0.0669)\end{array}$ & & $\begin{array}{c}0.00148 \\
(0.00273)\end{array}$ & $\begin{array}{l}0.00582 \\
(0.0484)\end{array}$ \\
\hline $\begin{array}{c}\triangle \mathrm{RMA},>10 \mathrm{~km} \text { from CBD } \\
\text { X School Quality Pctile }\end{array}$ & & $\begin{array}{c}0.991 * * \\
(0.446)\end{array}$ & $\begin{array}{l}-11.63 \\
(14.68)\end{array}$ & & $\begin{array}{c}140.2^{* * *} \\
(53.40)\end{array}$ & $\begin{array}{c}154.8 \\
(1,254)\end{array}$ & & $\begin{array}{l}-0.00296 * \\
(0.00180)\end{array}$ & $\begin{array}{c}0.105 \\
(0.0680)\end{array}$ & & $\begin{array}{c}0.00129 \\
(0.00188)\end{array}$ & $\begin{array}{l}0.00512 \\
(0.0492)\end{array}$ \\
\hline Observations & 9,736 & 9,374 & 9,374 & 9,736 & 9,372 & 9,372 & 9,736 & 9,372 & 9,372 & 9,736 & 9,372 & 9,372 \\
\hline School District FE & Yes & No & Yes & Yes & No & Yes & Yes & No & Yes & Yes & No & Yes \\
\hline Region-Ring FE & No & Yes & No & No & Yes & No & No & Yes & No & No & Yes & No \\
\hline
\end{tabular}

Notes: These estimates show robustness of Table 10 estimates to the inclusion Bartik ring controls. Standard errors are clustered by census tract of residence in 2000. 


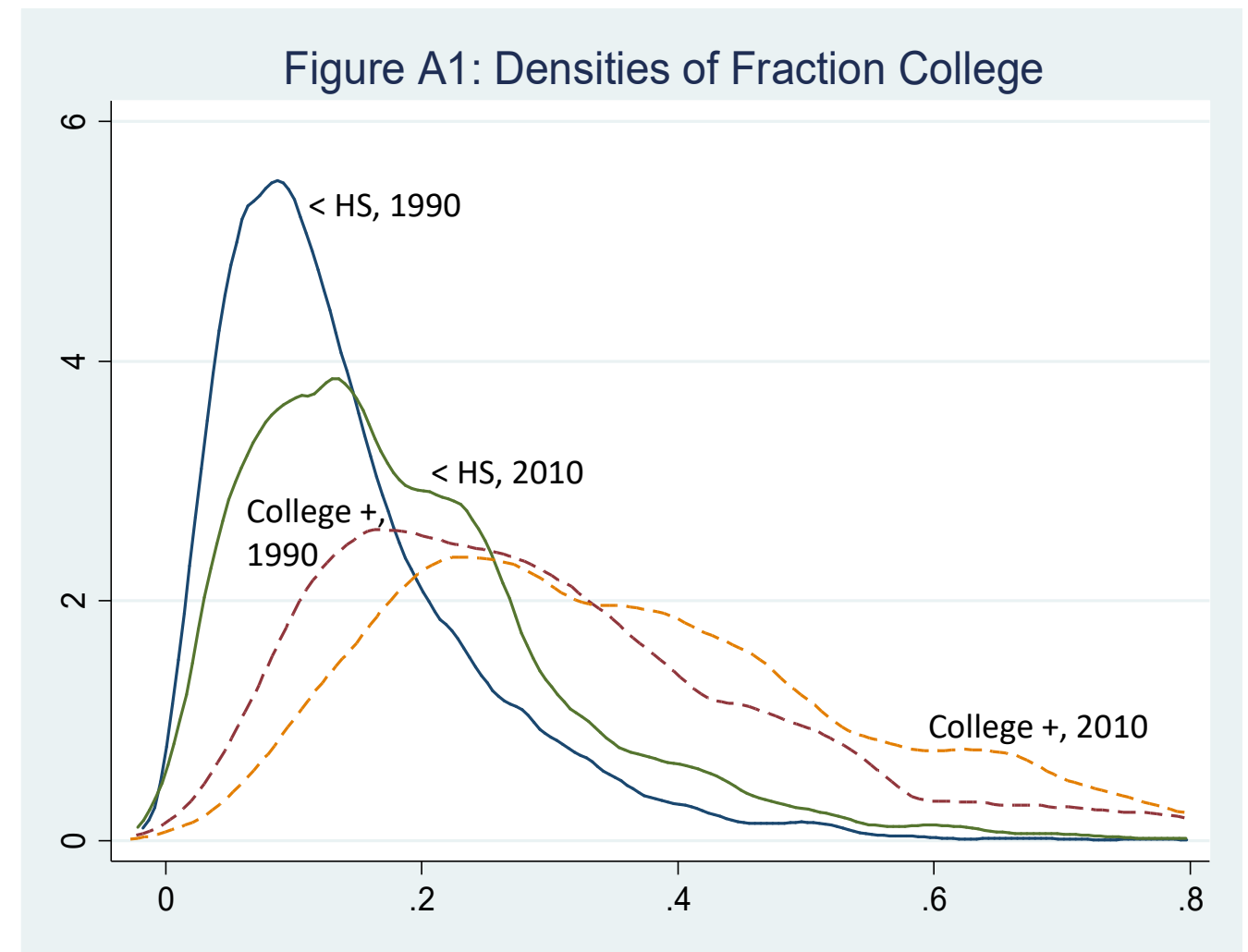

Notes: Densities are for children by parents' education and are calculated using census tract tabulations. See the notes to Figure 1 for more details. 
Figure A2: Fixed Effects Estimates from Commute Time Model

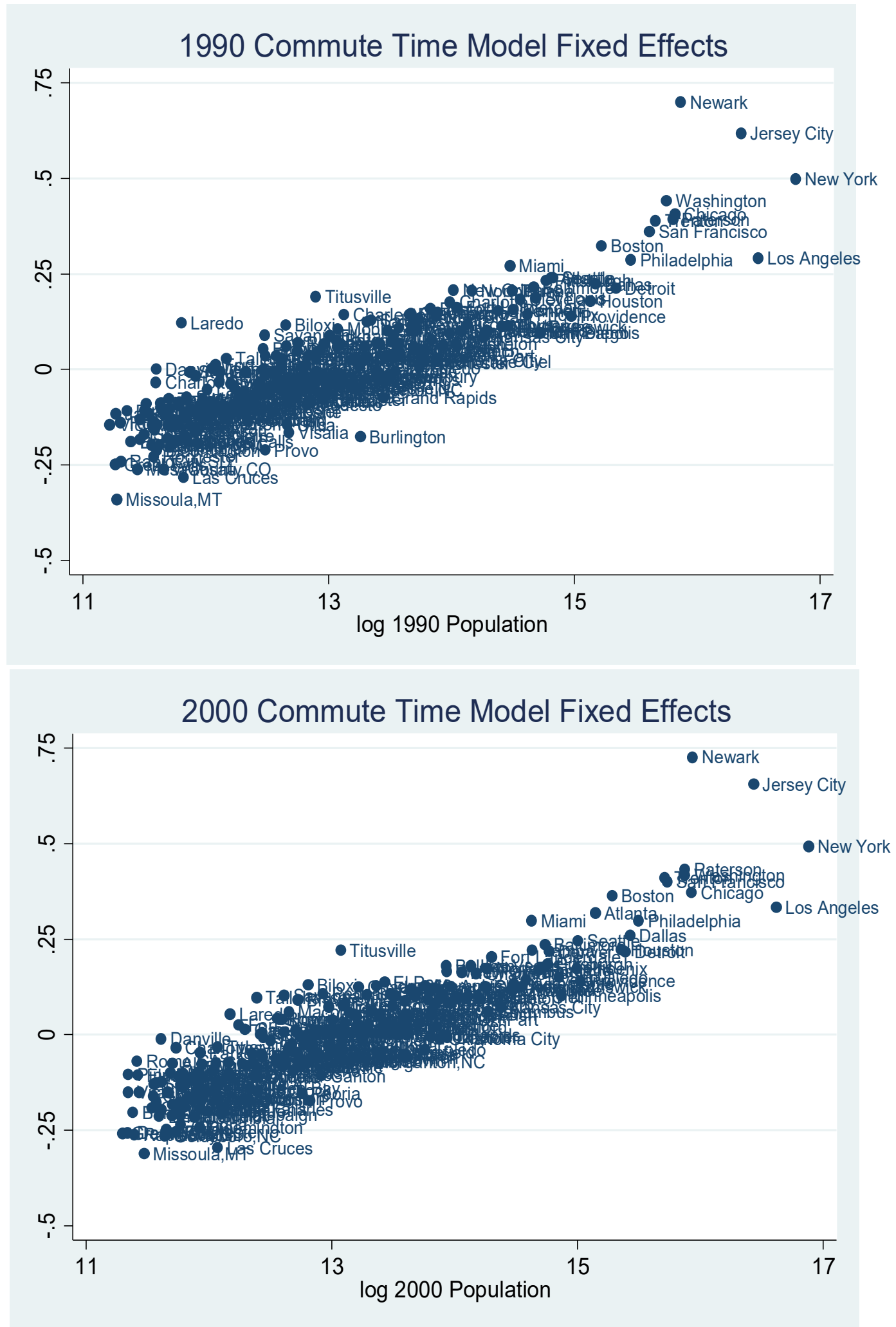

Notes: Fixed effects are normalized to be mean 0 across regions. 
Figure A3: Estimates of $\kappa \varepsilon$ by Metro Area

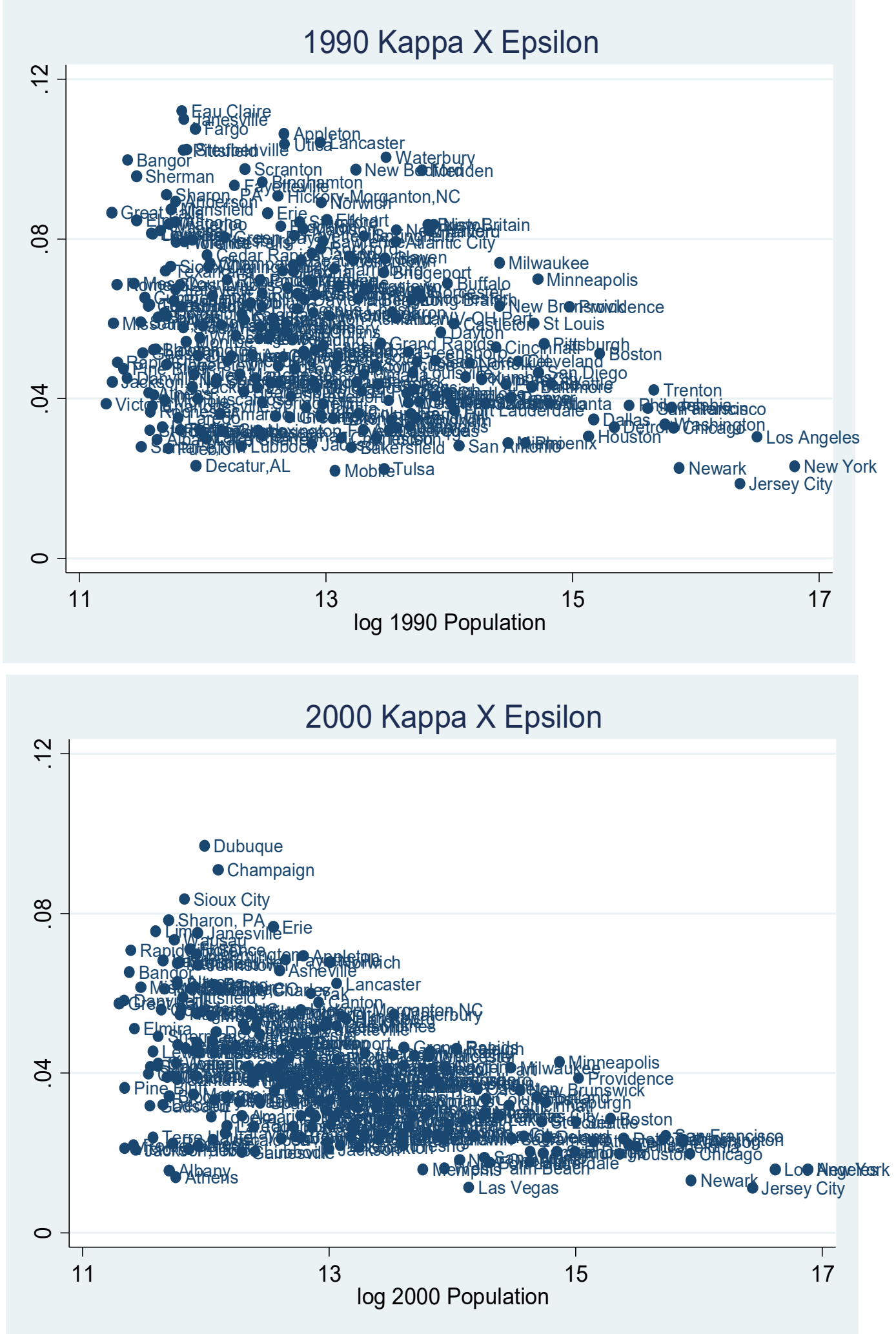

Notes: Plotted points are coefficients on one-way commute time from regressions of log commute flow on origin and destination fixed effects and the one-way commute time in minutes, weighted by commute flow. 